\title{
Cross Sections for Electron Collisions with $\mathrm{H}_{2} \mathrm{O}$
}

Cite as: J. Phys. Chem. Ref. Data 50, 023103 (2021); https://doi.org/10.1063/5.0035315

Submitted: 27 October 2020 . Accepted: 31 March 2021 . Published Online: 12 May 2021

(D) Mi-Young Song, Hyuck Cho, (D) Grzegorz P. Karwasz, (D) Viatcheslav Kokoouline, Yoshiharu Nakamura, (D) Jonathan Tennyson, (D) Alexandre Faure, (D) Nigel J. Mason, and Yukikazu Itikawa
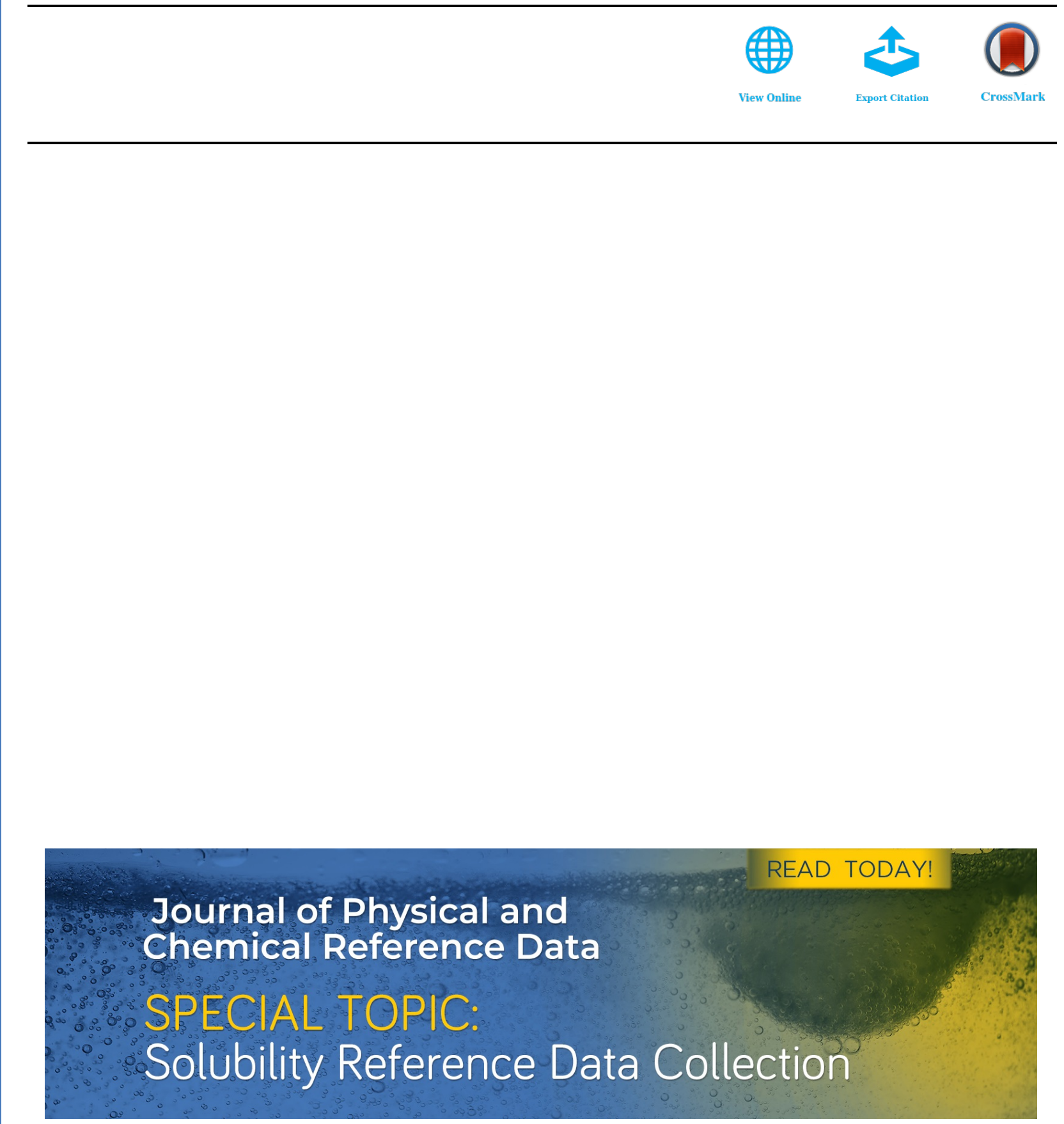


\title{
Cross Sections for Electron Collisions with $\mathrm{H}_{2} \mathrm{O}$
}

\author{
Cite as: J. Phys. Chem. Ref. Data 50, 023103 (2021); doi: 10.1063/5.0035315 \\ Submitted: 27 October 2020 • Accepted: 31 March 2021 • \\ Published Online: 12 May 2021
}

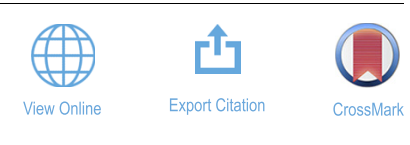

\section{Mi-Young Song, ${ }^{1, a)(D)}$ Hyuck Cho, ${ }^{2}$ Grzegorz P. Karwasz, ${ }^{3}$ (D) Viatcheslav Kokoouline, ${ }^{4}$ (D) Yoshiharu Nakamura, ${ }^{5}$ Jonathan Tennyson, ${ }^{6}$ (D) Alexandre Faure, ${ }^{7}$ (D) Nigel J. Mason, ${ }^{8}$ (D) and Yukikazu Itikawa ${ }^{9}$}

\author{
AFFILIATIONS \\ ${ }^{1}$ Institute of Plasma Technology, Korea Institute of Fusion Energy (KFE), 37, Dongjangsan-ro, Gunsan, Jeollabuk-do 54004, \\ South Korea \\ ${ }^{2}$ Department of Physics, Chungnam National University, Daejeon 34134, South Korea \\ ${ }^{3}$ Institute of Physics, Astronomy and Applied Informatics, University Nicolaus Copernicus, Grudziadzka 5, 87-100 Toruń, Poland \\ ${ }^{4}$ Department of Physics, University of Central Florida, Orlando, Florida 32816, USA \\ ${ }^{56-1-5-201 ~ M i y a z a k i, ~ M i y a m a e, ~ K a w a s a k i ~ 216-0033, ~ J a p a n ~}$ \\ ${ }^{6}$ Department of Physics and Astronomy, University College London, Gower Street, London WC1E 6BT, United Kingdom \\ ${ }^{7}$ Univ. Grenoble Alpes, CNRS, IPAG, F-38000 Grenoble, France \\ ${ }^{8}$ School of Physical Sciences, University of Kent, Canterbury CT2 7NH, United Kingdom \\ 93-16-3 Miwamidoriyama, Machida 195-0055, Japan
}

a) Author to whom correspondence should be addressed: mysong@kfe.re.kr

\begin{abstract}
Electron collision cross section data for the water molecule are compiled from the literature. Cross sections are collected and reviewed for total scattering, elastic scattering, momentum transfer, excitations of rotational and vibrational states, electronic excitation, dissociation, ionization, and dissociative attachment. For each of these processes, the recommended values of the cross sections are presented. The literature has been surveyed up to the end of 2019.
\end{abstract}

Published by AIP Publishing on behalf of the National Institute of Standards and Technology. https://doi.org/10.1063/5.0035315

Key words: attachment; dissociation; electron collisions; evaluation; ionization; total cross sections.

\section{CONTENTS}

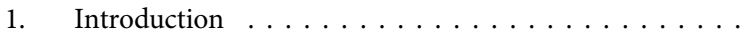

2. Cross Section Definitions $\ldots \ldots \ldots \ldots \ldots \ldots$

3. Total Scattering Cross Section . . . . . . . . . .

3.1. Comparison with positron scattering . . . . . .

4. Elastic Scattering Cross Section . . . . . . . . . . . .

5. Momentum-Transfer Cross Section . . . . . . . . .

6. Rotational Excitation Cross Sections . . . . . . . . .

7. Vibrational Excitation Cross Sections . . . . . . . . .

8. Electronic-Excitation Cross Section . . . . . . . . . .

9. Dissociation into Neutrals . . . . . . . . . . . .

10. Ionization Cross Section . . . . . . . . . . . .

11. Dissociative Electron Attachment (DEA)

Cross Section . . . . . . . . . . . . . . . . . . 19

12. Summary and Future Work . . . . . . . . . . . . . . 21

13. Supplementary Material . . . . . . . . . . 22
Acknowledgments . . . . . . . . . . . . . . . . . . . . . . . 22

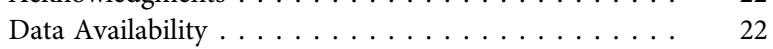

14. References................... 22

\section{List of Tables}

1. Recommended (in $10^{-16} \mathrm{~cm}^{2}$ ) TCSs for electron scattering on $\mathrm{H}_{2} \mathrm{O} \ldots \ldots \ldots \ldots \ldots \ldots \ldots \ldots \ldots$

2. Recommended elastic DCSs for $\mathrm{H}_{2} \mathrm{O}$ DCSs and uncertainties $(\delta)$ are in the units of $10^{-16} \mathrm{~cm}^{2} \mathrm{sr}^{-1} \ldots \ldots \ldots$

3. Recommended elastic ICSs for $\mathrm{H}_{2} \mathrm{O}$ in the units of $10^{-16}$ $\mathrm{cm}^{2}$ Energy in $\mathrm{eV} \ldots \ldots \ldots \ldots \ldots \ldots$

4. Recommended EMT cross section and TMT or effective momentum-transfer cross section for the water molecule The TMT cross section coincides with the EMT cross section in the energy range above $6 \mathrm{eV} \ldots \ldots \ldots$ 
5. Recommended cross sections for rotational excitation of $\mathrm{H}_{2} \mathrm{O}$ from the ground rotational level $0_{00}$ to excited rotational levels with $J^{\prime}=1,2$, and $3 \ldots \ldots \ldots$ Energies of the normal modes of $\mathrm{H}_{2} \mathrm{O}$ in the ground electric state ${ }^{96} \ldots \ldots \ldots \ldots \ldots \ldots \ldots$ Recommended vibrational excitation cross sections for $\mathrm{e}+$

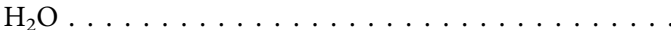
Excitation energies ${ }^{102}$ of the lowest electronic states of

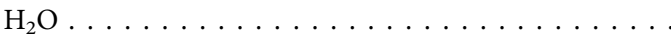
Electron impact electronic-excitation cross section for $\mathrm{H}_{2} \mathrm{O}\left(\mathrm{A}^{1} \mathrm{~B}_{1}\right) \ldots \ldots \ldots \ldots \ldots \ldots \ldots \ldots$

10. Cross sections for the production of the $\mathrm{OH}$ neutral fragment following electron impact on the $\mathrm{H}_{2} \mathrm{O}$ molecule . .

11. Cross sections for the production of the $\mathrm{O}\left({ }^{1} S_{0}\right)$ atom in the excited ${ }^{1} S$ state, from Ref . . . . . . . . . . . . . Recommended cross sections for the electron-impact ionization of $\mathrm{H}_{2} \mathrm{O}$ : data are from the review by Lindsay and Mangan $^{28}$ and are based on measurements performed by Straub et al . . . . . . . . . . . . . . . .

13. Recommended dissociative attachment cross sections (CS) for the ion formation from $\mathrm{H}_{2} \mathrm{O} \ldots \ldots \ldots \ldots \ldots$

\section{List of Figures}

1. Energies of the lowest dissociation channels for $\mathrm{H}_{2} \mathrm{O}$ and

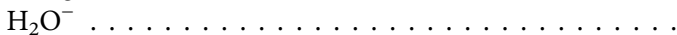
TCSs for electron scattering on $\mathrm{H}_{2} \mathrm{O} \quad \ldots \ldots \ldots \ldots$ TCSs for electron scattering on $\mathrm{H}_{2} \mathrm{O}$ in the high energy range $(100-3000 \mathrm{eV})$ approximated by the Born-Bethe dependence $[\mathrm{Eq} \ldots \ldots \ldots \ldots \ldots \ldots \ldots$ TCSs for positron scattering on $\mathrm{H}_{2} \mathrm{O} \ldots \ldots \ldots \ldots$ Recommended elastic DCSs for $\mathrm{H}_{2} \mathrm{O}$ at four representative energies taken from Ref . . . . . . . . . . . . . Recommended elastic ICSs for $\mathrm{H}_{2} \mathrm{O} \ldots \ldots \ldots \ldots$ Momentum-transfer cross sections for the water molecule Recommended cross sections for rotational excitation of $\mathrm{H}_{2} \mathrm{O}$ from the ground rotational level $\mathrm{O}_{00}$ to excited rotational levels with $J^{\prime}=1,2$, and $3 \ldots \ldots \ldots \ldots$

\section{Introduction}

Water is a unique substance. Compared to the isoelectronic molecules, $\mathrm{HF}, \mathrm{CH}_{4}$, and $\mathrm{NH}_{3}$, water remains liquid at relatively high (i.e., "ambient") temperatures. Thanks to its large dipole moment (1.84 D), water is an excellent solvent for many different classes of substances. Water vapor is transparent in the visible range owing to its relatively high threshold, compared, for example, to the $\mathrm{NO}_{2}$ or $\mathrm{SO}_{2}$ molecules, for electronic excitation (above $6.5 \mathrm{eV}$; see, for example, Ref. 1); however, it is opaque in much of the IR region extending to wavelengths of $10 \mu \mathrm{m}$ or excitations of a few $\mathrm{meV}$. An extensive set of empirical rotation-vibration levels for water has recently been provided by Furtenbacher et al., ${ }^{2,3}$ and a comprehensive list of rotation-vibration transitions has been given by the recently published POKAZATEL line list. ${ }^{4}$ In turn, even the lowest electronically excited states are strongly dissociative, leading to the formation of $\mathrm{H}$ and $\mathrm{OH}$ radicals, important in biological and environmental chemistry. Due to its closely spaced but widely spread
9. Comparison of cross sections for rotational excitation from different theoretical calculations . . . . . . . . . .

10. Comparison of cross sections for rotational excitation $J_{K_{a}, K_{c}} \rightarrow \dot{J}_{K^{\prime}, K^{\prime}}$ from different theoretical calculations . .

11. Comparison of cross sections available in the literature for the excitation of the bending mode $(000) \rightarrow(010) \ldots$.

12. Comparison of cross sections available in the literature for the excitation of the stretching modes $(000) \rightarrow(100)+$

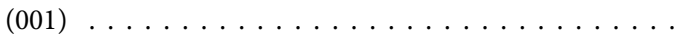

13. Recommended cross sections for the excitation of the stretching modes . . . . . . . . . . . . .

14. Cross sections for the electron impact electronic excitation of the ÂERROR!!

16. Comparison of the total ionization ${ }^{118,119}$ cross sections with measurements of the yield of two neutral species ${ }^{113,117}$ $\mathrm{OH}$ and $\mathrm{O}\left({ }^{1} \mathrm{~S}_{0}\right) \ldots \ldots \ldots \ldots \ldots \ldots$ Gross total ionization cross section in $\mathrm{H}_{2} \mathrm{O} \ldots \ldots$. . .

18. Partial ionization cross section for $\mathrm{H}_{2} \mathrm{O}^{+}$from the Landolt-Börnstein data collection, ${ }^{28}$ Märk and Egger, ${ }^{121}$ Orient and Srivastava, ${ }^{122}$ Rao et al . . . . . . . . . . . . .

19. Partial ionization cross section for $\mathrm{OH}^{+}$from the Landolt-Börnstein data collection, ${ }^{28}$ Orient and Srivastava, ${ }^{122}$ Rao et al . . . . . . . . . . . . . . . . . .

20. Partial ionization cross section for $\mathrm{H}^{+}$from the Landolt-Börnstein data collection, ${ }^{28}$ Orient and Srivastava, ${ }^{122}$ Rao et al . . . . . . . . . . . . . . . . . 21. Partial ionization cross section for $\mathrm{O}^{+2}$ from the Landolt-Börnstein data collection, ${ }^{28}$ Montenegro et al . . . . Partial ionization cross section for $\mathrm{H}_{2}^{+}$from the Landolt-Börnstein data collection, ${ }^{28}$ Montenegro et al . . .

23. Partial ionization cross section for $\mathrm{O}^{+}$from the Landolt-Börnstein data collection, ${ }^{28}$ Orient and Srivastava, ${ }^{122}$ Rao et al . . . . . . . . . . . . . . . . .

24. The recommended total and partial ionization cross sections for $\mathrm{H}_{2} \mathrm{O} \ldots \ldots \ldots \ldots \ldots \ldots$

25. Recommended cross sections for (a) $\mathrm{H}^{-}$, (b) $\mathrm{O}^{-}$, and (c) $\mathrm{OH}^{-}$ion formation from $\mathrm{H}_{2} \mathrm{O} \ldots \ldots \ldots \ldots$

26. Summary of the recommended cross section for electron collisions with $\mathrm{H}_{2} \mathrm{O} \ldots \ldots \ldots \ldots \ldots$

rotational levels, the $\mathrm{H}_{2} \mathrm{O}$ molecule is the main greenhouse gas; note that $\mathrm{CO}_{2}$ only fills the windows that remain between the $\mathrm{H}_{2} \mathrm{O}$ rotationvibration bands. Moreover, due to feedback effects, increasing temperature increases the saturation vapor pressure, and $\mathrm{H}_{2} \mathrm{O}$ plays an essential role in destabilizing the climate into glacial and interglacial periods.

Water in the liquid phase has been called the matrix of life. ${ }^{5}$ The thermodynamic, transport, and structural properties of bulk water are profoundly affected in incompletely understood ways by nanoscale confinement. The implications of this are effective energy storage, ice nucleation in clouds, desalination, and even replication of the influenza virus inside infected cells. ${ }^{6}$ The electrical interaction between $\mathrm{H}_{2} \mathrm{O}$ and metal surfaces, which is still only partially understood, is the basis for all Volta's cells. ${ }^{7}$ Finally, the presence of water in atmospheres of extra-solar planets ${ }^{8}$ is the sine qua non condition for their habitability.

Due to the importance of water, cross sections for electron scattering on $\mathrm{H}_{2} \mathrm{O}$ have been reviewed in numerous papers using different 
approaches-comparing partial cross sections and total cross sections (TCSs) ${ }^{9,10}$ and/or delivering self-consistent sets of cross sections to be used in plasma modeling ${ }^{11}$ and/or reproducing electron transport coefficients in the $\mathrm{H}_{2} \mathrm{O}$ gas phase ${ }^{12-14}$ and/or modeling electron slowing in liquid water. ${ }^{15-18}$ However, in some cases, significant differences appear in outcomes of those works; see our detailed comparison in Ref. 19. The differences in the "recommended" sets of cross sections result not only from alternative methodologies but also from different definitions of cross sections, as is discussed further in Sec. 2. Analytic parameterization of total and partial cross sections was performed by Shirai et al. ${ }^{20}$ Finally, we note that the comprehensive review made by two of us (Itikawa and Mason $)^{21}$ forms the starting point for the current study.

Cross sections for electron scattering were measured in early pioneering works, for example, the 1895 high energy beam study by Lenard ${ }^{22}$ (which looked at $\mathrm{NH}_{3}$ and $\mathrm{CH}_{4}$ ), but they were studied in a low energy beam experiment by Brüche ${ }^{23}$ at $1-50 \mathrm{eV}$ and at very low (below $0.1 \mathrm{eV}$ ) energies in a swarm experiment by Pack, Voshall, and Phelps ${ }^{24}$ and in a cyclotron-resonance experiment by Tice and Kievelson. ${ }^{25}$ Already, these early experiments indicated a rapid rise in the TCS in the zero energy limit. In spite of numerous past experiments and comparisons, cross sections for water vapor are still subject to intense research ${ }^{26,27}$ and the low-energy cross sections, important for the biochemistry, remain ambiguous.

The scope of this work is to give recommendations for electron collision cross sections with $\mathrm{H}_{2} \mathrm{O}$. For a number of important processes, we were unable to identify reliable cross sections; recommendations for future work are presented in the Conclusion. As seen from Fig. 1, several dissociation processes of $\mathrm{H}_{2} \mathrm{O}$ are open below $10 \mathrm{eV}$ collision energy, therefore influencing the low-energy biochemistry.

\section{Cross Section Definitions}

The very large rotational excitation cross sections exhibited by electron collisions with water combined with the very strong forward peak of the associated differential cross sections (DCSs) introduce some ambiguity into the definition of the cross section for a number of processes.

The TCS is unambiguously defined as the sum over all angles, that is, $4 \pi$ steradians, and over all processes for the scattering of electrons. TCSs are often used as benchmarks since, in principle, such cross sections can be measured using transmission experiments to high accuracy. However, even transmission experiments struggle to distinguish electrons that collide but continue in the forward direction, with little to distinguish them from electrons in the original beam that pass straight through the sample without colliding. Therefore, TCS measurements can be affected by the energy and angular resolution of the apparatus used; see Ref. 28. Accordingly, it is essential that the characteristics of the apparatus are described.

Elastic scattering conserves the kinetic energy of the colliding particles. This means that quantum numbers that determine the energy are unchanged, but other quantum numbers corresponding to degenerate states (e.g., helicity or spin flip) may change. For many measurements, not all states in the system are resolved; in particular, it is usual for measurements on water to not resolve the rotational state, which means that so-called elastic measurements actually include a contribution from rotationally inelastic collisions. In this case, effective elastic cross sections are determined, which we will below refer to as rotationally unresolved elastic cross sections. The strictly elastic cross section will be referred to as the rotationally elastic cross section.

\section{neutral anion}
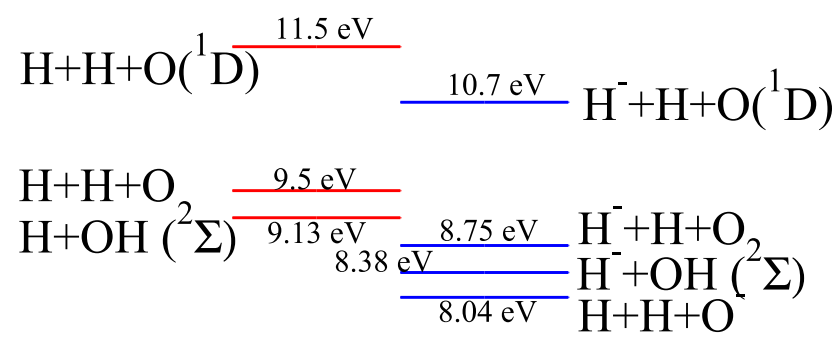

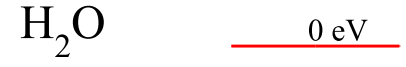

FIG. 1. Energies of the lowest dissociation channels for $\mathrm{H}_{2} \mathrm{O}$ and $\mathrm{H}_{2} \mathrm{O}^{-}$

The rotational distribution of the gas sample is temperature dependent, and for water at room temperature, the rotational probability distribution peaks for rotational states with $J=7$. Given the large rotational excitation cross sections, this raises the possibility that rotationally unresolved cross sections may in practice depend on the temperature of the target. In this case, the temperature or state distribution of the target may influence the resulting cross section. However, modeling performed as part of this work looked at the effect of target temperatures up to $1000 \mathrm{~K}$. The models used the recommended rotational excitation cross section discussed below and found that, in practice, the rotationally unresolved elastic cross sections showed little variation as a function of temperature, so this effect is ignored below.

Elastic cross sections are usually measured at specific energies and angles. These data are used to determine the integral elastic cross section by integrating over the angular range, which may involve extrapolation or use of theoretical models to extend the range of measurements. The sharp forward peak shown in water cross sections causes a number of issues, which are discussed extensively below. Measurements of the elastic DCS therefore provide a more stringent test of theory.

The elastic momentum-transfer (EMT) cross section is the $1-\cos (\theta)$ weighted, angle-integrated DCS for elastic scattering, where $\theta$ is the scattering angle. For water, the momentum-transfer cross section differs significantly from the elastic integral cross section (ICS) obtained by direct integration of the DCS over all angles. However, like the elastic cross section, momentum-transfer cross section is often determined rotationally unresolved. Below, we consider both rotationally unresolved and rotational EMT cross sections. 
Other cross sections considered, in particular, excitation cross sections, ionization cross sections, dissociation cross sections, and attachment cross sections, probably do not depend strongly on the details of the rotational distribution and so are only considered rotationally unresolved below. The vibrational excitation cross section may well depend on the rotational state concerned, but at present, there is no information available on this for water, so these too are only considered rotationally unresolved below.

Ambiguities may rise also in experiments on partial cross sections. Resolving the fundamental stretching modes (100) and (001) is not possible by presently used techniques and requires theory. Furthermore, determining absolute values in the experiment requires normalization to the elastic peak and this is significantly broadened by rotational excitations.

Determining the electronic-excitation cross sections (in energyloss experiments) requires de-convolution of the overlapping bands that are so dense in the vibrational and rotational progression that no separate levels are distinguishable. The electronic-excitation cross section in the theory could be compared with the cross sections for optical emission. In practice, these two measurements are not fully compatible as optical emission can occur in steps (i.e., in a cascade process). Furthermore, in $\mathrm{H}_{2} \mathrm{O}$, it turns out that the electronic excitation leads mainly to the dissociation of the molecule, so the optical emission from different neutral (and ionized) fragments must be collected. Experiments on dissociation into neutrals require special techniques (such as laser-induced fluorescence or formation of $\mathrm{XeO}^{*}$ excimers), and again, normalization is required.

In ionization processes, one has to define the gross total ionization cross section, which is the signal of the overall ion charge collected (with doubly charged ions counted twice in the ion-tube experiment and/or two fragment ions coming from the same ionization event in coincidence experiments) and the counting ionization cross section, which gives correct information on the number of ionizing collisions. In $\mathrm{H}_{2} \mathrm{O}$, the small difference in mass between $\mathrm{O}^{+}$ and $\mathrm{OH}^{+}$makes it necessary to perform measurement on $\mathrm{D}_{2} \mathrm{O}$. The same difficulty shows up in experiments on the formation of negative ions [i.e., in dissociative electron attachment (DEA)]. However, in contrast with the positive ionization, the dynamics of the DEA in $\mathrm{D}_{2} \mathrm{O}$ differs much from that in $\mathrm{H}_{2} \mathrm{O}$, so data cannot be transferred between isotopologues. Furthermore, the amplitude of signals from $\mathrm{O}^{-}$and $\mathrm{OH}^{-}$ions differ by a few orders of magnitude, so experiments are tedious.

Overall, the intrinsic molecular properties of $\mathrm{H}_{2} \mathrm{O}$ lead to significant experimental difficulties in determining electron-scattering cross sections and, in turn, in recommending them.

\section{Total Scattering Cross Section}

The magnitude of the TCS in water is a question of essential importance. For example, radiation damage in DNA may come not from high energy electrons but via the dissociative attachment of lowenergy electrons. ${ }^{29}$ In addition, water due to close spacing (and low thresholds) for rotational excitations facilitates the efficient slowing of electrons to thermal energies. Hence, the magnitude of the very lowenergy cross sections in water is of vital importance for models of radiation damage in living organisms. Very high values of TCS and momentum-transfer cross sections $\left(10000 \times 10^{-16} \mathrm{~cm}^{2}\right)$ in the limit of zero energy were already derived from the swarm experiments performed by Pack, Voshall, and Phelps ${ }^{24}$ in the 1960s but have not been confirmed by beam measurements. This led to a serious discrepancy in the recommended values: Hayashi ${ }^{30}$ (and the beam data of Sueoka, ${ }^{31,32}$ corrected by Kimura et al. ${ }^{33}$ for the angular resolution error) reported a constant rise in the TCS in the limit of zero energy (see Fig. 2), while Karwasz et al., ${ }^{34}$ following beam experiments, recommended lower values, with a maximum of TCS at about $10 \mathrm{eV}$, similar to that in $\mathrm{NH}_{3}$ and $\mathrm{CH}_{4}$ (see Ref. 9).

Figure 2 presents the available beam measurement of the TCS. Data were obtained in different experimental setups. Szmytkowski and collaborators ${ }^{35}$ used a transmission configuration with a $127^{\circ}$, cylindrical energy monochromator ( $80 \mathrm{meV}$ energy resolution) and $30 \mathrm{~mm}$-long scattering cell (1 $\mathrm{ms}$ angular resolution of the detector). Szmytkowski reported TCS in $\mathrm{H}_{2} \mathrm{O}$ twice: from the setup without a retarding field analyzer ${ }^{35}$ and with the analyzer. ${ }^{39}$ For $\mathrm{H}_{2} \mathrm{O}$, the two results coincide; this differs from similar measurements in $\mathrm{NO}_{2}$ (see Ref. 45), for which the use of the retarding field analyzer produced higher (by a few percent) TCS in the energy range of $10-100 \mathrm{eV}$. Relying on this comparison, one could deduce that the electronic excitation (that can be discriminated with the analyzer) is lower in $\mathrm{H}_{2} \mathrm{O}$ than $\mathrm{N}_{2} \mathrm{O}$.

Sueoka and collaborators ${ }^{31,32}$ measured the TCS for electron (and positron) scattering in the energy range of 1-400 eV using a longitudinal guiding magnetic field, rather a short $(67 \mathrm{~mm})$ scattering cell and wide ( $8 \mathrm{~mm}$ in diameter) entrance and exit apertures. In electrostatically guided beams, the angular resolution is defined as the solid angle of the exit aperture as seen from the center of the scattering cell; the determination of the angular resolution error in magnetically guided beams is not straightforward, requiring the calculation of the cyclotronic radius of electrons (positrons). ${ }^{46}$ Therefore, Sueoka and $\mathrm{Mori}^{31}$ checked that raising the magnetic field in their apparatus from 0.3 to $0.6 \mathrm{mT}$ lowers the electron-scattering TCS in $\mathrm{H}_{2} \mathrm{O}$ at $1.2 \mathrm{eV}$ by

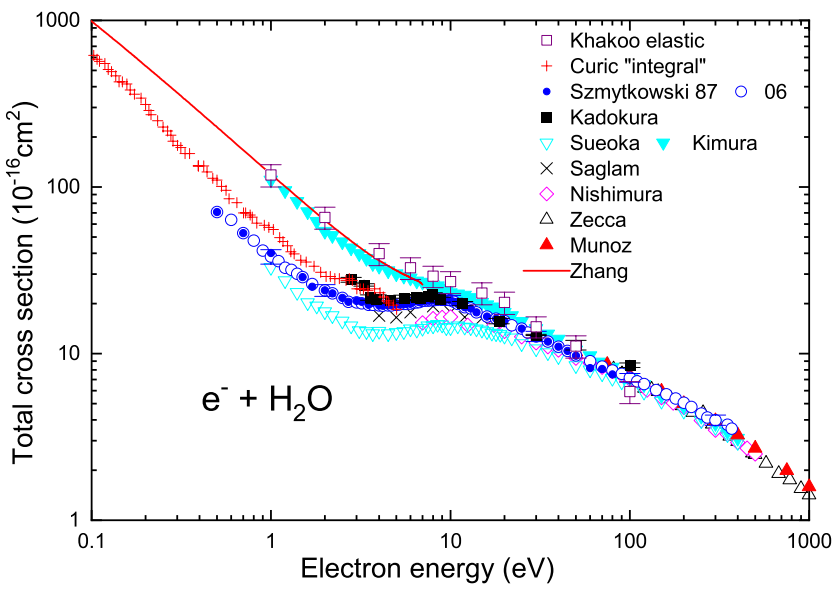

FIG. 2. TCSs for electron scattering on $\mathrm{H}_{2} \mathrm{O}$. Crosses, "integral CS" from Aarhus laboratory ${ }^{36}$ digitized from Ref. 37 , open squares, ${ }^{38}$ closed squares, ${ }^{26}$ points, circles, ${ }^{39}$ open inverted triangles; ${ }^{31}$ closed inverted triangles, Sueoka and Mori data corrected for the angular resolution error, tilted crosses, ${ }^{40,41}$ diamonds, ${ }^{42}$ open triangles, ${ }^{43}$ closed triangles; ${ }^{44}$ and line, R-matrix calculation. ${ }^{37}$ Recommended TCS are based on the data of Zhang et al..$^{37}$ up to $7 \mathrm{eV}$, those of Szmytkowski and Mozejko ${ }^{39}$ up to $100 \mathrm{eV}$, and those of Munoz et al. ${ }^{44}$ above $100 \mathrm{eV}$. 
some $20 \%$. The original measurements of Sueoka and collaborators, $^{31,32}$ open inverted triangles in Fig. 2, have been corrected $^{33}$ a posteriori for the forward-angle scattering using the Born approximation, ${ }^{47}$ closed inverted triangles in Fig. 2 . While at $100 \mathrm{eV}$ the correction is merely $+10 \%$, it amounts to a factor of 3 in the $1-5 \mathrm{eV}$ energy range.

Sağlam and Aktekin ${ }^{40,41}$ used a linear beam ("that of Nickel et al. $\left.{ }^{48 ”}\right)$ with a rather long $(141 \mathrm{~mm})$ scattering cell and small $(1 \mathrm{~mm}$ in diameter) apertures. However, due to the lack of a monochromator, the energy resolution was $0.35 \mathrm{eV}$, hence not allowing discrimination of even vibrational excitation. In fact, their results ${ }^{40}$ are slightly (4\% at $25 \mathrm{eV}$ ) lower than those of Szmytkowski; ${ }^{35}$ the difference ${ }^{41}$ amounts to $15 \%$ at $4 \mathrm{eV}$. Nishimura and Yano ${ }^{42}$ used a similar linear geometry but a short $(2.5 \mathrm{~mm})$ scattering cell, which straightforwardly leads to large angular resolution errors: their TCS at $10 \mathrm{eV}$ is $20 \%$ lower than that of Szmytkowski. ${ }^{35}$ We discuss these earlier beam results to indicate the role of the angular resolution in the quality of TCS measurements in polar molecules. In fact, for $\mathrm{CH}_{4}$, which is isoelectronic with $\mathrm{H}_{2} \mathrm{O}$, the agreement between the TCSs measured using the various apparatuses compared here was within $5 \%$ at $10 \mathrm{eV}$; see Ref. 49. The angular resolution (and the energy-loss discrimination) influences the TCS in $\mathrm{H}_{2} \mathrm{O}$ in two limits: at very low energies (below $1 \mathrm{eV}$ ), where scattering is extremely forward-centered (see the R-matrix calculation augmented with Born corrections by Tennyson and collaborators), ${ }^{37,50}$ and at high energies (above $1000 \mathrm{eV}$ ), where elastic scattering is forward-centered and also the electronic-excitation cross sections, for dipole-allowed states, are forward-centered. Therefore, also the high energy TCS may be underestimated if measured without using an energy-loss analyzer. This is the case of the measurements performed by Zecca et al.: ${ }^{43}$ their apparatus, even though it featured a good geometrical angular resolution of $0.34 \mathrm{~ms}$, lacked means to discriminate inelastically scattered electrons with energy loss less than $15 \%$ of their kinetic energy. As stated by Zecca et al., ${ }^{51}$ the error induced by these experimental limitations may amount to some $25 \%-30 \%$ in the limit of $3 \mathrm{keV}$ projectile energy. Figure 3 shows the more recent TCS measured by Garcia and collaborators ${ }^{44}$ in the high energy limit: they used an energy selector at the exit of the scattering cell, and the geometrical angular resolution was $0.02 \mathrm{~ms}$. The figure uses a so-called Bethe-Born plot: at high energies, the TCS should follow the dependence,

$$
\sigma(E)=A / E+B \log (E) / E,
$$

where the energy is expressed in Rydbergs, $R=13.6 \mathrm{eV}$, and the cross section is expressed in atomic units, $a_{0}^{2}=0.28 \times 10^{-16} \mathrm{~cm}^{2}$. As seen from the figure, the TCS of Munoz et al. ${ }^{44}$ can be fitted by a straightline with $A=12 \pm 5, B=219 \pm 10$. At $350 \mathrm{eV}$, the four experiments $^{39,42-44}$ agree within $15 \%$, and at $3000 \mathrm{eV}$, the TCS measured without energy-loss discrimination ${ }^{43}$ is lower by $35 \%$. Both parameters $\mathrm{A}$ and $\mathrm{B}$ in water vapor are lower than those in methane: ${ }^{49}$ for $\mathrm{H}_{2} \mathrm{O}$, the presently recommended TCSs are $20.9 \times 10^{-16} \mathrm{~cm}^{2}$ at $10 \mathrm{eV}$ and $1.58 \times 10^{-16} \mathrm{~cm}^{2}$ at $1000 \mathrm{eV}$, while for $\mathrm{CH}_{4}$, they are $25.7 \times 10^{-16} \mathrm{~cm}^{2}$ and $1.82 \times 10^{-16} \mathrm{~cm}^{2}$, respectively.

In the low energy limit, the discrepancy between direct experimental determinations $\mathrm{s}^{31,35,39,41,42}$ and TCS corrected for forward scattering $^{33}$ is serious. R-matrix calculations ${ }^{37,50}$ with Born closure agree well with the TCS of Sueoka and Mori ${ }^{31}$ as corrected by Kimura et al.; ${ }^{33}$ see Fig. 2. Similar corrections would be possible ${ }^{46}$ also for other experiments, in particular for that from Gdansk laboratory, ${ }^{35,39,46}$ but details of the measurement procedure used must be known.

The physical reason for the difficulty in very low-energy measurements in $\mathrm{H}_{2} \mathrm{O}$ comes from a big contribution of the rotational excitation at energies below $5 \mathrm{eV}$. According to the R-matrix calculation with Born closure, ${ }^{50}$ at $3 \mathrm{eV}$, where the integral elastic cross section shows the minimum, the ICS for the rotational $0 \rightarrow 1$ excitation exceeds the rotationally elastic cross section by a factor of 30 and at $1 \mathrm{eV}$ by a factor of nearly 10 . Rotational excitation is strongly forward-centered: $: 50$ at $0.25 \mathrm{eV}$, the DCS for the $0 \rightarrow 1$ excitation rises from about $100 \mathrm{~A}^{2} / \mathrm{sr}$ at $20^{\circ}$ to more than $1000 \mathrm{~A}^{2} / \mathrm{sr}$ at $5^{\circ}$. This makes the experimental TCS very sensitive to the angular resolution.

Previous recommended values were those given by Karwasz et al. ${ }^{34}$ in 2003 and by Itikawa and Mason ${ }^{21}$ in 2005 . Since then, there have been measurements performed by Muñoz et al. ${ }^{44}$ at high energies, very low (17-250 meV) measurements from Aarhus synchrotron laboratory, ${ }^{36}$ and small-angle experiments performed by Kadokura et al. ${ }^{26}$ [University College London (UCL)] down to $2.8 \mathrm{eV}$. The first measurement is decisive for the choice of recommended TCS that substitutes earlier, ${ }^{21,34}$ and other two put into doubts the quality of earlier measurements ${ }^{35}$ at low energies. Čurík et al. ${ }^{36}$ used a synchrotron-radiation source for electrons (obtaining $1.6 \mathrm{meV}$ energy resolution) and a $30 \mathrm{~mm}$-long scattering cell with a $3 \mathrm{~mm}$ exit aperture. They corrected results for the forward scattering error, reporting "ICSs." In the independent measurement, with the longitudinal magnetic field, they measured the signal of electrons scattered into $90^{\circ}$ angles (obtaining the "backward cross section"). We present their ICSs in Fig. 2. They lie higher that Gdańsk TCS ${ }^{39}$ but lower than corrected $^{33}$ Sueoka's TCS.

Kadokura et al. ${ }^{26}$ used a beam with electrostatic guiding exclusively, a $53 \mathrm{~mm}$-long scattering cell with $1 \mathrm{~mm}$ diameter apertures. To improve the angular resolution, a position-sensitive detector was positioned $8 \mathrm{~cm}$ from the scattering cell. This allowed them

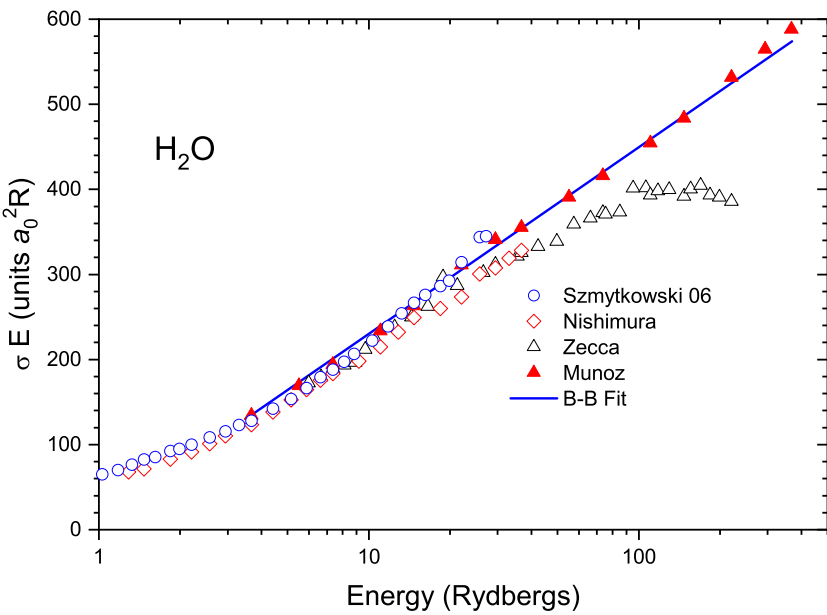

FIG. 3. TCSs for electron scattering on $\mathrm{H}_{2} \mathrm{O}$ in the high energy range $(100-3000 \mathrm{eV})$ approximated by the Born-Bethe dependence [Eq. (1)]: circles, ${ }^{39}$ diamonds, ${ }^{42}$ open triangles, ${ }^{43}$ and closed triangles. ${ }^{44}$ The data of Zecca et al. in the high energy limit suffered from the lack of energy-loss discriminator and so are underestimated. 
to study directly the dependence of the TCS on the angular resolution. The reported TCSs were measured with $0.5 \mathrm{~ms}$ angular acceptance: at $10-100 \mathrm{eV}$, they agree with those from Gdańsk laboratory ${ }^{39}$ within combined error bars, but below $4 \mathrm{eV}$, they are about $30 \%$ higher; they merge well with Aarhus ICSs. Laricchia and collaborators used the same machine ${ }^{26}$ for positron scattering ${ }^{52}$ TCSs: positron sources are much more stable than thermionic electron sources; see Ref. 53.

\subsection{Comparison with positron scattering}

In order to understand the experimental reasons for the discrepancies in the TCS from different laboratories, it is useful to compare TCSs for positron scattering. While at intermediate energies (5-10 eV) the TCS for positron scattering is, tendentiously, lower than that for electrons (due to a weaker scattering potential ${ }^{53}$ ), in the very low-energy range scattering on polar molecules, the TCS for the two projectiles should coincide (the point-charge interaction with a permanent dipole does not distinguish the sign of the projectile).

In Fig. 4, we compare the early and recent measurements of positron scattering from four laboratories: Yamaguchi University ${ }^{31}$ with a guiding magnetic field, measurements performed by Zecca et al. ${ }^{54}$ using the Trento apparatus ${ }^{55}$ (using a $9 \mathrm{G}$ guiding magnetic field and $100 \mathrm{~mm}$-long scattering cell), measurements performed by Buckman and collaborators ${ }^{5,57}$ at Australian National University (ANU) with an apparatus using $0.53 \mathrm{~T}$ field, and experiments performed by Laricchia and collaborators from UCL on two distinct machines-with a magnetic field ${ }^{58}$ (up to $0.22 \mathrm{~T}$ ) and exclusively with electrostatic focusing.

Among recent experiments, the TCS obtained by Zecca et al. ${ }^{54}$ coincides below $2 \mathrm{eV}$, surprisingly, with the electron-scattering TCS obtained by Szmytkowski. ${ }^{35}$ At $10 \mathrm{eV}$, the electron-scattering TCS is, as can be expected, higher than the positron one; ${ }^{54}$ see Fig. 3. The

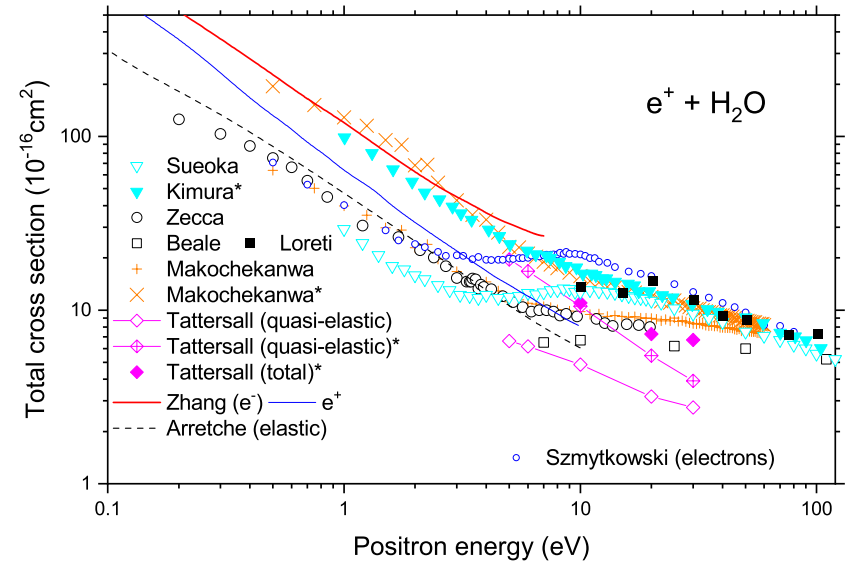

FIG. 4. TCSs for positron scattering on $\mathrm{H}_{2} \mathrm{O}$. Data corrected for the angular resolution are signed with asterisks. Inverted triangles-Yamaguchi University, crosses and tilted crosses-TCS from ANU ${ }^{56}$ and UCL measurements on two different machines, ${ }^{22,58}$ diamonds-quasi-elastic (i.e., elastic + rotational + vibrational) and inelastic (i.e., electronic excitation, positronium formation, and ionization) from ANU. Zecca et al. ${ }^{54}$ measurements on the Trento apparatus; theory-R-matrix with Born closure ${ }^{37}$ (elastic + rotational) and Schwinger multichannel. measurements from $\mathrm{ANU},{ }^{56}$ if uncorrected for the angular resolution, coincide with those performed by Zecca et al. ${ }^{54}$ A correction for the angular resolution error using R-matrix calculations with Born closure done by Zhang et al. ${ }^{37}$ raises the positron TCS in the very low $(0.5-2 \mathrm{eV})$ energy range by a factor of 3; see Fig. 4 . In subsequent work, Tattersall et al., ${ }^{57}$ using the same apparatus but by changing the intensity of the magnetic field in the retarding field analyzer, were able to distinguish the quasi-elastic (i.e., elastic + rotational + vibrational) cross section from the inelastic one (ionization + electronic excitation + positron formation). They corrected the quasi-elastic cross section for forward scattering using again the R-matrix method. ${ }^{37}$ We show their results in Fig. 4, separately for the quasi-elastic uncorrected and corrected and total (quasi-elastic corrected plus inelastic) cross sections. This comparison confirms that the angular resolution error causes a strong (by a factor of 3 at $5 \mathrm{eV}$ ) underestimation of the TCS. Furthermore, while at $20 \mathrm{eV}$ the corrected TCS of Tattersall et al. ${ }^{57}$ coincides with that of Zecca et al., ${ }^{54}$ at $5 \mathrm{eV}$, it is higher by a factor of 2; see Fig. 4 .

Sueoka et al..$^{31,32}$ in their 1986-1987 measurements used a weak (0.3-0.9 $\mathrm{mT})$ magnetic field but large apertures (9 $\mathrm{mm}$ diameter) in the scattering cell, compared with more recent measurements (1.5 and $5 \mathrm{~mm}$ in Trento and ANU, respectively). Therefore, Sueoka's original data suffered from high angular error: uncorrected ${ }^{32}$ data at $1 \mathrm{eV}$ are a factor of 2 lower than those by Zecca et al. ${ }^{54}$ and corrected ${ }^{33}$ data are higher by a similar factor, coinciding within error bars with the corrected measurements from ANU. ${ }^{56}$

Measurements from UCL with the magnetic field ${ }^{58}$ lie lower than those by Zecca et al. ${ }^{54}$ In turn, UCL measurements with the electrostatic beam agree, within error bars, with those of Sueoka et al. ${ }^{31}$ and corrected TCS of Makochekanwa et al. ${ }^{56}$ but lie higher than the cross sections of Tattersall et al. ${ }^{5}$

R-matrix calculation ${ }^{37,60}$ (elastic + rotational) in the low energy range lie in between the two sets: corrected ${ }^{33,56,57}$ and uncorrected. ${ }^{31,54,56,57}$ In Fig. 4, we show also the integral elastic cross sections for positron scattering using the Schwinger multichannel (SMC) model of Arretche et al. ${ }^{59}$ The (pure) elastic cross section below $5 \mathrm{eV}$ coincides with the results of Zecca et al. ${ }^{54}$ and uncorrected results of Makochekanwa et al. ${ }^{56}$ This would indicate that experiments (with both positrons and electrons) easily miss the rotational excitation part of the TCS.

In conclusion, even if several comparisons indicate that the recommended TCS in the low energy range should be the theoretical Rmatrix with the Born closure result, experimental evidence is still weak: in spite of the importance of $\mathrm{H}_{2} \mathrm{O}$ for modeling live tissues, only the UCL team performed experiments intended to cross check earlier measurements. TCS in polar molecules requires further special experimental attention. ${ }^{61,62}$ On summarizing, our recommended TCSs are given in Table 1. They are based on the (elastic + rotational excitation) R-matrix calculations performed by Tennyson and collaborators up to $7 \mathrm{eV}$, measurements of Szmytkowski and Mozejko ${ }^{39}$ up to $100 \mathrm{eV}$, and experiment of Munoz et al. above $100 \mathrm{eV}$ (we give values resulting from the Bethe-Born fit, as described above). The estimated error bars are asymmetric: $-15 \%$ to $+5 \%$ at $0.1-7 \mathrm{eV}$ (our recommended values are rather an upper limit than lower in this energy range), $-5 \%$ to $+10 \%$ at $8-100 \mathrm{eV}$, and $\pm 7 \%$ at $150-1000 \mathrm{eV}$.

\section{Elastic Scattering Cross Section}

Even though there are many experimental and theoretical reports on elastic DCSs and ICSs of electron-water vapor interactions, 
TABLE 1. Recommended (in $10^{-16} \mathrm{~cm}^{2}$ ) TCSs for electron scattering on $\mathrm{H}_{2} \mathrm{O}$. At energies of $0.1-7 \mathrm{eV}$, recommended values are based on R-matrix calculation, ${ }^{37,60}$ at 7-50 eV, they are based on experiments performed by Szmytkowski and collaborators ${ }^{35,39}$ and Kadokura et al., ${ }^{26}$ and at $50-1000 \mathrm{eV}$, they are based on measurements performed by Munoz et al. ${ }^{44}$ Uncertainty ranges are asymmetric: $-15 \%$ to $+5 \%$ at $0.1-7 \mathrm{eV},-5 \%$ to $+10 \%$ at $8-100 \mathrm{eV}$, and $\pm 7 \%$ at $150-1000 \mathrm{eV}$

\begin{tabular}{lrcc}
\hline \hline Electron energy $(\mathrm{eV})$ & TCS $\left(10^{-16} \mathrm{~cm}^{2}\right)$ & Electron energy $(\mathrm{eV})$ & TCS $\left(10^{-16} \mathrm{~cm}^{2}\right)$ \\
\hline 0.1 & 987.8 & 10 & 20.9 \\
0.2 & 533.1 & 12 & 19.5 \\
0.3 & 368.1 & 15 & 17.2 \\
0.4 & 282.1 & 17 & 16.5 \\
0.5 & 229.0 & 20 & 15.7 \\
0.6 & 193.0 & 25 & 14.1 \\
0.7 & 166.9 & 30 & 12.9 \\
0.8 & 147.2 & 35 & 12.2 \\
0.9 & 131.7 & 40 & 11.5 \\
1.0 & 119.3 & 45 & 10.9 \\
1.2 & 100.6 & 50 & 10.2 \\
1.5 & 81.8 & 75 & 8.60 \\
2.0 & 63.1 & 100 & 7.39 \\
3.0 & 43.6 & 150 & 5.94 \\
4.0 & 36.2 & 200 & 5.01 \\
5.0 & 31.5 & 300 & 3.95 \\
6.0 & 28.6 & 400 & 3.25 \\
6.99 & 25.5 & 500 & 2.70 \\
8.0 & 22.8 & 750 & 1.99 \\
9.0 & 21.2 & 1000 & 1.58 \\
\hline \hline
\end{tabular}

there have been disagreements and controversies until recently. Among them, a few rather old results relevant to this report are the following: Danjo and Nishimura ${ }^{63}$ measured the DCS in the energy range from 4 to $200 \mathrm{eV}$ and in the angular range from $10^{\circ}$ to $120^{\circ}$; Shyn and $\mathrm{Cho}^{64}$ used a modulated crossed beam method to measure the DCS for the energy and angular ranges from 2.2 to $20 \mathrm{eV}$ and from $15^{\circ}$ to $150^{\circ}$, respectively; and later, Shyn and Grafe ${ }^{65}$ reported further cross section measurements in the energy range from 30 to $200 \mathrm{eV}$ and the angular range from $12^{\circ}$ to $156^{\circ}$. They made considerable efforts with the design and layout of their electron spectrometer to reduce the mechanical constraints that the spectrometer placed on the accessible angular range. In doing so, they could cover higher scattering angles, up to $156^{\circ}$, and they reported strong backward scattering; Johnstone and Newell ${ }^{66}$ reported the elastic DCS in the energy range of 6-50 eV for scattering angles from $10^{\circ}$ to $120^{\circ}$. More recently, Cho et al. ${ }^{67}$ reported DCSs for the energy range of $4-50 \mathrm{eV}$ measured at the angular range from $10^{\circ}$ up to $180^{\circ}$ with the use of a magnetic-anglechanging device. They estimated the ICS from these DCS results without applying Born-dipole extrapolation to extrapolate at forward angles. Later, the Khakoo group (Silva et al. ${ }^{68}$ and Khakoo et al. ${ }^{38}$ ) reported experimental and theoretical DCSs for the energies from 1 to $100 \mathrm{eV}$ and for scattering angles ranging from $5^{\circ}$ to $130^{\circ}$ and integrated over angles to obtain ICSs using the Born-dipole extrapolation. Their DCS and ICS are generally higher than those of Cho et al. ${ }^{67}$ Very recently, Matsui et al. ${ }^{69}$ reported the DCS and ICS for electron scattering in the incident energy range of $2-100 \mathrm{eV}$ and in the scattering angle range of $10^{\circ}-130^{\circ}$, as a part of the works to measure electronic-excitation cross sections. Their DCS generally agrees better with that of Cho et al. ${ }^{67}$ than that of Khakoo et al. ${ }^{38}$ Theoretical calculations include, among others, those of Rescigno and Lengsfield, ${ }^{70}$ Okamoto et al., ${ }^{47}$ Gianturco et al., ${ }^{71}$ and Varella et al. ${ }^{72}$ More recently, Tennyson and his colleagues (Gorfinkiel et al., ${ }^{73}$ Faure et al., ${ }^{60}$ and Zhang et al. ${ }^{37}$ ) obtained elastic DCSs and ICSs using the R-matrix theory. Machado et al. ${ }^{74}$ and Vinodkumar et al. ${ }^{75}$ also reported the theoretical elastic cross sections. We would like to conclude that the DCSs of Cho et al. ${ }^{67}$ and Matsui et al. ${ }^{69}$ agree quite well with each other and tend to be lower than the DCS of the Khakoo group (Silva et al. ${ }^{68}$ and Khakoo et al. ${ }^{38}$ ). In addition, the DCS of Cho et al. ${ }^{67}$ agrees quite well with the theory of Faure et al. ${ }^{60}$ Therefore, we choose the more recent measurements of Matsui et al. ${ }^{69}$ as the recommended values of elastic DCSs of electron scattering for the water molecule.

For the ICS, we mainly decided to follow the recommendation made by Itikawa and Mason. ${ }^{21}$ They recommend the theoretical cross sections of Gorfinkel et al. ${ }^{73}$ for use at $6 \mathrm{eV}$ and below. At a higher energy of $50 \mathrm{eV}$, only the theoretical DCS of Okamoto et al. ${ }^{47}$ is available for comparison with experiments and the recommended cross sections of Buckman et al. ${ }^{34}$ From this comparison, Itikawa and Mason conclude that the theoretical ICS is too large compared with the experiment at $50 \mathrm{eV}$. Hence, they recommend the experimental data at $50 \mathrm{eV}$ and above. To provide the recommended cross section in the energy region of 6-50 eV, Itikawa and Mason interpolated the two sets of cross sections: the theoretical ones below $6 \mathrm{eV}$ and the experimental ones above $50 \mathrm{eV}$. They provided the recommended elastic ICS for the energy range from 1 to $100 \mathrm{eV}$. To this recommendation, we added the theoretical values of Faure et al. ${ }^{60}$ between 


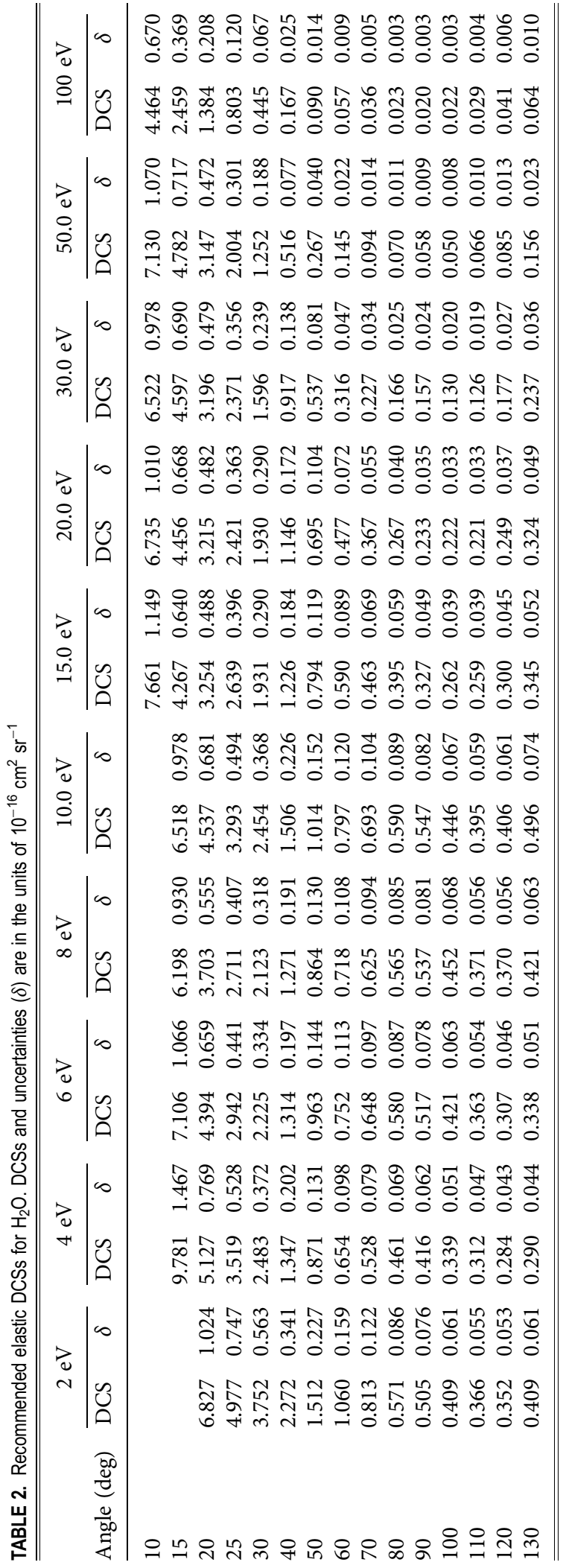

0.1 and $7 \mathrm{eV}$. Accordingly, to recommend the ICS between 7 and $50 \mathrm{eV}$, we interpolated the theoretical values of Faure et al. ${ }^{60}$ and the experimental data at $50 \mathrm{eV}$ and above recommended by Itikawa and Mason. ${ }^{21}$ The recommended DCSs at 10 different energies from 2 to $100 \mathrm{eV}$ are tabulated in Table 2, and the four representative figures are presented in Fig. 5. Similarly, the recommended ICSs from 0.1 to $100 \mathrm{eV}$ are presented in Table 3 and Fig. 6, respectively. Uncertainties in the DCS of Matsui et al.$^{69}$ are claimed to be typically $10 \%-15 \%$. The recommended ICS is mostly based on the theoretical results, the uncertainties of which are not known to the authors.

\section{Momentum-Transfer Cross Section}

As the definition of the momentum-transfer cross section,

$$
Q(m)=2 \pi \int_{0}^{\theta}(1-\cos \theta) q_{\mathrm{elas}}(\theta) \sin \theta d \theta,
$$

indicates, the EMT cross section can be obtained experimentally by measuring the elastic scattering DCS, $q_{\text {elas }}(\theta)$. Typical examples of the EMT cross section of the water molecule obtained by electron beam experiments ${ }^{38,63,67,76}$ are shown in Fig. 7 by plots. Measurements were carried out in the energy range above $1 \mathrm{eV}$. Consistency among these results seems fine, and uncertainties claimed by the authors are typically $12 \%-20 \%$. Because of the fractional momentum loss factor, $1-\cos \theta$, in the above definition, the contribution of the forward scattering to the momentum-transfer cross section, especially in the scattering angle range less than $10^{\circ}$, is less significant than to the elastic ICS. In addition to this, Cho et al. ${ }^{67}$ measured the differential elastic cross section of the water molecule in the backward direction up to $180^{\circ}$ by using a magnetic-angle-changing device based on the design of Read and co-workers ${ }^{77,78}$ and removed possible uncertainties due to backward extrapolation that are otherwise unavoidable. Therefore, their momentum-transfer cross section should be the most reliable. It also seems to be extended smoothly to a higher energy range by the result of Katase et al. ${ }^{76}$ It should be noted, however, that most of the current electron beam experiments do not have enough energy resolution to resolve each of the rotational excitation states and the experimental data cited above are all vibrationally elastic. ${ }^{21}$ While there are no electron beam measurements at energies below $1 \mathrm{eV}$, there are several results of electron swarm studies. Some of them are shown by curves also in Fig. 7. The results seem to be grouped into two: one with larger magnitude obtained by Pack, Voshall, and Phelps $^{24}$ and Ness and Robson ${ }^{79}$ and the other with slightly smaller magnitude obtained by Yousfi and Benabdessadock. ${ }^{13}$ In electron swarm studies, a set of electron collision cross sections is determined in a trial and error manner by solving the Boltzmann equation repeatedly in order that the resultant cross section set can reproduce all electron transport parameters measured in the gas. Obtaining cross sections from a swarm study is therefore an inverse problem. A twoterm spherical harmonic expansion has widely been used historically, and in many cases, the effect of inelastic collision processes (rotational excitations with small energy loss around $10^{-3} \mathrm{eV} /$ collision) is effectively included in the momentum-transfer cross section. This momentum-transfer cross section is called the effective (or total) momentum-transfer cross section ${ }^{80}$ and is considered approximately as the sum of the inelastic cross sections and the EMT cross section. Pack et al. ${ }^{24}$ actually did not solve the Boltzmann equation numerically but analytically determined this total momentum-transfer 

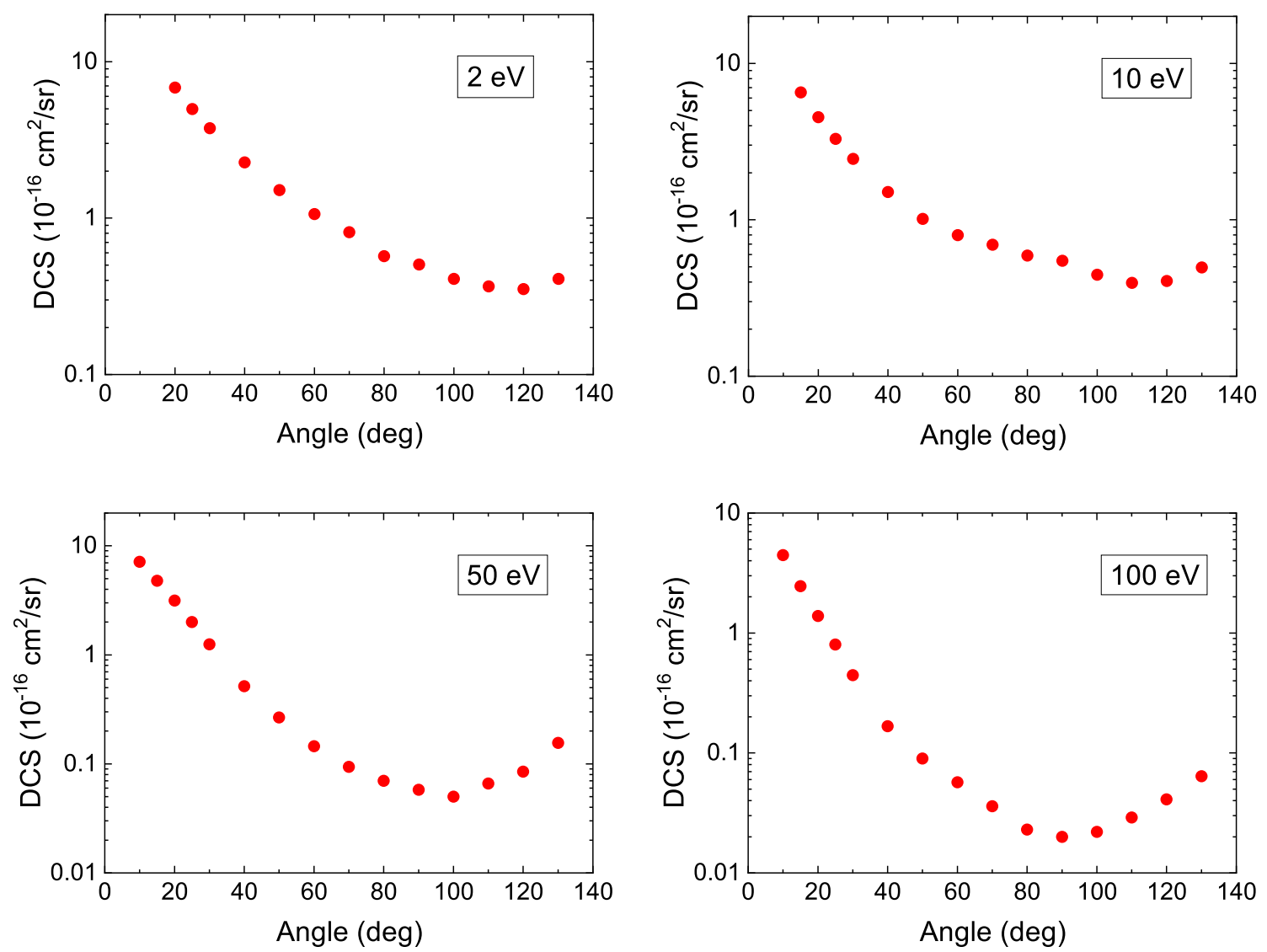

FIG. 5. Recommended elastic DCSs for $\mathrm{H}_{2} \mathrm{O}$ at four representative energies taken from Ref. 69.

TABLE 3. Recommended elastic ICSs for $\mathrm{H}_{2} \mathrm{O}$ in the units of $10^{-16} \mathrm{~cm}^{2}$. Energy in eV

\begin{tabular}{lccc}
\hline \hline Electron energy $(\mathrm{eV})$ & ICS $\left(10^{-16} \mathrm{~cm}^{2}\right)$ & Electron energy $(\mathrm{eV})$ & ICS $\left(10^{-16} \mathrm{~cm}^{2}\right)$ \\
\hline 0.1 & 987.8 & 6 & 28.6 \\
0.2 & 533.1 & 10 & 20.8 \\
0.3 & 368.1 & 20 & 13.6 \\
0.4 & 282.1 & 30 & 10.1 \\
0.5 & 229.0 & 40 & 7.90 \\
0.6 & 193.0 & 50 & 6.62 \\
0.7 & 166.9 & 60 & 5.37 \\
0.8 & 147.2 & 70 & 4.72 \\
0.9 & 131.7 & 80 & 4.13 \\
1 & 119.3 & 90 & 3.60 \\
2 & 63.1 & 100 & 3.43 \\
4 & 36.2 & & \\
\hline \hline
\end{tabular}

(TMT) cross section from their electron drift velocity measurements in water vapor at two different temperatures, 300 and $443 \mathrm{~K}$. Ness and Robson $^{79}$ collected a set of cross sections for water vapor consistent with electron swarm parameters measured at $294 \mathrm{~K}$ using their rigorous solution of the Boltzmann equation (the moment method) including the TMT cross section. Their TMT cross section was further confirmed by measuring electron drift velocities in water vaporhelium mixtures (de Urquijo et al. ${ }^{14}$ ) and in water vapor-argon mixtures (White et al. ${ }^{81}$ ). Faure, Gorfinkiel, and Tennyson ${ }^{50}$ calculated the elastic (rotationally summed) momentum-transfer cross 


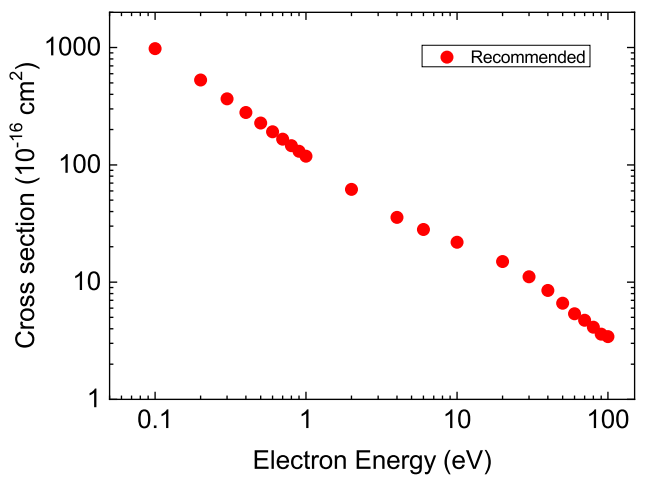

FIG. 6. Recommended elastic ICSs for $\mathrm{H}_{2} \mathrm{O}$.

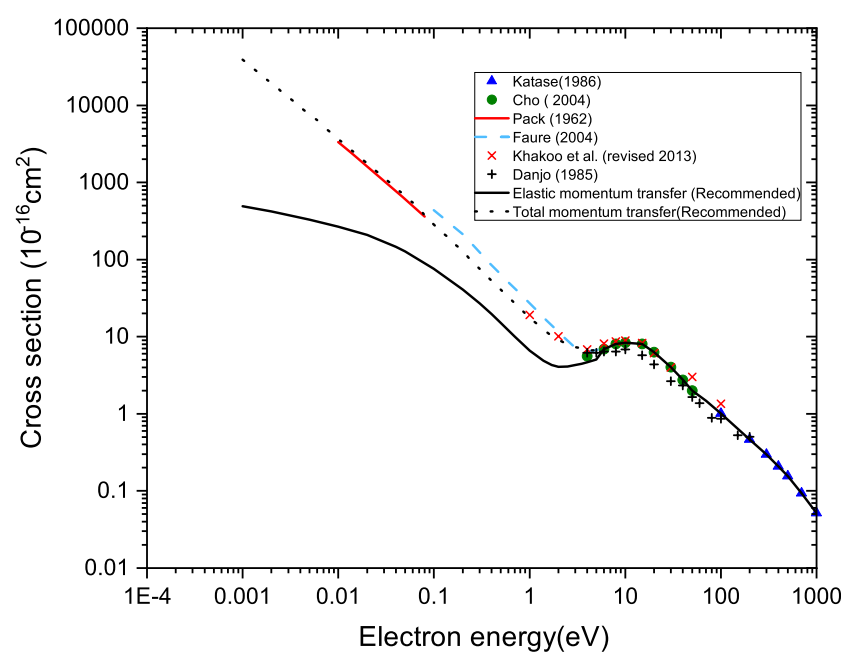

FIG. 7. Momentum-transfer cross sections for the water molecule. Electron beam experiments: crosses, Danjo and Nishimura; ${ }^{63}$ open triangles, Katase et al.; ${ }^{76}$ open circles, Cho et al.; ${ }^{67}$ and tilted crosses, Khakoo et al. (revised in 2013). ${ }^{38}$ Electron swarm study (TMT): solid line (red), Pack, Voshall, and Phelps ${ }^{24}$ and short broken line (black), Ness and Robson ${ }^{79}$ and present recommended for $294 \mathrm{~K}$. Electron swarm study (EMT): solid line (black), Yousfi and Benabdessadok ${ }^{13}$ to $500 \mathrm{eV}$ and present recommended for $1000 \mathrm{eV}$. Theory (elastic, rotationally summed): broken line (cyan), Faure, Gorfinkiel, and Tennyson ${ }^{50}$ (R-matrix method).

section using an R-matrix method, and the result is reasonably consistent with the TMT cross sections in magnitude and in energy dependence although the two cross sections may not be identical in principle. Rotational transition frequencies depend not only on the cross sections but also on the fractional populations of thermally excited rotational states, and therefore, the TMT cross section depends on the gas temperature. The electron drift velocity of Pack, Voshall, and Phelps ${ }^{24}$ actually depends on the vapor temperature, and it increases about $30 \%$ by changing the temperature from 300 to $443 \mathrm{~K}$ in a low reduced electric field where electrons are expected to be in thermal equilibrium with water molecules. Yousfi and Benabdessa$\operatorname{dok}^{13}$ used another rigorous Boltzmann analysis (a multi-term analysis) and obtained an EMT cross section along with several
TABLE 4. Recommended EMT cross section and TMT or effective momentum-transfer cross section for the water molecule. The TMT cross section coincides with the EMT cross section in the energy range above $6 \mathrm{eV}$

\begin{tabular}{lcc}
\hline \hline Electron energy $(\mathrm{eV})$ & EMT $\left(10^{-16} \mathrm{~cm}^{2}\right)$ & TMT $\left(10^{-16} \mathrm{~cm}^{2}\right)$ \\
\hline 0.001 & 490 & 39000 \\
0.002 & 420 & 19300 \\
0.005 & 330 & 7530 \\
0.01 & 267 & 3670 \\
0.02 & 208 & 1770 \\
0.05 & 127 & 665 \\
0.1 & 76.0 & 284 \\
0.2 & 40.7 & 126 \\
0.3 & 27.0 & 75.9 \\
0.5 & 15.1 & 40.7 \\
1.0 & 6.60 & 17.8 \\
1.4 & 4.90 & 12.3 \\
1.7 & 4.30 & 10.3 \\
2.0 & 4.05 & 9.11 \\
2.5 & 4.10 & 7.89 \\
3.0 & 4.30 & 7.33 \\
3.5 & 4.47 & 6.95 \\
4.0 & 4.66 & 6.72 \\
5.0 & 5.05 & 6.61 \\
6.0 & 6.88 & 6.88 \\
8.0 & 8.04 & \\
10 & 8.37 & \\
15 & 8.05 & \\
20 & 6.31 & \\
30 & 4.04 & \\
50 & 2.00 & \\
70 & 1.48 & \\
200 & 1.01 & \\
300 & 0.464 & \\
400 & 0.296 & \\
500 & 0.208 & \\
700 & 0.156 & \\
\hline \hline & 0.093 & \\
\hline
\end{tabular}

representative rotational excitation cross sections. Their EMT cross section is also recommended by Itikawa and Mason. ${ }^{21}$ In fact, it can be confirmed by using a two-term Boltzmann calculation that the EMT cross section of Yousfi and Benabdessadok, ${ }^{13}$ the 48 largest rotational excitation cross sections out of the 182 cross sections calculated using the molecular R-matrix method, ${ }^{50}$ and the 48 corresponding rotational de-excitation cross sections prepared by using the principle of detailed valance, each of the latter two cross section groups being weighted by the fractional population of the thermally excited initial rotational state ${ }^{82}$ at the vapor temperatures, 300 and $443 \mathrm{~K}$, can reproduce the above-mentioned temperature dependence of the drift velocity observed by Pack, Voshall, and Phelps ${ }^{24}$ quantitatively (unpublished). In conclusion, both the EMT and the TMT cross sections shown in Fig. 7 are recommended depending on the situation and are tabulated in Table 4. 


\section{Rotational Excitation Cross Sections}

The previous review by Itikawa and Mason ${ }^{21}$ recommended rotational excitation cross sections computed by Faure, Gorfinkiel, and Tennyson. ${ }^{50,60}$ There are no other published data on this process since that review. Therefore, we recommend the same data, given in Table 7 of Ref. 21, but extend it to somewhat higher energies using the cross sections computed by Machado et al. ${ }^{83}$ The recommended cross sections for the excitation from the ground rotational level $0_{00}$ to the levels with the angular momenta $J^{\prime}=0-4$ and summed up over allowed projections of $J^{\prime}$ on molecular axes are shown in Fig. 8.

Because no new data are available since the previous review, we comment only on the data ${ }^{83}$ added to the recommendation of Ref. 21. These cross sections for energies up to $500 \mathrm{eV}$ are calculated by Machado et al. ${ }^{83}$ using the Schwinger variational method combined with the distorted-wave approximation. Figure 9 compares these calculations with the two other calculations performed by Faure, Gorfinkiel, and Tennyson ${ }^{50,60}$ and by Gianturco et al. ${ }^{71}$ As one can see, the cross sections for $J=0 \rightarrow J^{\prime}=0,2,3$ transitions agree well with each other in the region of higher energies, where the distorted-wave approximation is applicable. However, for the $0 \rightarrow 1$ transition, the cross section computed by Machado et al. ${ }^{83}$ is about a factor of 1.5-2 smaller than in the two other calculations. This is the reason why we have not included the $0 \rightarrow 1$ cross section computed by Machado et al. ${ }^{83}$ into the recommended dataset. The recommended datasets are shown in Fig. 8 and given in Table 5.

In addition, in the supplementary material, we give the cross sections for individual transitions $J_{K_{a}, K_{c}} \rightarrow J_{K_{a}^{\prime}, K_{c}^{\prime}}^{\prime}$ obtained by Faure, Gorfinkiel, and Tennyson. ${ }^{50,60}$ The energies of different rotational levels $J_{K_{a}, K_{c}}$ are given in Table 6 of Itikawa and Mason ${ }^{21}$ (reproduced from Ref. 84). Figure 10 shows a few examples of the cross section for individual transitions $J_{K_{a}, K_{c}} \rightarrow J_{K_{a}^{\prime}, K_{c}^{\prime}}^{\prime}$ obtained in the two calculations,

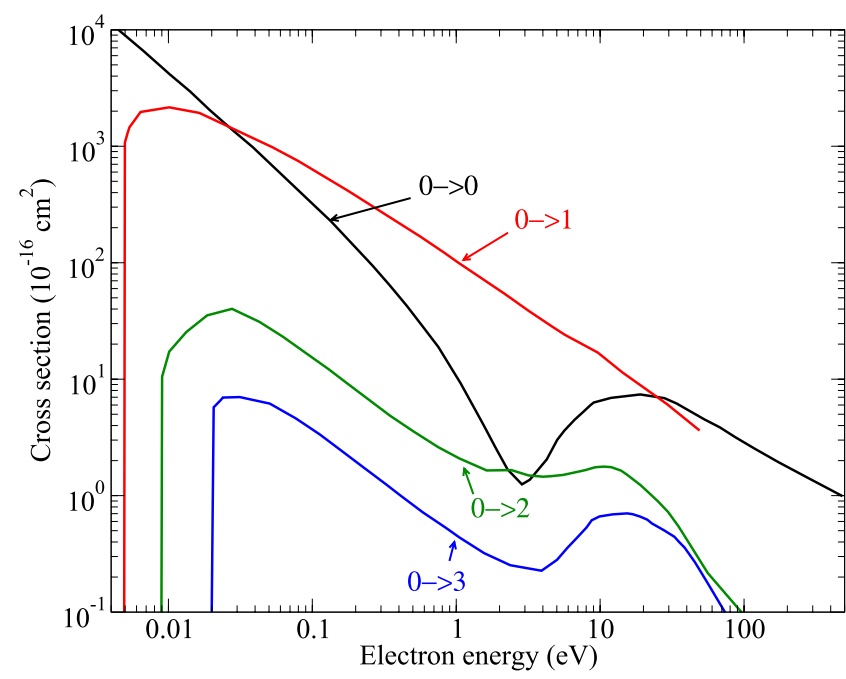

FIG. 8. Recommended cross sections for rotational excitation of $\mathrm{H}_{2} \mathrm{O}$ from the ground rotational level $0_{00}$ to excited rotational levels with $\mathrm{J}^{\prime}=1,2$, and 3 . The rotationally elastic cross section $0_{00} \rightarrow 0_{00}$ is also shown.

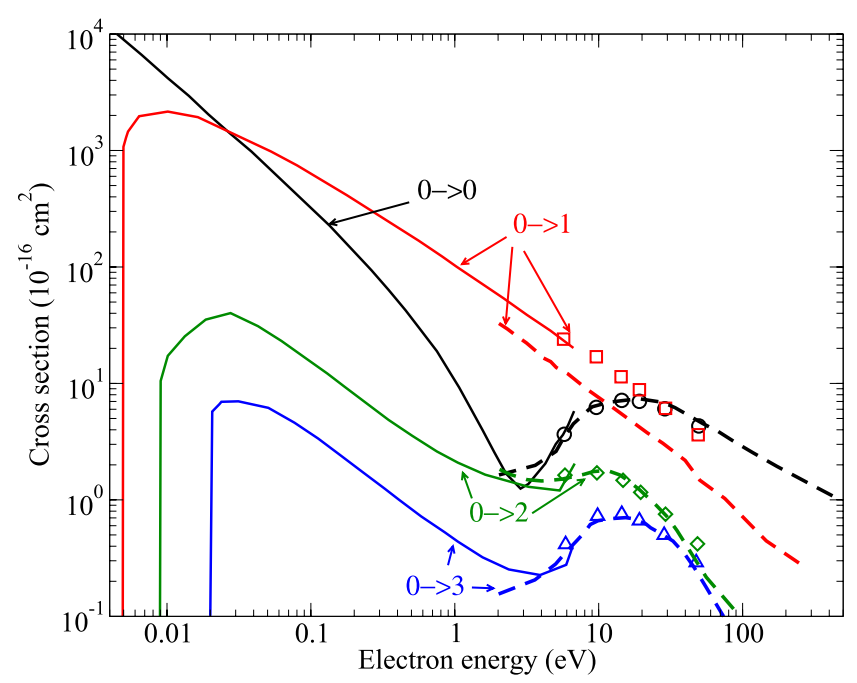

FIG. 9. Comparison of cross sections for rotational excitation from different theoretical calculations. The shown cross sections correspond to the transitions $0_{00} \rightarrow J^{\prime}=0-3$ where a summation over final states with the same $J^{\prime}$ but different $K_{a}^{\prime}$ and $K_{c}^{\prime}$ is performed. Solid lines represent the cross sections computed by Faure, Gorfinkiel, and Tennyson ${ }^{50,60}$ (as cited by Itikawa and Mason ${ }^{21}$ ), symbols are the data of Gianturco et al., and dashed lines are the cross sections computed by Machado et al.

performed by Faure, Gorfinkiel, and Tennyson ${ }^{50,60}$ and by Čurík et al. ${ }^{36}$

It is quite extraordinary that no beam measurements of the rotational excitation of such an important molecule have been made so far. We are aware of only one study ${ }^{82}$ where rotational excitation of $\mathrm{H}_{2} \mathrm{O}$ was investigated experimentally. In this study, the DCS of rotational excitation and de-excitation was estimated from the energy loss in electron $-\mathrm{H}_{2} \mathrm{O}$ collisions at two scattering energies in a gas with a relatively broad distribution over initial rotational states of $\mathrm{H}_{2} \mathrm{O}$ so that the cross sections were not measured for individual rotational transitions. It is highly desirable to have experimental data, especially at energies very close to rotational thresholds and near the resonance region around $3 \mathrm{eV}$.

\section{Vibrational Excitation Cross Sections}

Water has three vibrational modes whose excitation energies are given in Table 6 . All modes can be excited by dipole-allowed transitions. In the absence of any low-lying resonances in the electronwater system, vibrational excitation is dominated by $\Delta v=1$ excitations. There are a number of evaluations of the vibrational cross sections for $\mathrm{H}_{2} \mathrm{O}$, including ones from swarm and beam experiments as well as from theory. The closeness of the excitation energy of the two stretching modes means that, except for fragmentary results (i.e., only a few DCSs) of Allan and Moreira ${ }^{85}$ and Makochekanwa et al., ${ }^{56}$ no experimental information is available on the vibrational cross sections of the individual stretching mode, $(000) \rightarrow(100)$ and $(000) \rightarrow(001)$. As the experiment has not distinguished between stretching excitations, measurements usually provide two cross sections: one for bending excitation and the other for stretching, which is the sum of the (100) and (001) excitation cross sections. 
TABLE 5. Recommended cross sections for rotational excitation of $\mathrm{H}_{2} \mathrm{O}$ from the ground rotational level $0_{00}$ to excited rotational levels with $J^{\prime}=1,2$, and 3

\begin{tabular}{|c|c|c|c|c|c|c|c|}
\hline Energy (eV) & $\begin{array}{c}J=0-J^{\prime}=0 \\
\left(10^{-16} \mathrm{~cm}^{2}\right)\end{array}$ & $\begin{array}{l}\text { Energy } \\
(\mathrm{eV})\end{array}$ & $\begin{array}{c}J=0-J^{\prime}=1 \\
\left(10^{-16} \mathrm{~cm}^{2}\right)\end{array}$ & $\begin{array}{l}\text { Energy } \\
(\mathrm{eV})\end{array}$ & $\begin{array}{c}J=0-J^{\prime}=2 \\
\left(10^{-16} \mathrm{~cm}^{2}\right)\end{array}$ & $\begin{array}{c}\text { Energy } \\
(\mathrm{eV})\end{array}$ & $\begin{array}{c}J=0-J^{\prime}=3 \\
\left(10^{-16} \mathrm{~cm}^{2}\right)\end{array}$ \\
\hline $1.0173 \times 10^{-3}$ & 47186 & $4.9290 \times 10^{-3}$ & 0.10004 & $8.9430 \times 10^{-3}$ & 0.09822 & $1.9997 \times 10^{-2}$ & 0.10096 \\
\hline $1.4213 \times 10^{-3}$ & 33906 & $4.9810 \times 10^{-3}$ & 1074.3 & $9.0370 \times 10^{-3}$ & 10.511 & $2.0634 \times 10^{-2}$ & 5.734 \\
\hline $2.0277 \times 10^{-3}$ & 23920 & $5.1940 \times 10^{-3}$ & 1290.8 & $1.0138 \times 10^{-2}$ & 17.256 & $2.3148 \times 10^{-2}$ & 6.642 \\
\hline $2.8330 \times 10^{-3}$ & 16568 & $5.3590 \times 10^{-3}$ & 1454.5 & $1.3303 \times 10^{-2}$ & 25.375 & $2.3885 \times 10^{-2}$ & 6.954 \\
\hline $3.8762 \times 10^{-3}$ & 11689 & $6.4010 \times 10^{-3}$ & 1969.1 & $1.8587 \times 10^{-2}$ & 35.313 & $3.1342 \times 10^{-2}$ & 7.018 \\
\hline $4.7770 \times 10^{-3}$ & 9377 & $1.0138 \times 10^{-2}$ & 2158.5 & $2.7648 \times 10^{-2}$ & 40.156 & $5.0690 \times 10^{-2}$ & 6.171 \\
\hline $6.6740 \times 10^{-3}$ & 6616 & $1.6396 \times 10^{-2}$ & 1933.3 & $4.2883 \times 10^{-2}$ & 31.054 & $7.6990 \times 10^{-2}$ & 4.6004 \\
\hline $9.3250 \times 10^{-3}$ & 4582.4 & $5.2850 \times 10^{-2}$ & 980.1 & $6.2470 \times 10^{-2}$ & 23.149 & $1.1216 \times 10^{-1}$ & 3.367 \\
\hline $1.0138 \times 10^{-2}$ & 4180.4 & $8.0280 \times 10^{-2}$ & 744.1 & $9.1010 \times 10^{-2}$ & 16.634 & $1.6001 \times 10^{-1}$ & 2.4194 \\
\hline $1.4164 \times 10^{-2}$ & 2949.2 & $1.1942 \times 10^{-1}$ & 554.7 & $1.2983 \times 10^{-1}$ & 12.174 & $2.2828 \times 10^{-1}$ & 1.7385 \\
\hline $1.9380 \times 10^{-2}$ & 2042.8 & $1.7764 \times 10^{-1}$ & 413.5 & $1.7037 \times 10^{-1}$ & 9.414 & $3.2567 \times 10^{-1}$ & 1.2492 \\
\hline $2.7648 \times 10^{-2}$ & 1389.2 & $2.5878 \times 10^{-1}$ & 308.24 & $2.4305 \times 10^{-1}$ & 6.765 & $4.0986 \times 10^{-1}$ & 1.0022 \\
\hline $3.8628 \times 10^{-2}$ & 980.1 & $3.8495 \times 10^{-1}$ & 225.59 & $3.4675 \times 10^{-1}$ & 4.861 & $5.8470 \times 10^{-1}$ & 0.7201 \\
\hline $5.2850 \times 10^{-2}$ & 678.9 & $5.6080 \times 10^{-1}$ & 168.17 & $5.0510 \times 10^{-1}$ & 3.5576 & $8.5180 \times 10^{-1}$ & 0.52704 \\
\hline $7.2310 \times 10^{-2}$ & 470.21 & $8.1690 \times 10^{-1}$ & 123.08 & $7.5140 \times 10^{-1}$ & 2.6038 & $1.0498 \times 10^{0}$ & 0.43864 \\
\hline $9.8940 \times 10^{-2}$ & 325.69 & $1.0281 \times 10^{0}$ & 100.57 & $1.0498 \times 10^{0}$ & 2.0889 & $1.5616 \times 10^{0}$ & 0.32103 \\
\hline $1.3537 \times 10^{-1}$ & 225.59 & $1.4977 \times 10^{0}$ & 73.6 & $1.6283 \times 10^{0}$ & 1.6453 & $2.3720 \times 10^{0}$ & 0.25286 \\
\hline $1.8139 \times 10^{-1}$ & 153.41 & $2.1818 \times 10^{0}$ & 53.869 & $2.4159 \times 10^{0}$ & 1.65692 & $3.9172 \times 10^{0}$ & 0.22648 \\
\hline $2.4305 \times 10^{-1}$ & 104.33 & $3.1783 \times 10^{0}$ & 38.708 & $3.1825 \times 10^{0}$ & 1.49218 & $5.0200 \times 10^{0}$ & 0.28117 \\
\hline $2.6425 \times 10^{-1}$ & 93.45 & $4.6301 \times 10^{0}$ & 28.33 & $4.0100 \times 10^{0}$ & 1.45384 & $5.9280 \times 10^{0}$ & 0.35654 \\
\hline $3.4675 \times 10^{-1}$ & 63.55 & $5.7060 \times 10^{0}$ & 24.015 & $4.5280 \times 10^{0}$ & 1.46732 & $7.0000 \times 10^{0}$ & 0.44266 \\
\hline $4.5501 \times 10^{-1}$ & 42.43 & $9.6230 \times 10^{0}$ & 16.942 & $5.5220 \times 10^{0}$ & 1.50629 & $8.0420 \times 10^{0}$ & 0.53237 \\
\hline $5.8470 \times 10^{-1}$ & 28.33 & $1.4314 \times 10^{1}$ & 11.416 & $7.0490 \times 10^{0}$ & 1.60696 & $8.7430 \times 10^{0}$ & 0.6149 \\
\hline $7.5140 \times 10^{-1}$ & 18.915 & $1.9180 \times 10^{1}$ & 8.828 & $7.9010 \times 10^{0}$ & 1.65649 & $9.8920 \times 10^{0}$ & 0.66256 \\
\hline $9.2610 \times 10^{-1}$ & 12.4 & $2.9133 \times 10^{1}$ & 6.115 & $9.2260 \times 10^{0}$ & 1.75117 & $1.2183 \times 10^{1}$ & 0.69029 \\
\hline $1.0720 \times 10^{0}$ & 9.243 & $4.9130 \times 10^{1}$ & 3.6236 & $1.0600 \times 10^{1}$ & 1.77592 & $1.5415 \times 10^{1}$ & 0.70445 \\
\hline $1.2938 \times 10^{0}$ & 6.059 & & & $1.1945 \times 10^{1}$ & 1.75656 & $1.6813 \times 10^{1}$ & 0.69317 \\
\hline $1.5616 \times 10^{0}$ & 3.972 & & & $1.3994 \times 10^{1}$ & 1.63828 & $1.8940 \times 10^{1}$ & 0.66167 \\
\hline $1.8848 \times 10^{0}$ & 2.5564 & & & $1.5396 \times 10^{1}$ & 1.51197 & $2.1247 \times 10^{1}$ & 0.62202 \\
\hline $2.2749 \times 10^{0}$ & 1.6758 & & & $1.7235 \times 10^{1}$ & 1.35635 & $2.2967 \times 10^{1}$ & 0.57571 \\
\hline $2.8630 \times 10^{0}$ & 1.2492 & & & $1.9126 \times 10^{1}$ & 1.23005 & $2.7789 \times 10^{1}$ & 0.50456 \\
\hline $3.2455 \times 10^{0}$ & 1.3693 & & & $2.1411 \times 10^{1}$ & 1.08119 & $3.2828 \times 10^{1}$ & 0.44295 \\
\hline $4.2587 \times 10^{0}$ & 2.0509 & & & $2.3556 \times 10^{1}$ & 0.96616 & $3.5721 \times 10^{1}$ & 0.395 \\
\hline $5.0340 \times 10^{0}$ & 3.0157 & & & $2.5137 \times 10^{1}$ & 0.89727 & $3.8710 \times 10^{1}$ & 0.35688 \\
\hline $5.6470 \times 10^{0}$ & 3.6236 & & & $2.9657 \times 10^{1}$ & 0.72541 & $4.5640 \times 10^{1}$ & 0.26722 \\
\hline $6.6690 \times 10^{0}$ & 4.5001 & & & $3.4989 \times 10^{1}$ & 0.54638 & $5.5330 \times 10^{1}$ & 0.18116 \\
\hline $7.6440 \times 10^{0}$ & 5.2455 & & & $4.2430 \times 10^{1}$ & 0.37451 & $7.2860 \times 10^{1}$ & 0.10229 \\
\hline $8.5370 \times 10^{0}$ & 5.9619 & & & $5.5900 \times 10^{1}$ & 0.21692 & $9.4290 \times 10^{1}$ & 0.06297 \\
\hline $9.0220 \times 10^{0}$ & 6.3057 & & & $9.4350 \times 10^{1}$ & 0.1022 & $1.2303 \times 10^{2}$ & 0.04858 \\
\hline $1.1894 \times 10^{1}$ & 6.9069 & & & $1.7783 \times 10^{2}$ & 0.05186 & $1.6875 \times 10^{2}$ & 0.0337 \\
\hline $1.9026 \times 10^{1}$ & 7.3929 & & & $3.5416 \times 10^{2}$ & 0.03013 & $2.3853 \times 10^{2}$ & 0.02717 \\
\hline $2.8013 \times 10^{1}$ & 6.8757 & & & $4.8290 \times 10^{2}$ & 0.02707 & $4.6250 \times 10^{2}$ & 0.01294 \\
\hline $3.3991 \times 10^{1}$ & 6.1872 & & & & & & \\
\hline $5.2890 \times 10^{1}$ & 4.5232 & & & & & & \\
\hline $6.7820 \times 10^{1}$ & 3.8632 & & & & & & \\
\hline $8.6980 \times 10^{1}$ & 3.1745 & & & & & & \\
\hline $1.1787 \times 10^{2}$ & 2.5429 & & & & & & \\
\hline $1.7355 \times 10^{2}$ & 1.9398 & & & & & & \\
\hline $2.7761 \times 10^{2}$ & 1.4225 & & & & & & \\
\hline $4.8250 \times 10^{2}$ & 0.9909 & & & & & & \\
\hline
\end{tabular}




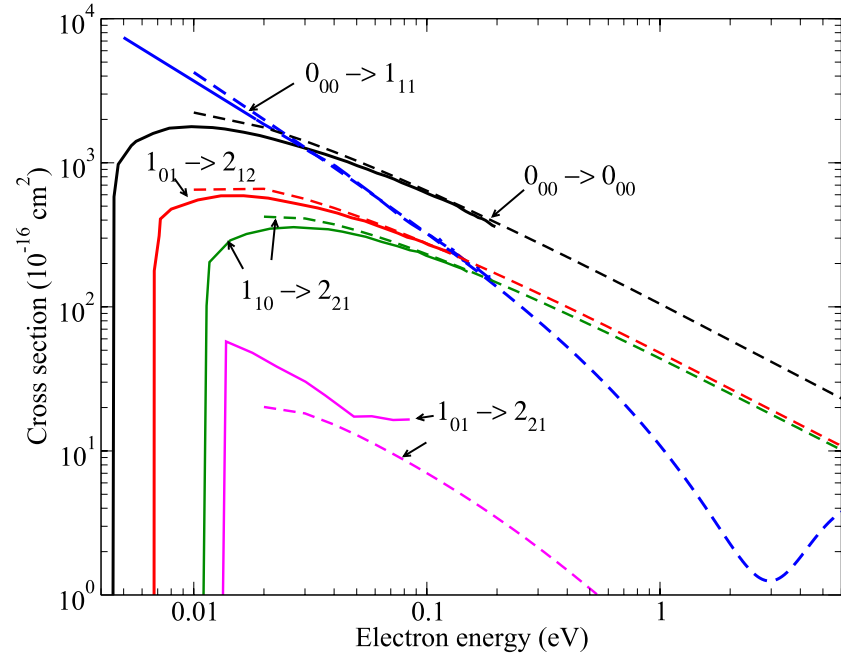

FIG. 10. Comparison of cross sections for rotational excitation $J_{K_{a}, K_{c}} \rightarrow j_{j}$, from different theoretical calculations. In contrast to Fig. 9, cross sections for indivividual final states $J^{\prime}$ are shown. Solid lines represent the cross sections obtained by Curik et al., ${ }^{3{ }^{3}}$ and dashed lines are the data of Faure, Gorfinkiel, and Tennyson. ${ }^{5}$

Below, we discuss studies separately for low energies, up to $3 \mathrm{eV}$, and higher energies.

In their review, Itikawa and Mason ${ }^{21}$ adopted the vibrational cross sections derived from the swarm experiment of Yousfi and Benabdessadok ${ }^{13}$ to extend recommended cross sections determined by beam measurement to energies below $1 \mathrm{eV}$. Recently, Ness et al. ${ }^{12}$ tested the swarm data of Yousfi and Benabdessadok with a new analysis of the transport coefficients of electrons in water vapor. Ness et al. ${ }^{12}$ solved the Boltzmann equation using an improved method. Their analysis showed that the vibrational cross sections of Yousfi and Benabdessadok cannot reproduce the experimental values of the drift velocity. With the use of their own recommended vibrational cross sections (based on the experiment of Seng and Linder ${ }^{86}$ ), Ness et al. ${ }^{12}$ succeeded in reproducing the measured values of the drift velocity. The cross sections of Seng and Linder are shown in Figs. 11 and 12. Except for near the threshold peak, the data of Seng and Linder are consistent with the previous recommended values. The analysis shows that the most important vibrational cross section in the swarm is near thresholds. Accordingly, we adopt the vibrational excitation cross sections of Seng and Linder near the threshold as our recommended value at low energy, up to $3 \mathrm{eV}$.

There are four beam measurements of cross sections for vibrational excitation by Seng and Linder, ${ }^{86}$ by Shyn, Cho, and Cravens, ${ }^{87}$ by El-Zein, Brunger, and Newell, ${ }^{88}$ and by the group of Khakoo. ${ }^{89}$ The data are shown in Figs. 11 and 12. The two older

TABLE 6. Energies of the normal modes of $\mathrm{H}_{2} \mathrm{O}$ in the ground electric state ${ }^{96}$

Mode Energy (eV)

Bending (010)

0.198

Symmetric stretching (100)

0.453

Asymmetric stretching (001)

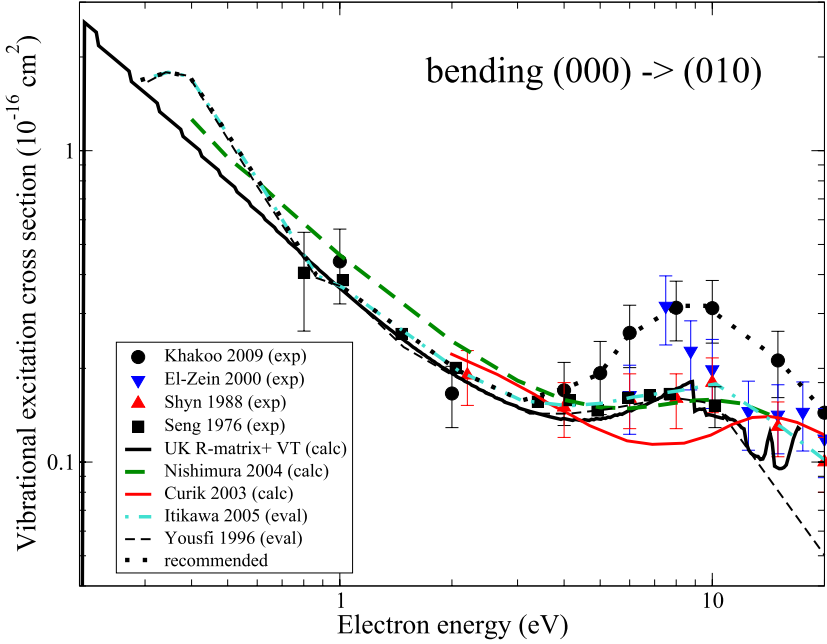

FIG. 11. Comparison of cross sections available in the literature for the excitation of the bending mode $(000) \rightarrow(010)$. The black dotted line is the cross section recommended in this study. The black solid line, representing UK R-matrix + VT, is the theoretical result obtained in this study.

experiments $^{86,87}$ agree well with each other for the bending and stretching excitation. The stretching excitation cross section of ElZein et al. ${ }^{88}$ also agrees with the older experiments. However, the most recent measurements performed by Khakoo et al. ${ }^{89}$ for both types of modes as well as the bending excitation cross section by El-Zein et al. are all significantly larger than the data from the older experiments at energies above $3 \mathrm{eV}$.

For energies above $3 \mathrm{eV}$, we recommend the cross sections obtained using a beam experiment by Khakoo et al. ${ }^{89}$ At energies

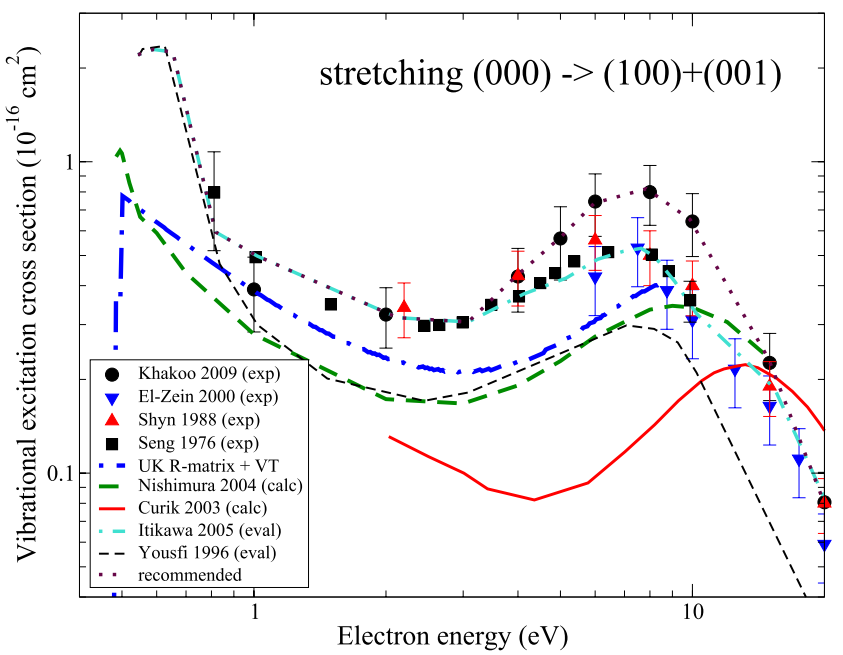

FIG. 12. Comparison of cross sections available in the literature for the excitation of the stretching modes $(000) \rightarrow(100)+(001)$. The blue dotted-dashed line, representing UK R-matrix $+V T$, is the theoretical result obtained in this study. 


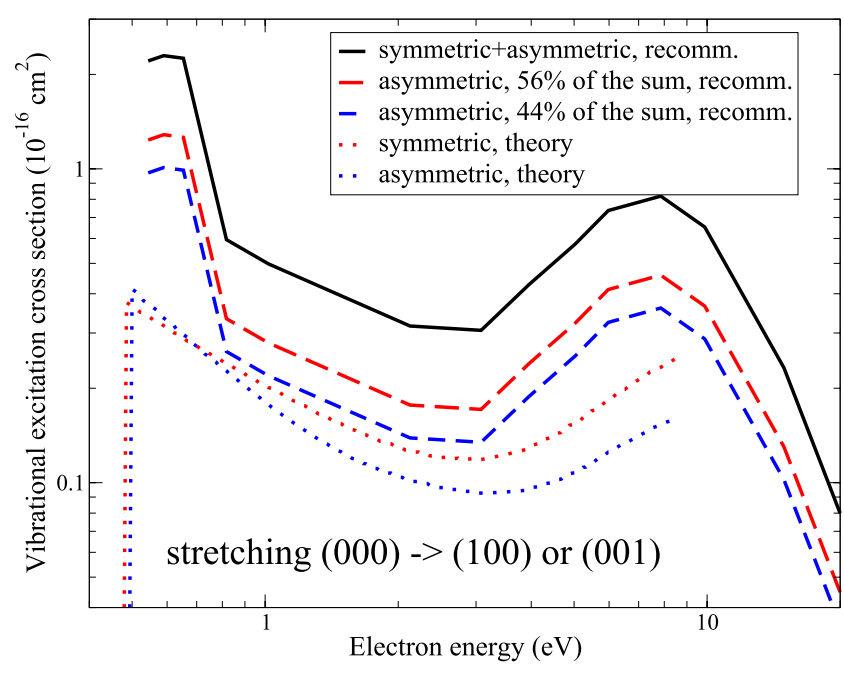

FIG. 13. Recommended cross sections for the excitation of the stretching modes. Relative magnitudes of the symmetriclasymmetric theoretical cross sections at $3 \mathrm{eV}$ are $0.56 / 0.44$. The recommended cross sections (red and blue dashed lines) for the symmetric and asymmetric modes are $56 \%$ and $44 \%$ of the sum of the two cross sections, represented by the solid curve in the figure. The dotted lines show the results of R-matrix calculations performed in this study.

about $100 \mathrm{eV}$ we take the data of Seng and Linder which extend to the lower energies. The resulting values are shown in Fig. 13 and Table 7. The uncertainty of those values is $30 \%$ below $1 \mathrm{eV}$ and $27 \%$ above that energy, as derived from the respective original papers. ${ }^{86,89}$

Several theoretical studies were devoted to the vibrational excitation of $\mathrm{H}_{2} \mathrm{O}$ by electron impact. In their study, Nishimura and Itikawa $^{90}$ used a close-coupling method taking into account an $a b$ initio electrostatic potential of interaction between the incident electron and the target. The effects of electron exchange and target polarization are taken into account approximately. Curik and Carsky $^{91}$ also used an $a b$ initio approach based on two-channel Lippmann-Schwinger equations expanded in momentum space with static and exchange contributions accounted for explicitly. The theoretical study of Nishimura and Gianturco ${ }^{92}$ described the electron scattering using vibrational close-coupling equations with the electron-target interaction potential represented by a sum of an $a b$ initio electrostatic, an electron exchange, and a polarization term. The data from the three theoretical studies are also shown in Figs. 11 and 12 . The most recent study by Nishimura and Gianturco ${ }^{92}$ seems to be the most accurate one in terms of the theoretical method. The cross section for the bending mode from this work agrees well with the two older experiments, ${ }^{86,87}$ but the theoretical stretching-mode cross section is about two times smaller than the experimental data for energies below $10 \mathrm{eV}$. We note that de-excitation rate coefficients given by Faure and Josselin ${ }^{93}$ were obtained from the data of Nishimura and Gianturco ${ }^{92}$ using the principle of detailed balance.

In this study, we have also performed calculations of the vibrational excitation cross sections using the approach developed by Liu et al. ${ }^{94}$ and applied to the excitation of $\mathrm{NO}_{2}$. The approach combines the UK R-matrix calculations and the vibrational frame transformation. In the R-matrix calculations, we used the DZP electronic basis set, using the configuration interaction (CI) method $^{95}$ built on Hartree-Fock orbitals. Only the lowest orbital was frozen in the calculations. The remaining 8 electrons of $\mathrm{H}_{2} \mathrm{O}$ were allowed to be distributed over the 8 lowest-energy orbitals. The $\mathrm{R}$-matrix radius was chosen to be $10 \mathrm{a}_{0}$. The results of the calculations are shown in Figs. 11-13.

While in this review we recommend the mentioned experimental cross sections, the ratio of the calculated cross sections for the individual stretching modes allows us to deconvolve the experimental cross section and estimate individual contributions for the excitation of the symmetric and asymmetric stretching modes. We recommend the ratio of $0.56 / 0.44$ between the symmetric/asymmetric stretching mode contributions. The ratio is derived from the theoretical

TABLE 7. Recommended vibrational excitation cross sections for e $+\mathrm{H}_{2} \mathrm{O}$

\begin{tabular}{|c|c|c|c|}
\hline \multicolumn{2}{|c|}{$(010)$} & \multicolumn{2}{|c|}{$(100)+(001)$} \\
\hline Electron energy $(\mathrm{eV})$ & $\operatorname{CS}\left(10^{-16} \mathrm{~cm}^{2}\right)$ & Electron energy $(\mathrm{eV})$ & $\operatorname{CS}\left(10^{-16} \mathrm{~cm}^{2}\right)$ \\
\hline 0.198 & 0 & 0.453 & 0 \\
\hline 0.26 & 2.15 & 0.53 & 4.44 \\
\hline 0.5 & 1.162 & 0.875 & 0.81 \\
\hline 1 & 0.441 & 1 & 0.389 \\
\hline 2 & 0.166 & 2 & 0.323 \\
\hline 4 & 0.17 & 4 & 0.428 \\
\hline 5 & 0.193 & 5 & 0.567 \\
\hline 6 & 0.26 & 6 & 0.745 \\
\hline 8 & 0.313 & 8 & 0.799 \\
\hline 10 & 0.312 & 10 & 0.643 \\
\hline 15 & 0.212 & 15 & 0.226 \\
\hline 20 & 0.144 & 20 & 0.0806 \\
\hline 30 & 0.0972 & 30 & 0.0245 \\
\hline 50 & 0.0458 & 50 & 0.0159 \\
\hline 100 & 0.0108 & 100 & 0.006 \\
\hline
\end{tabular}


calculations performed in this study at $3 \mathrm{eV}$. As one can see in Fig. 13, the symmetric/asymmetric stretching mode ratio in the calculation changes but not much between 1 and $20 \mathrm{eV}$. The recommended cross sections for the excitation of the symmetric and asymmetric stretching modes are shown in the figure by red and blue dashed lines, respectively.

\section{Electronic-Excitation Cross Section}

Experimentally, cross sections for the $\mathrm{H}_{2} \mathrm{O}$ electronic excitation to the lowest electronic states were measured by Lassettre et al., ${ }^{97}$ Trajmar et al., ${ }^{98}$ and, more recently, by Khakoo's group, ${ }^{99,100}$ Brunger's group, ${ }^{101-104}$ and Matsui et al. ${ }^{69}$ There have also been several theoretical studies of electronic excitation of $\mathrm{H}_{2} \mathrm{O}$, in particular, using the UK R-matrix approach, ${ }^{73}$ the SMC method, ${ }^{99,100}$ and the Kohn variational method. ${ }^{70}$ Data from the most recent experimental and theoretical studies for the excitation to the two lowest electronic states are shown in Figs. 14 and 15. In the most recent experimental work, Matsui et al. ${ }^{69}$ claimed that the ambiguity in the deconvolution of electron energy-loss spectra is reduced compared to the previous studies. They also found that the $\mathrm{BE} f$-scaling model $^{101,105}$ for the spin-allowed $X^{1} A_{1} \rightarrow \tilde{A}^{1} B_{1}$ transition reproduces well the ICS, as shown in Fig. 14 . However, the BE $f$-scaling model is less reliable at low energies. ${ }^{106}$ Therefore, for the excitation of the $\tilde{A}^{1} B_{1}$ state, see Table 9, we recommend the data of Ralphs et al. for energies below $17 \mathrm{eV}$ and the $\mathrm{BE} f$ data for energies above $17 \mathrm{eV}$, which agree well with Matsui's data. For the excitation of the $\tilde{a}^{3} B_{1}$ sate, we recommend Matsui's data for energies below $12 \mathrm{eV}$ and Ralphs's data for energies above $12 \mathrm{eV}$. Ralphs et al. ${ }^{100}$ gave also cross sections for the excitation of four more electronic states, ${ }^{3} A_{2},{ }^{1} A_{2},{ }^{\sim} b^{3} A_{1}$, and ${ }^{1} B^{1} A_{1}$. Energies of these states are given in Table 8. Due to the disagreement with theoretical calculations and with the available previous experimental data of Thorn et al., ${ }^{101}$ these cross sections should be used with caution; see also Ref. 107.

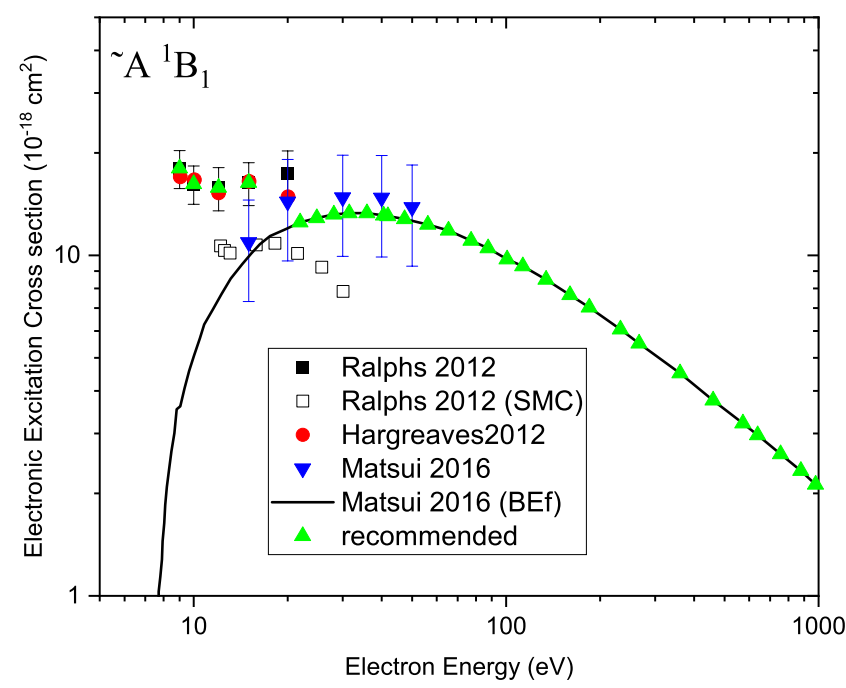

FIG. 14. Cross sections for the electron impact electronic excitation of the $\tilde{A}^{1} B_{1}$ state obtained by Hargeaves et al., ${ }^{99}$ Ralphs et al., ${ }^{100}$ and Matsui et al. ${ }^{6}$

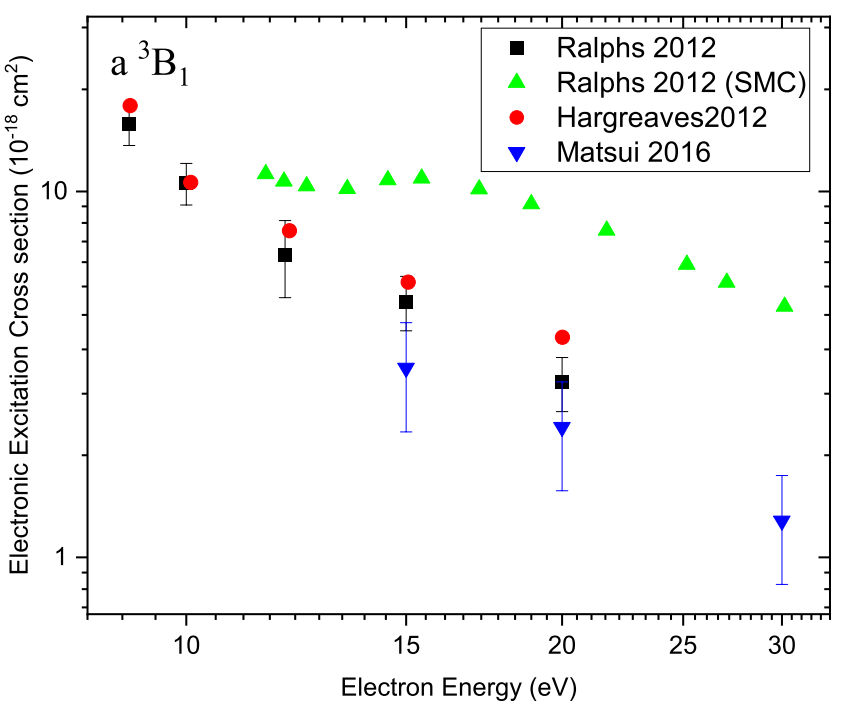

FIG. 15. Cross sections for the electron impact electronic excitation of the $\tilde{a}^{3} B_{1}$ state obtained by Hargeaves et al.. ${ }^{99}$ Ralphs et al.. ${ }^{100}$ and Matsui et al. ${ }^{9}$

TABLE 8. Excitation energies ${ }^{102}$ of the lowest electronic states of $\mathrm{H}_{2} \mathrm{O}$

\begin{tabular}{lc}
\hline \hline State & Excitation energy $(\mathrm{eV})$ \\
\hline$\tilde{a}^{3} B_{1}$ & 7.14 \\
$\tilde{A}{ }^{1} B_{1}$ & 7.49 \\
${ }^{3} A_{2}$ & 8.90 \\
${ }^{1} A_{2}$ & 9.20 \\
$\tilde{b}^{3} A_{1}$ & 9.46 \\
$\tilde{B}{ }^{1} A_{1}$ & 9.73 \\
\hline \hline
\end{tabular}

\section{Dissociation into Neutrals}

As discussed above, the ionization cross section in $\mathrm{H}_{2} \mathrm{O}$ is significantly smaller than in the isoelectronic $\mathrm{CH}_{4}$, and cross sections for the formation of $\mathrm{H}^{+}$and $\mathrm{OH}^{+}$ions are less than $20 \%$ of the total ionization each. Out of these fragments, the hydroxyl ions (and radical) are of primary importance for the chemical processes in the Earth's atmosphere. ${ }^{108}$ "Hydroxyl radicals are a key component of the self-cleaning capacity of the atmosphere, as they rid the air of many dangerous pollutants," says a comment ${ }^{109}$ to a detailed study of the $\mathrm{OH}$ atmospheric concentration. ${ }^{110}$ As far as the yield of the $\mathrm{OH}^{-}$ion is very small (see Sec. 9 on dissociative attachment), it seems that the formation of the neutral radical $\mathrm{OH}$ is one of the main "exit" channels in electron scattering on $\mathrm{H}_{2} \mathrm{O}$. McConkey and collaborators ${ }^{111}$ used laser-induced fluorescence to measure the formation of the $\mathrm{OH}$ radical; they normalized the relative yields to the $\mathrm{H}^{-}$formation at $6.5 \mathrm{eV}$ according to Melton. ${ }^{112}$ In the present work, we recommend a lower (not $6.7 \times 10^{-18} \mathrm{~cm}^{2}$ but $4.6 \times 10^{-18} \mathrm{~cm}^{2}$ ) cross section for the formation of $\mathrm{H}^{-}$; as a consequence, we renormalized also the $\mathrm{OH}$ yield. Even after such a renormalization, the cross section for the formation of the $\mathrm{OH}$ neutral fragment ${ }^{113}$ is still very high, almost $1.5 \times 10^{-16} \mathrm{~cm}^{2}$ at $75 \mathrm{eV}$; see Fig. 16 . 


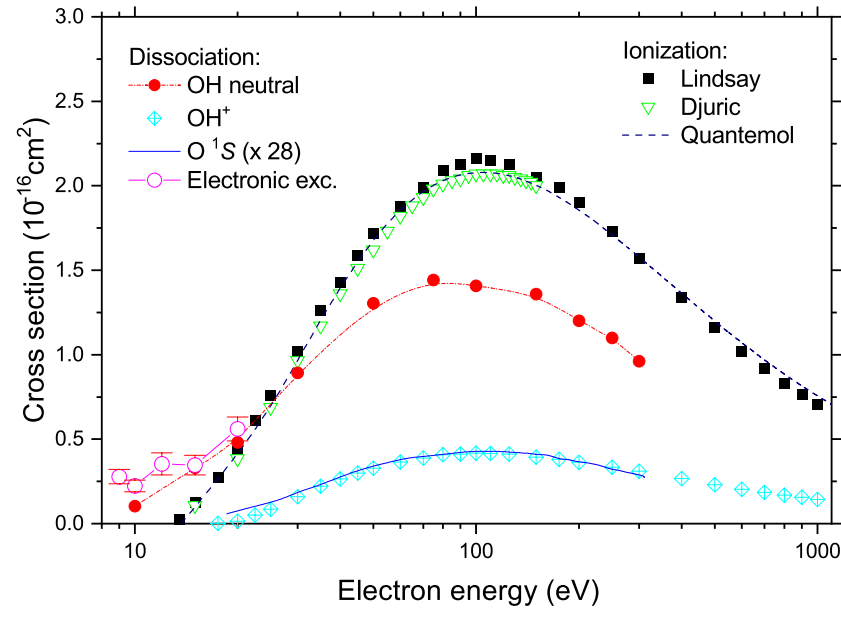

FIG. 16. Comparison of the total ionization ${ }^{118,119}$ cross sections with measurements of the yield of two neutral species ${ }^{113,117} \mathrm{OH}$ and $\mathrm{O}\left({ }^{1} \mathrm{~S}_{0}\right)$. The sum of the electronic excitation into six states ${ }^{100}$ up to $20 \mathrm{eV}$ is also shown. Tabulated data for $\mathrm{OH}$ and $\mathrm{O}$ are taken from the review by McConkey et al.

As noted by Harb et al., ${ }^{113}$ the $\mathrm{OH}$ radical was produced in high rotational states, which indicates that optically allowed electronic excitations are the leading mechanism. As seen in Fig. 16, the energy dependence of the $\mathrm{OH}$ production falls slowly with energy (which is typical for dipole-allowed electronic excitations) and does not follow the cross sections for partial ionizations. The most probable channel is therefore the formation of the two neutral species,

$$
\mathbf{e}+\mathbf{H}_{2} \mathbf{O} \rightarrow \mathbf{O H}+\mathbf{H}\left({ }^{2} \mathbf{S}_{1 / 2}\right)+\mathbf{e} .
$$

In Fig. 16, we give also the sum of the electronic-excitation cross section to $\operatorname{six}\left({ }^{3} B_{1},{ }^{1} B_{1},{ }^{3} A_{2},{ }^{1} A_{2},{ }^{3} A_{1},{ }^{1} A_{1}\right)$ states measured by Ralphs et al. ${ }^{100}$ (we use their data, as giving the excitation into six states, even if somewhat different from the more recent experiment performed by Matsui et al. ${ }^{69}$ of the excitation to the ${ }^{3} B_{1}$ and ${ }^{1} B_{1}$ states in the energy range of 2-100 eV). As seen from that figure, the absolute values for the sum of electronic excitations and the formation of the $\mathrm{OH}$ radical at $20 \mathrm{eV}$ coincide within the error bar. The optical emission from the $\mathrm{OH}$ radical formed in electron-induced dissociation was reviewed in detail by Itikawa and Mason. ${ }^{21}$ The two more recent measurements of the $\mathrm{OH}$ optical emission band $\tilde{A}^{2} \Sigma^{+} \rightarrow X^{2} \Pi$ disagree: the data of Schappe and Urban ${ }^{114}$ confirm the earlier experiment performed by Beenakker et al., ${ }^{115}$ with the maximum of $0.9 \times 10^{-18} \mathrm{~cm}^{2}$, and those by Khodorkovskii et al. ${ }^{116}$ are by few folds lower. All measurements agree that the (sharp) maximum of the $\mathrm{OH} \tilde{A}^{2} \Sigma^{+} \rightarrow X^{2} \Pi$ optical emission is situated at about $15-20 \mathrm{eV}$. As recalled by Khodorkovskii et al. ${ }^{116}$ the $\mathrm{OH}$ radical in the $\tilde{A}^{2} \Sigma^{+}$excited state may come from the dissociation of two excited $\mathrm{H}_{2} \mathrm{O}$ molecular electronic states: ${ }^{1} A_{1}$ and ${ }^{3} A_{1}$. According to Ralph et al., ${ }^{100}$ the cross section for the excitation of the $\mathrm{H}_{2} \mathrm{O}$ molecule to these states amounts at $20 \mathrm{eV}$ to about $20 \times 10^{-18} \mathrm{~cm}^{2}$. While the cross section for the production of the $\mathrm{OH}$ fragment is very large, the yield of $\mathrm{O}$ (in the ${ }^{1} S_{0}$ excited state) is two orders of magnitude lower, reaching a maximum of $1.5 \times 10^{-18} \mathrm{~cm}^{2}$ at $100 \mathrm{eV}$; see Ref. 111. This cross section was measured by the $\mathrm{XeO}^{*}$ excimer technique. ${ }^{117}$ An analog cross section for the production of $\mathrm{O}\left({ }^{1} S_{0}\right)$ from $\mathrm{O}_{2}$ amounts in its maximum to $2.08 \times 10^{-18} \mathrm{~cm}^{2}$, by a factor of 10 lower than the $\mathrm{O}\left({ }^{1} S_{0}\right)$ production from $\mathrm{N}_{2} \mathrm{O}$; see Ref. 111 .

The cross section for the production of $\mathrm{O}\left({ }^{1} S_{0}\right)$, multiplied by an arbitrary chosen factor, is shown in Fig. 16. As far as the $\mathrm{OH}$ radical seems to be produced mainly via the electronic excitation, the energy dependence of the $\mathrm{O}\left({ }^{1} S_{0}\right)$ cross sections suggests that this atomic species is produced in some partial ionization processes. Optical emission from $\mathrm{H}$ and $\mathrm{O}$ atoms (and $\mathrm{O}^{+}, \mathrm{O}_{2}^{+}$ions) was extensively reviewed by Itikawa and Mason. ${ }^{21}$ All cross sections show broad maxima at around $100 \mathrm{eV}$, indicating that also the atomic emission comes from the prior ionization rather than from the neutral dissociation of the $\mathrm{H}_{2} \mathrm{O}$ molecule. As a reference number for the sum of the UV emission from the two atomic species (and $\mathrm{O}^{+}, \mathrm{O}_{2}^{+}$ions) at $200 \mathrm{eV}$, we recall ${ }^{21}$ the number of $1.9 \times 10^{-18} \mathrm{~cm}^{2}$. Quite abundant (and pretty congruent) measurements of the electronic excitation, optical emission, and neutral dissociation open, potentially, the way for detailed theoretical studies of the excited states for the $\mathrm{H}_{2} \mathrm{O}$ molecule.

TABLE 9. Electron impact electronic-excitation cross section for $\mathrm{H}_{2} \mathrm{O}\left(\mathrm{A}^{1} \mathrm{~B}_{1}\right)$

\begin{tabular}{lccc}
\hline \hline For electron energy $(\mathrm{eV})$ & $\mathrm{CS}\left(10^{-18} \mathrm{~cm}^{2}\right)$ & Electron energy $(\mathrm{eV})$ & $\mathrm{CS} A^{1} B_{1}\left(10^{-18} \mathrm{~cm}^{2}\right)$ \\
\hline 9.0 & 18.02 & 87.5 & 10.51 \\
10.0 & 16.21 & 100.7 & 9.73 \\
12.0 & 15.80 & 113.1 & 9.29 \\
15.0 & 16.35 & 134.1 & 8.50 \\
21.9 & 12.50 & 160.1 & 7.64 \\
24.8 & 12.87 & 184.4 & 7.03 \\
28.1 & 13.19 & 232.3 & 6.06 \\
31.5 & 13.31 & 266.2 & 5.52 \\
35.8 & 13.31 & 360.4 & 4.51 \\
40.6 & 13.11 & 459.9 & 3.75 \\
41.8 & 13.04 & 572.0 & 3.21 \\
47.4 & 12.78 & 638.7 & 2.96 \\
56.1 & 12.31 & 756.5 & 2.61 \\
65.4 & 11.83 & 877.9 & 2.33 \\
77.3 & 11.04 & 977.7 & 2.12 \\
\hline \hline
\end{tabular}


TABLE 10. Cross sections for the production of the $\mathrm{OH}$ neutral fragment following electron impact on the $\mathrm{H}_{2} \mathrm{O}$ molecule. Measurements performed by Harb et al., ${ }^{1}$ tabulated data from Ref. 111 , renormalized to the present value of the DEA cross section (see text). The uncertainty is $\pm 40 \%$

\begin{tabular}{lc}
\hline \hline Electron $(\mathrm{eV})$ & Cross section $\left(10^{-16} \mathrm{~cm}^{2}\right)$ \\
\hline 10 & 0.103 \\
15 & 0.330 \\
20 & 0.481 \\
30 & 0.893 \\
50 & 1.30 \\
75 & 1.44 \\
100 & 1.41 \\
150 & 1.36 \\
200 & 1.20 \\
250 & 1.09 \\
300 & 0.96 \\
\hline \hline
\end{tabular}

The recommended values for the formation of the $\mathrm{OH}$ radical and $\mathrm{O}\left({ }^{1} S_{0}\right)$ atom are given in Tables 10 and 11 . Error bars on the given values are, according to the original experimental papers, ${ }^{113,117} 36 \%$ and $30 \%$, respectively.

\section{Ionization Cross Section}

Ionization cross sections for $\mathrm{H}_{2} \mathrm{O}$ have been investigated in many experiments. ${ }^{19,126}$ Similarly, several alternative approaches exist. ${ }^{127-129}$ In $\mathrm{CH}_{4}$ (see Ref. 49 ) and $\mathrm{N}_{2} \mathrm{O},{ }^{45}$ we found that the early experiment performed by Rapp and Briglia ${ }^{130}$ gave a very reliable integral ionization cross section. They used a simple method, measuring the total ion current; unfortunately, they did not publish data for $\mathrm{H}_{2} \mathrm{O}$. Similar methods of collecting the total ion current were used in the energy region of $0.1-20 \mathrm{keV}$ by Schutten et al. ${ }^{131}$ and by Djuric et al. ${ }^{119}$ from threshold up to $150 \mathrm{eV}$ : merging between these two sets gives good results; see Fig. 17. Orient and Srivastava ${ }^{122}$ used the method of crossed electron and target gas beams and a quadrupole mass spectrometer to get partial cross sections. Their data are higher by a factor of 2 at the maximum; see Fig. 17. A possible source of this increase could be the method of estimating the density of target molecules in the effusive beam: such density depends much on gas dynamic properties, different for each type of molecule. ${ }^{132}$ Note that also in $\mathrm{CH}_{4}{ }^{49}$ the data of Orient and Srivastava were slightly higher than other measurements. In the successive measurement, ${ }^{123}$ they improved the collection of ions, so the energy dependence of the total ionization cross sections is, within the error bar, the same as in other experiments, ${ }^{119,131}$ but a normalization by a factor of 0.7 is still needed; see Fig. 17.

The total ionization cross sections of Bolorizadeh and Rudd ${ }^{126}$ in the energy range of $50-2000 \mathrm{eV}$ were obtained by integration of DCSs-the declared error is $15 \%$. Straub et al. ${ }^{118}$ used a parallel plate apparatus with a time-of-flight spectrometer and position-sensitive detector. Their total ionization cross section agrees very well with the data of Djuric ${ }^{119}$ and Schutten et al., ${ }^{131}$ see Fig. 17. Lindsay and Mangan $^{28}$ recommended the results of Straub et al., rectifying some values (but within 1\%). As partial cross sections for the formation of $\mathrm{H}_{2} \mathrm{O}^{+}, \mathrm{OH}^{+}$, and $\mathrm{H}_{2}^{+}$, Lindsay and Mangan recommended the results of Straub et al. ${ }^{118}$ for $\mathrm{D}_{2} \mathrm{O}$ as the spectrometer used did not assure adequate precision for these signals in $\mathrm{H}_{2} \mathrm{O}$. More recently, the total ionization cross section in the range $50-5000 \mathrm{eV}$ was measured by Muñoz et ll $^{44}$ on the same apparatus as the TCS and using normalization to $\mathrm{N}_{2}$ ionization. Their data are in good (within 10\%) agreement with those of Straub et al. ${ }^{118}$ and Djuric et al. ${ }^{119}$ The maximum ${ }^{28}$ of the total ionization is $2.16 \times 10^{-16} \mathrm{~cm}^{2}$, much lower than the maximum in $\mathrm{CH}_{4}, 3.79 \times 10^{-16} \mathrm{~cm}^{2}$. This, roughly, reflects ${ }^{133}$ the "rule of thumb" that the maximum value of ionization cross sections is numerically $4 / 3 \alpha$ if the dipole polarizability $\alpha$ is expressed in $\AA^{3}$ ( $\alpha=1.5$ and 2.45 for $\mathrm{H}_{2} \mathrm{O}$ and $\mathrm{CH}_{4}$, respectively).

The Bethe-Born binary encounter (BEB) model, as applied to $\mathrm{H}_{2} \mathrm{O}$ by Hwang et al. ${ }^{134}$ slightly overestimates the total ionization cross section; see Fig. 17. The newer application of the BEB model, in the Quantemol package, ${ }^{120}$ with Hartree-Fock frozen orbitals agrees

TABLE 11. Cross sections for the production of the $O\left({ }^{1} S_{0}\right)$ atom in the excited ${ }^{1} S$ state, from Ref. 111 , measurements performed by Kedzierski et al. ${ }^{117}$ The uncertainty is $\pm 30 \%$

\begin{tabular}{lccc}
\hline \hline Electron $(\mathrm{eV})$ & Cross section $\left(10^{-16} \mathrm{~cm}^{2}\right)$ & Electron $(\mathrm{eV})$ & Cross section $\left(10^{-16} \mathrm{~cm}^{2}\right)$ \\
\hline 18.6 & 0.20 & 133.4 & 1.47 \\
22.5 & 0.36 & 141.3 & 1.46 \\
26.5 & 0.48 & 153.2 & 1.43 \\
30.4 & 0.67 & 161.1 & 1.42 \\
34.4 & 0.78 & 173.0 & 1.36 \\
42.3 & 1.04 & 180.9 & 1.33 \\
50.2 & 1.20 & 192.8 & 1.30 \\
54.2 & 1.25 & 200.7 & 1.28 \\
62.1 & 1.36 & 220.5 & 1.24 \\
70.0 & 1.39 & 240.3 & 1.16 \\
81.9 & 1.45 & 260.1 & 1.11 \\
93.8 & 1.49 & 283.9 & 1.05 \\
101.7 & 1.50 & 303.7 & 1.00 \\
113.6 & 1.50 & 319.5 & 0.95 \\
121.5 & 1.49 & & \\
\hline \hline
\end{tabular}




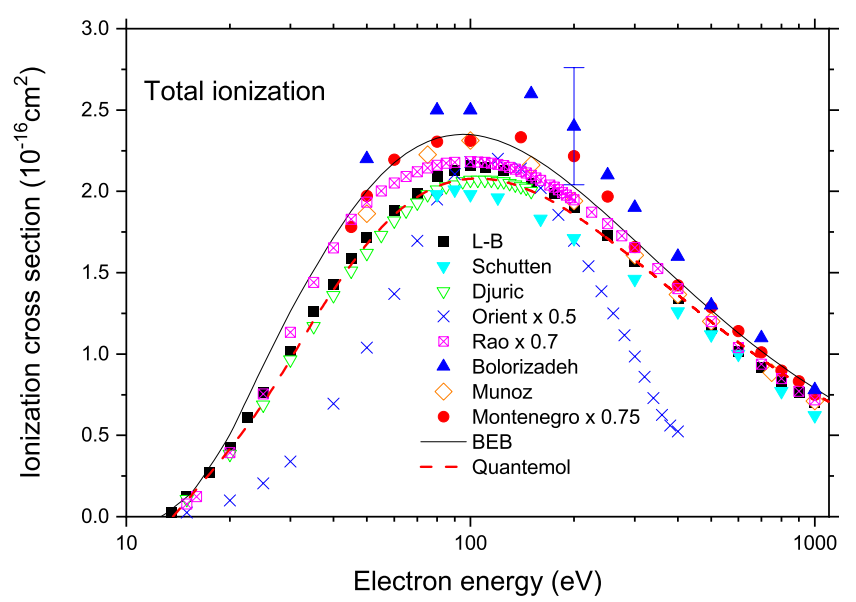

FIG. 17. Gross total ionization cross section in $\mathrm{H}_{2} \mathrm{O}$. "L-B" stands for the recommended cross section by Lindsay and Mangan, ${ }^{28}$ from Landolt-Börnstein data collection. These recommended cross sections are based on the measurements performed by Straub ${ }^{118}$ and are used as recommended also in the present work. "Quantemol ${ }^{120 "}$ stands for the BEB model, calculated in the suit of programs (HF frozen orbitals were used).

better with recommended values. Hwang et al. used the experimental threshold ionization energy $(12.61 \mathrm{eV})$, which is lowered by the effect of molecular vibrations; the vertical ionization threshold calculated by Quantemol is $13.67 \mathrm{eV}$. We checked for a series of fluorocarbons that more elaborated molecular orbital sets (such as complete active space or from density functional theory) give higher ionization cross sections than the HF method. ${ }^{135}$ This is also the case of $\mathrm{H}_{2} \mathrm{O}$; see the Quantemol internet site for details. Partial ionization cross sections were measured first by Märk and Egger ${ }^{121}$ for $\mathrm{H}_{2} \mathrm{O}^{+}$ion only: they used normalization to Ar cross sections, and their spectrometer probably suffered from incomplete collection of ions at low energies

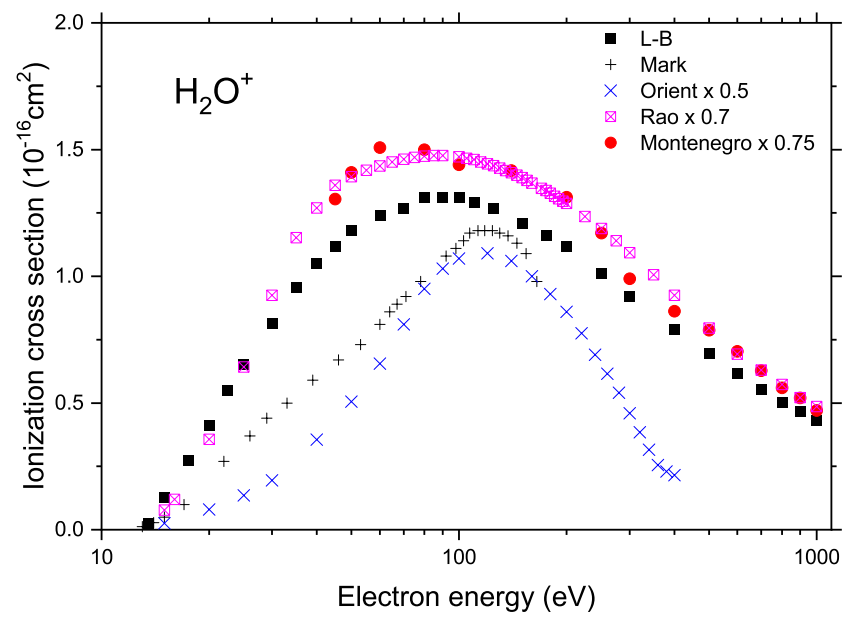

FIG. 18. Partial ionization cross section for $\mathrm{H}_{2} \mathrm{O}^{+}$from the Landolt-Börnstein data collection, ${ }^{28}$ Märk and Egger, ${ }^{121}$ Orient and Srivastava, ${ }^{122}$ Rao et al., ${ }^{123}$ and Montenegro et al. ${ }^{124}$ with renormalization factors.

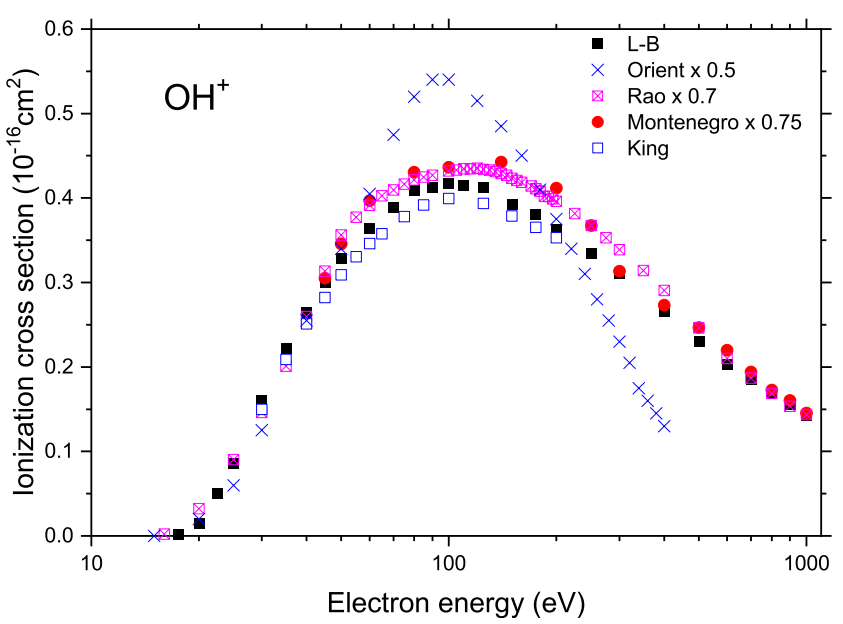

FIG. 19. Partial ionization cross section for $\mathrm{OH}^{+}$from the Landolt-Börnstein data collection, ${ }^{28}$ Orient and Srivastava, ${ }^{122}$ Rao et al., ${ }^{123}$ Montenegro et al.. ${ }^{124}$ and King et al. ${ }^{125}$ with renormalization factors.

(compare the discussion for $\mathrm{CF}_{4}$ in Ref. 9); see Fig. 18. In the same figure, we present partial $\mathrm{H}_{2} \mathrm{O}^{+}$cross sections from Orient and Srivastava $^{122}$ and Rao et al., ${ }^{123}$ renormalized by the same factors as their total ionization: the agreement is fair. In two recent experiments, ${ }^{124,125}$ production of ion pairs was monitored in coincidence, allowing one to distinguish processes such as $\mathrm{H}_{2} \mathrm{O}+\mathrm{e} \rightarrow$ $\mathrm{H}^{+}+\mathrm{OH}^{+}+\mathrm{e}$ from $\mathrm{H}_{2} \mathrm{O}+\mathrm{e} \rightarrow \mathrm{H}^{+}+\mathrm{O}^{+}+\mathrm{H}+$ e. Montenegro et al. ${ }^{124}$ used a method of effusive gas outflow, similar to that of Orient and Srivastava ${ }^{122}$ and Rao et al., ${ }^{123}$ and applied normalization to measured $\mathrm{CH}_{4}$. As a consequence, similar discrepancies in absolute values between Montenegro et al. and Straub et al. emerged: we renormalized the partial ionization cross sections of Montenegro et al. by a

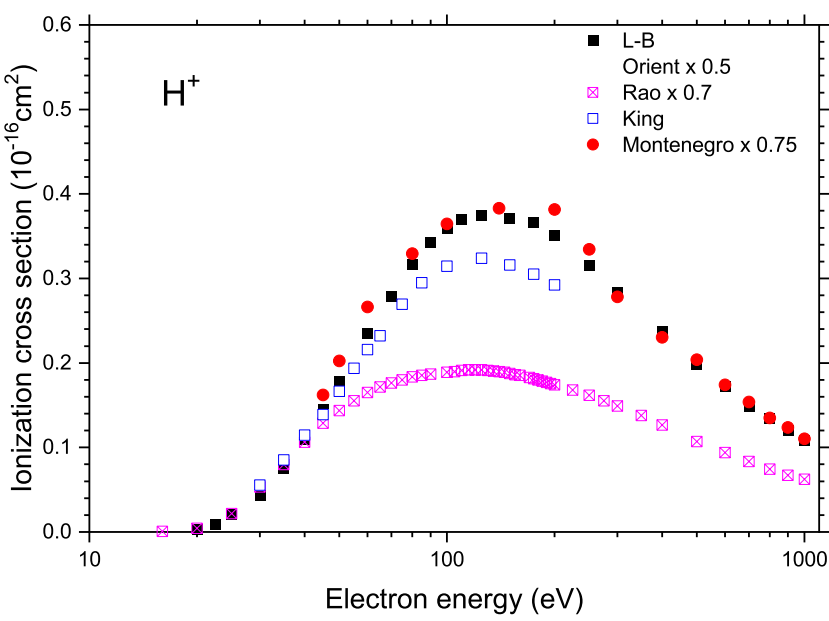

FIG. 20. Partial ionization cross section for $\mathrm{H}^{+}$from the Landolt-Börnstein data collection, ${ }^{28}$ Orient and Srivastava, ${ }^{122}$ Rao et al.., ${ }^{123}$ Montenegro et al., ${ }^{124}$ and King et al. ${ }^{125}$ with renormalization factors. 


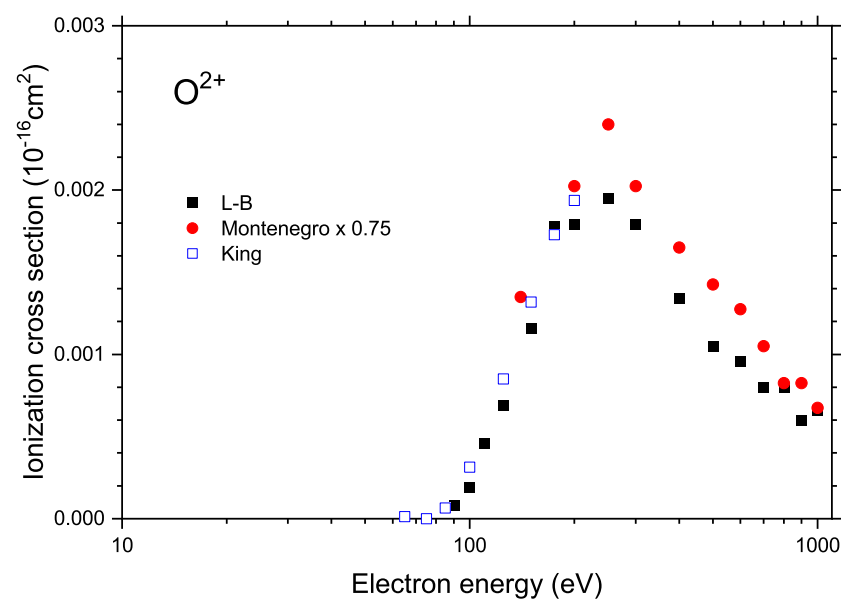

FIG. 21. Partial ionization cross section for $\mathrm{O}^{+2}$ from the Landolt-Börnstein data collection, ${ }^{28}$ Montenegro et al., ${ }^{124}$ and King et al. ${ }^{125}$ with renormalization factors.

factor of 0.75 . In this way, their partial and the total ionization cross sections agree with other recent sets; $;^{28,44,119,125}$ see Figs. $18-23$.

The yield for the heaviest dissociated ion $\left(\mathrm{OH}^{+}\right)$is $\sim 1 / 3$ of the parent (i.e., $\mathrm{H}_{2} \mathrm{O}^{+}$) ion; see Fig. 19. This contrasts with $\mathrm{CH}_{4}$, in which the $\mathrm{CH}_{3}^{+}$ion is produced with almost the same yield as $\mathrm{CH}_{4}^{+}$. The hydrogen $\mathrm{H}^{+}$ion is produced almost with the same intensity as $\mathrm{OH}^{+}$; see Fig. 20. The agreement for $\mathrm{H}^{+}$between recent data ${ }^{28,124,125}$ is good, while the early measurement by Rao et al. ${ }^{123}$ suffered, probably, from incomplete collection of this light ion. $\mathrm{O}^{2+}$ and $\mathrm{H}_{2}^{+}$ions are each produced in less than $0.1 \%$ of ionization events; see Figs. 21 and 22.

The cross sections for the two types of fragmentation, resulting from a double ionization, i.e., $\left(\mathrm{H}^{+}+\mathrm{OH}^{+}\right)$and $\left(\mathrm{H}^{+}+\mathrm{O}^{+}+\mathrm{H}\right)$, coincide at high collision energies; at $200 \mathrm{eV}$ collision energy, they amount to $0.7 \times 10^{-16} \mathrm{~cm}^{2}$ each; at lower energies, the first type of fragmentation dominates; see Ref. 124.

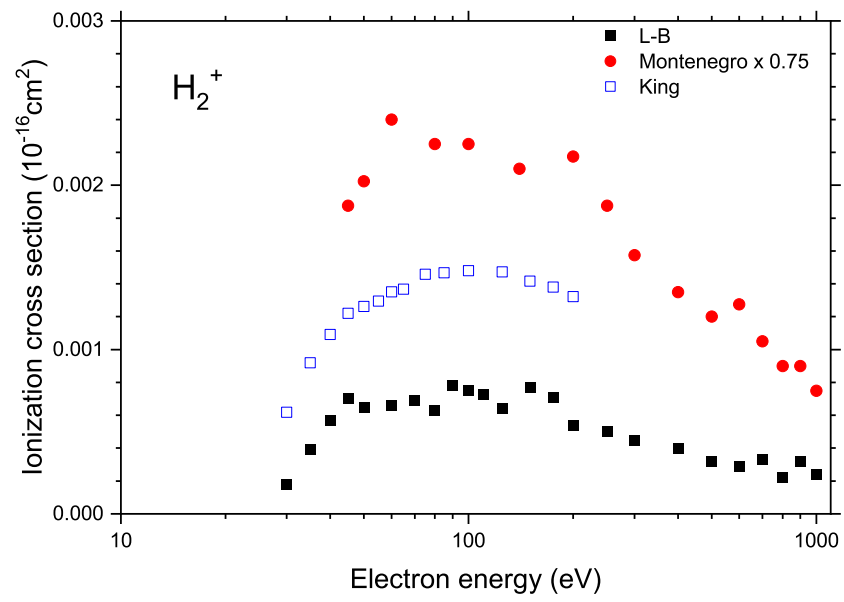

FIG. 22. Partial ionization cross section for $\mathrm{H}_{2}^{+}$from the Landolt-Börnstein data collection, ${ }^{28}$ Montenegro et al., ${ }^{124}$ and King and Price ${ }^{125}$ with renormalization factors.

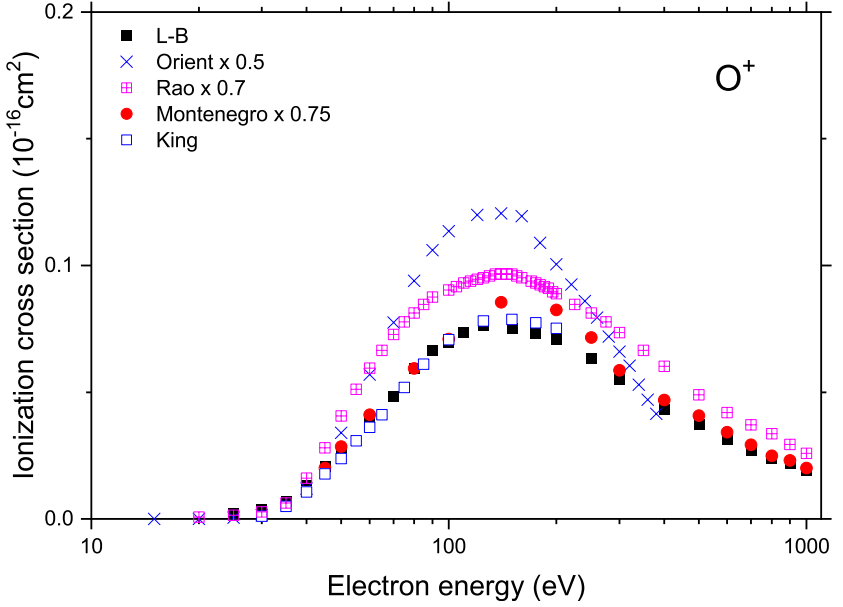

FIG. 23. Partial ionization cross section for $\mathrm{O}^{+}$from the Landolt-Börnstein data collection, ${ }^{28}$ Orient and Srivastava, ${ }^{122}$ Rao et al., ${ }^{123}$ Montenegro et al.. ${ }^{124}$ and King et al..$^{125}$ with renormalization factors.

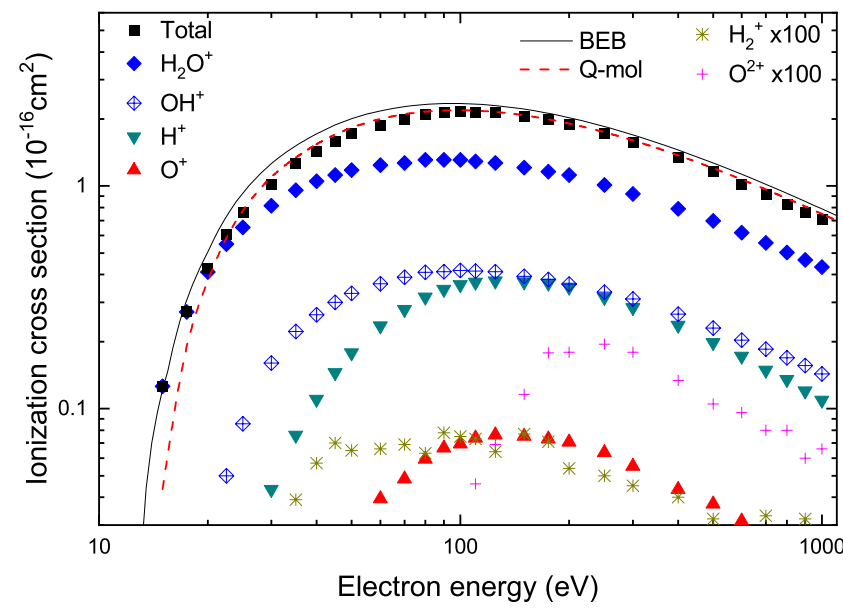

FIG. 24. The recommended total and partial ionization cross sections for $\mathrm{H}_{2} \mathrm{O}$.

King et al. ${ }^{125}$ managed to identify the yield of fragment ions, resulting from single, double, and triple ionization. Cross sections for the production of $\mathrm{H}^{+}, \mathrm{O}^{+}$, and $\mathrm{OH}^{+}$ions in single vs double ionization events scale, at $85 \mathrm{eV}$ collision energy, approximately as 10:1; see Ref. 125. At $200 \mathrm{eV}$, the double ionization is $\sim 7 \%$ of the total ionization cross section. ${ }^{124}$

The recommended total and partial ionization cross sections are resumed in Fig. 24 and in Table 12.

\section{Dissociative Electron Attachment (DEA) Cross Section}

Early measurements of DEA to water were made by Compton and Christophorou ${ }^{127}$ and by Melton. ${ }^{112}$ Melton found good agreement with the results of Compton and Christophorou, ${ }^{127}$ and DEA resulted in three kinds of negative ion fragments, $\mathrm{H}^{-}, \mathrm{O}^{-}$, and 
TABLE 12. Recommended cross sections for the electron-impact ionization of $\mathrm{H}_{2} \mathrm{O}$ : data are from the review by Lindsay and Mangan ${ }^{28}$ and are based on measurements performed by Straub et al..$^{118}$ The values of partial cross sections for $\mathrm{H}_{2} \mathrm{O}^{+}, \mathrm{OH}^{+}, \mathrm{O}^{+}$, and $\mathrm{H}_{2}^{+}$are based on measurements on $\mathrm{D}_{2} \mathrm{O}$. The uncertainty on the total ionization cross section is $6 \%$ and on partial cross sections is $\pm 6 \%, \pm 7 \%, \pm 9 \%, \pm 7 \%, \pm 13 \%$, and $\pm 16 \%$ for $\mathrm{H}_{2} \mathrm{O}^{+}, \mathrm{OH}^{+}, \mathrm{O}^{+}, \mathrm{O}^{2+}, \mathrm{H}_{2}^{+}$, and $\mathrm{H}^{+}$, respectively

\begin{tabular}{|c|c|c|c|c|c|c|c|}
\hline Energy (eV) & $\mathrm{H}_{2} \mathrm{O}^{+}\left(10^{-16} \mathrm{~cm}^{2}\right)$ & $\mathrm{OH}^{+}\left(10^{-16} \mathrm{~cm}^{2}\right)$ & $\mathrm{O}^{+}\left(10^{-16} \mathrm{~cm}^{2}\right)$ & $\mathrm{O}^{2+}\left(10^{-16} \mathrm{~cm}^{2}\right)$ & $\mathrm{H}_{2}^{+}\left(10^{-16} \mathrm{~cm}^{2}\right)$ & $\mathrm{H}^{+}\left(10^{-16} \mathrm{~cm}^{2}\right)$ & Total $\left(10^{-16} \mathrm{~cm}^{2}\right)$ \\
\hline 13.5 & 0.025 & $\ldots$ & $\ldots$ & $\ldots$ & $\ldots$ & $\ldots$ & 0.025 \\
\hline 15 & 0.126 & $\ldots$ & $\ldots$ & $\ldots$ & $\ldots$ & $\ldots$ & 0.126 \\
\hline 17.5 & 0.272 & 0.0013 & $\ldots$ & $\ldots$ & $\ldots$ & & 0.274 \\
\hline 20 & 0.411 & 0.0145 & $\ldots$ & $\ldots$ & $\ldots$ & 0.0024 & 0.428 \\
\hline 22.5 & 0.549 & 0.0500 & $\ldots$ & $\ldots$ & $\ldots$ & 0.0091 & 0.609 \\
\hline 25 & 0.652 & 0.0855 & 0.0022 & $\ldots$ & $\ldots$ & 0.0207 & 0.761 \\
\hline 30 & 0.815 & 0.1600 & 0.0037 & $\ldots$ & $1.8 \times 10^{-4}$ & 0.0433 & 1.02 \\
\hline 35 & 0.958 & 0.222 & 0.0070 & $\ldots$ & $3.9 \times 10^{-4}$ & 0.0759 & 1.26 \\
\hline 40 & 1.05 & 0.264 & 0.0132 & $\ldots$ & $5.7 \times 10^{-4}$ & 0.110 & 1.43 \\
\hline 45 & 1.12 & 0.300 & 0.0207 & $\ldots$ & $7.0 \times 10^{-4}$ & 0.145 & 1.59 \\
\hline 50 & 1.18 & 0.329 & 0.0275 & $\ldots$ & $6.5 \times 10^{-4}$ & 0.178 & 1.72 \\
\hline 60 & 1.24 & 0.364 & 0.0394 & $\ldots$ & $6.6 \times 10^{-4}$ & 0.235 & 1.88 \\
\hline 70 & 1.27 & 0.389 & 0.0484 & $\ldots$ & $6.9 \times 10^{-4}$ & 0.279 & 1.99 \\
\hline 80 & 1.31 & 0.409 & 0.0594 & $\ldots$ & $6.3 \times 10^{-4}$ & 0.317 & 2.09 \\
\hline 90 & 1.31 & 0.412 & 0.0666 & $8.00 \times 10^{-5}$ & $7.8 \times 10^{-4}$ & 0.343 & 2.13 \\
\hline 100 & 1.31 & 0.418 & 0.0695 & $1.94 \times 10^{-4}$ & $7.5 \times 10^{-4}$ & 0.360 & 2.16 \\
\hline 110 & 1.29 & 0.415 & 0.0738 & $4.60 \times 10^{-4}$ & $7.3 \times 10^{-4}$ & 0.370 & 2.15 \\
\hline 125 & 1.27 & 0.412 & 0.0763 & $6.90 \times 10^{-4}$ & $6.4 \times 10^{-4}$ & 0.375 & 2.13 \\
\hline 150 & 1.21 & 0.393 & 0.0752 & $1.16 \times 10^{-3}$ & $7.7 \times 10^{-4}$ & 0.371 & 2.05 \\
\hline 175 & 1.16 & 0.381 & 0.0731 & $1.78 \times 10^{-3}$ & $7.1 \times 10^{-4}$ & 0.366 & 1.99 \\
\hline 200 & 1.12 & 0.363 & 0.0707 & $1.79 \times 10^{-3}$ & $5.4 \times 10^{-4}$ & 0.351 & 1.90 \\
\hline 250 & 1.01 & 0.334 & 0.0634 & $1.95 \times 10^{-3}$ & $5.0 \times 10^{-4}$ & 0.316 & 1.73 \\
\hline 300 & 0.921 & 0.311 & 0.0551 & $1.79 \times 10^{-3}$ & $4.5 \times 10^{-4}$ & 0.284 & 1.57 \\
\hline 400 & 0.789 & 0.266 & 0.0434 & $1.34 \times 10^{-3}$ & $4.0 \times 10^{-4}$ & 0.237 & 1.34 \\
\hline 500 & 0.696 & 0.23 & 0.0373 & $1.05 \times 10^{-3}$ & $3.2 \times 10^{-4}$ & 0.198 & 1.16 \\
\hline 600 & 0.618 & 0.203 & 0.0313 & $9.60 \times 10^{-4}$ & $2.9 \times 10^{-4}$ & 0.172 & 1.02 \\
\hline 700 & 0.555 & 0.185 & 0.0271 & $8.00 \times 10^{-4}$ & $3.3 \times 10^{-4}$ & 0.149 & 0.917 \\
\hline 800 & 0.502 & 0.169 & 0.0240 & $8.00 \times 10^{-4}$ & $2.2 \times 10^{-4}$ & 0.135 & 0.830 \\
\hline 900 & 0.465 & 0.156 & 0.0220 & $6.00 \times 10^{-4}$ & $3.2 \times 10^{-4}$ & 0.120 & 0.763 \\
\hline 1000 & 0.432 & 0.143 & 0.0194 & $6.60 \times 10^{-4}$ & $2.4 \times 10^{-4}$ & 0.109 & 0.705 \\
\hline
\end{tabular}

$\mathrm{OH}^{-}$. However, Melton did not detect a third peak in the $\mathrm{H}^{-}$curve observed later by others as we will see soon. Belic et al. ${ }^{136}$ observed $\mathrm{H}^{-}$ at three peaks in the cross sections at $6.5,8.6$, and $11.8 \mathrm{eV}$ and interpreted these peaks as being due to the Feshbach resonances. As mentioned above, Melton showed no third peak in the $\mathrm{H}^{-}$curve. Belic et al. ${ }^{136}$ observed a third $\mathrm{H}^{-}$peak at around $11.8 \mathrm{eV}$ and concluded its intensity to be $\sim 600$ times weaker than the value at $6.5 \mathrm{eV}$. Fedor et al. ${ }^{137}$ studied DEA to water and measured $\mathrm{H}^{-}, \mathrm{O}^{-}$, and very weak $\mathrm{OH}^{-}$ion peaks as a function of the incident electron energies. However, they measured only relative intensities and reported no absolute cross sections. In the work of Rawat et al. ${ }^{138}$ on DEA to water, the apparatus used eliminates discrimination due to the kinetic energy and angular distribution of the ions. As Itikawa and Mason ${ }^{21}$ pointed out, many early measurements of anions produced by electron impact suffered from kinetic energy discrimination of the anions. They normalized the DEA cross sections to absolute values using the cross section for production of $\mathrm{O}^{-}$from $\mathrm{O}_{2}$ (Ref. 130). However, in the results of Rawat et al., ${ }^{138}$ no $\mathrm{OH}^{-}$was reported. They tried complete collection of all ions irrespective of their kinetic energies and angular distributions at the cost of mass resolution. Thus, it was not possible to separate $\mathrm{OH}^{-}$from $\mathrm{O}^{-}$. As we have seen, $\mathrm{OH}^{-}$ions were observed in some experiments but not in some others. Melton ${ }^{112}$ argued that $\mathrm{OH}^{-}+\mathrm{H}$ was a true channel of DEA to $\mathrm{H}_{2} \mathrm{O}$, while Klots and Compton ${ }^{139}$ argued that $\mathrm{OH}^{-}$is produced by DEA to water clusters $\left[\mathrm{H}_{2} \mathrm{O}\right]_{n}$. Later, Fedor et al. ${ }^{137}$ concluded that it is a direct product of DEA to water. Haxton et al. ${ }^{140}$ argued that the energetically lowest $\mathrm{H}+\mathrm{OH}^{-}$channel does not directly correlate with the three Feshbach states $\left({ }^{2} \mathrm{~B}_{1},{ }^{2} \mathrm{~A}_{1}\right.$, and $\left.{ }^{2} \mathrm{~B}_{2}\right)$. They therefore concluded that the $\mathrm{OH}^{-}$ production must be due to nonadiabatic effects. We would conclude that $\mathrm{OH}^{-}$ions are produced in the process of DEA to water but could not be observed in certain experiments depending on the experimental conditions. Finally, we recommend Ref. 138 for the DEA cross sections of $\mathrm{H}^{-}$and $\mathrm{O}^{-}$ions. For $\mathrm{OH}^{-}$ions, Melton reported the $\mathrm{OH}^{-}$ peak, but Rawat et al. ${ }^{138}$ did not, while their absolute intensities are more trusted. Therefore, we first normalized the $\mathrm{O}^{-}$peak of Melton ${ }^{112}$ to the $\mathrm{O}^{-}$peak of Rawat et al. ${ }^{138}$ and then scaled the $\mathrm{OH}^{-}$peak of Melton by that normalization factor to get the recommended cross section for $\mathrm{OH}^{-}$DEA to water. We chose the $\mathrm{O}^{-}$peak for normalization instead of the $\mathrm{H}^{-}$peak because the mass of $\mathrm{O}^{-}$ions is closer to that of $\mathrm{OH}^{-}$ions, considering the kinetic energy discrimination of the anions of the experimental apparatus. Uncertainties in the cross section for producing $\mathrm{O}^{-}$and $\mathrm{H}^{-}$are claimed to be $\pm 15 \%$ by Rawat 
TABLE 13. Recommended dissociative attachment cross sections (CS) for the ion formation from $\mathrm{H}_{2} \mathrm{O}$. Note the different units for the different ions. $\mathrm{H}^{-}$and $\mathrm{O}^{-}$from the cross sections of Rawat et $\mathrm{al}^{138}$ and $\mathrm{OH}^{-}$from the corrected cross sections of Melton et $\mathrm{al}^{112}$

\begin{tabular}{|c|c|c|c|c|c|}
\hline \multicolumn{2}{|c|}{$\mathrm{H}^{-}$} & \multicolumn{2}{|c|}{$\mathrm{O}^{-}$} & \multicolumn{2}{|c|}{$\mathrm{OH}^{-}$} \\
\hline Energy (eV) & $\mathrm{CS}\left(10^{-18} \mathrm{~cm}^{2}\right)$ & Energy (eV) & $\operatorname{CS}\left(10^{-19} \mathrm{~cm}^{2}\right)$ & Energy (eV) & $\operatorname{CS}\left(10^{-20} \mathrm{~cm}^{2}\right)$ \\
\hline 4.5 & 0 & 4.5 & 0.01 & 4.5 & 0.04 \\
\hline 5.0 & 0.06 & 5.0 & 0.03 & 5.0 & 0.19 \\
\hline 5.5 & 0.68 & 5.5 & 0.09 & 5.5 & 0.79 \\
\hline 6.0 & 3.02 & 6.0 & 0.10 & 6.0 & 2.56 \\
\hline 6.5 & 4.61 & 6.5 & 0.20 & 6.5 & 5.50 \\
\hline 7.0 & 2.98 & 7.0 & 0.31 & 7.0 & 2.97 \\
\hline 7.5 & 1.22 & 7.5 & 0.23 & 7.5 & 1.65 \\
\hline 8.0 & 0.94 & 8.0 & 0.24 & 8.0 & 3.20 \\
\hline 8.5 & 1.26 & 8.5 & 0.80 & 8.5 & 3.86 \\
\hline 9.0 & 1.12 & 9.0 & 1.12 & 9.0 & 2.08 \\
\hline 9.5 & 0.60 & 9.5 & 1.24 & 9.5 & 0.96 \\
\hline 10.0 & 0.26 & 10.0 & 1.14 & 10.0 & 1.71 \\
\hline 10.5 & 0.13 & 10.5 & 1.36 & 10.5 & 3.19 \\
\hline 11.0 & 0.11 & 11.0 & 1.96 & 11.0 & 3.93 \\
\hline 11.5 & 0.12 & 11.5 & 2.65 & 11.5 & 3.79 \\
\hline 12.0 & 0.08 & 12.0 & 2.74 & 12.0 & 1.92 \\
\hline 12.5 & 0.07 & 12.5 & 2.41 & 12.5 & 0.88 \\
\hline 13.0 & 0.05 & 13.0 & 1.89 & & \\
\hline 13.5 & 0.04 & 13.5 & 1.10 & & \\
\hline 14.0 & 0.02 & 14.0 & 0.56 & & \\
\hline 14.5 & 0.02 & 14.5 & 0.28 & & \\
\hline 15.0 & 0.01 & 15.0 & 0.26 & & \\
\hline 15.5 & 0.01 & 15.5 & 0.16 & & \\
\hline 16.0 & 0.01 & 16.0 & 0.11 & & \\
\hline 16.5 & 0.01 & & & & \\
\hline 17.5 & 0.01 & & & & \\
\hline 18.0 & 0.01 & & & & \\
\hline 18.5 & 0.01 & & & & \\
\hline 19.0 & 0.01 & & & & \\
\hline 19.5 & 0.02 & & & & \\
\hline
\end{tabular}

et al., ${ }^{138}$ but for $\mathrm{OH}^{-}$, no uncertainty is given by Melton et al. ${ }^{11}$ Recommended cross sections for DEA to water are given in Table 13 and Fig. 25, respectively.

\section{Summary and Future Work}

Since the most recent comprehensive review ${ }^{21}$ in 2005 on $\mathrm{H}_{2} \mathrm{O}$, substantial experimental (and theoretical) progress has been made. Figure 26 summarizes our recommended electron collision cross sections for $\mathrm{H}_{2} \mathrm{O}$. TCSs in the low energy range have been measured with a high angular resolution, ${ }^{26}$ indicating that earlier measurements were underestimated due to the angular resolution error; in this way, also the theoretical corrections ${ }^{37}$ to the TCS gain an experimental validation. Long-standing contradictions on elastic scattering (and therefore also the beam measurements of the momentum-transfer cross sections) got an important experimental contribution from California State University $(\mathrm{CSU})^{69}$ and now seem to correspond to the theoretical indications. ${ }^{50}$

With support from the theory, ${ }^{50}$ we solve the earlier ambiguities in defining total and EMT cross sections; ${ }^{19}$ see Fig. 7. Earlier electronic-excitation cross sections, which were measured, were also subject to experimental uncertainties and seem to converge to a selfconsistent set, thanks to new experiments from CSU, ${ }^{141}$ Tokyo Sophia University, and Adelaide Flinders University.

The same holds true also for the vibrational excitation, with a new measurement ${ }^{89}$ in 2009. However, as the non-resonant vibrational excitation in $\mathrm{H}_{2} \mathrm{O}$ is a theoretical "classics," ${ }^{142}$ the theory of the resonant vibrational excitation ${ }^{90,92,143}$ would profit from new contributions.

Still single (and normalized) measurements ${ }^{113,117}$ on the dissociation into neutrals exist, and the agreement with optical-emission cross sections is poor.

We do not make corrections to earlier recommended ionization cross sections. ${ }^{21,28}$ However, we note new, detailed studies using the ion-coincidence technique, ${ }^{124,125}$ which potentially bring important information on the ion-fragmentation of the molecule.

The controversy between the theory ${ }^{140}$ and early experiment ${ }^{112}$ on the production of the $\mathrm{OH}^{-}$ion got the verification, ${ }^{137,138}$ but the yield of $\mathrm{OH}^{-}$is very low, so some theoretical understanding of possible mechanisms is needed. 

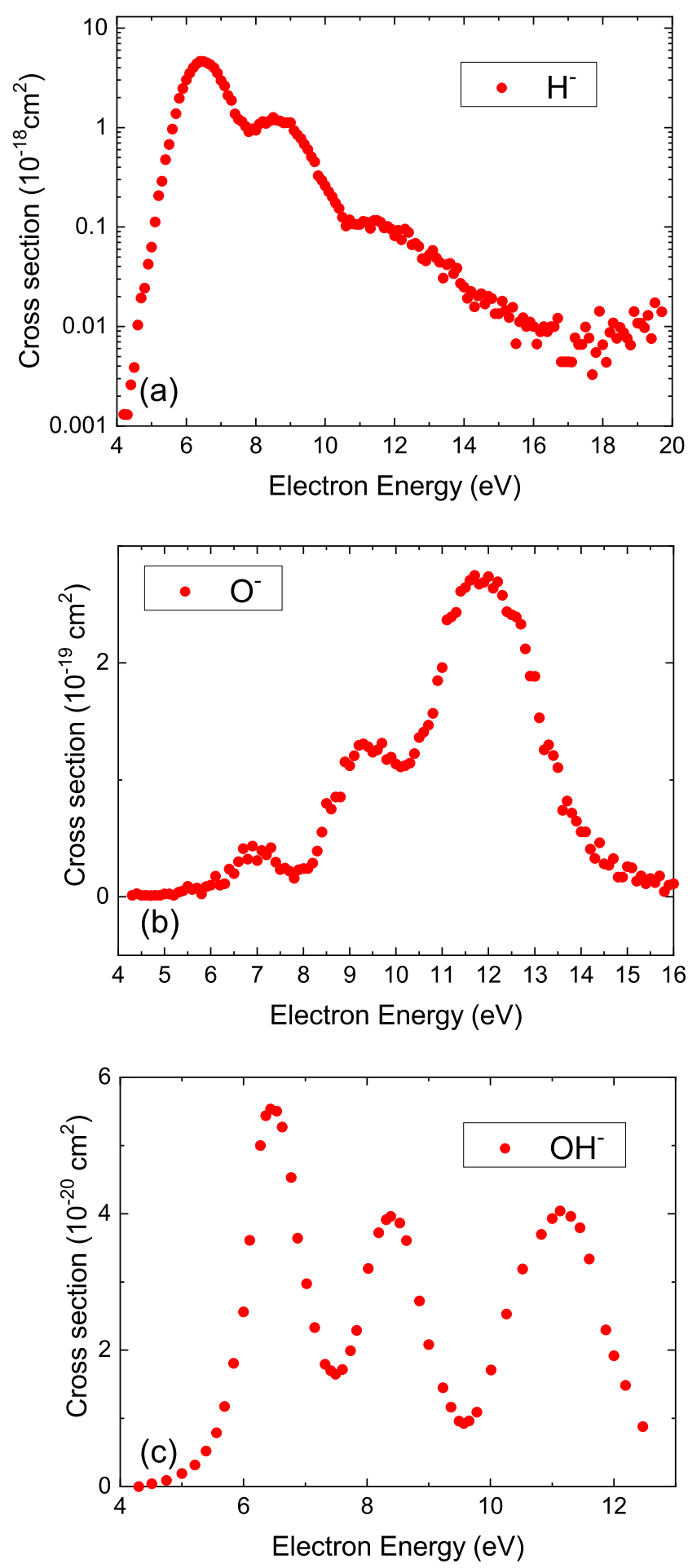

FIG. 25. Recommended cross sections for (a) $\mathrm{H}^{-}$, (b) $\mathrm{O}^{-}$, and (c) $\mathrm{OH}^{-}$ion formation from $\mathrm{H}_{2} \mathrm{O}$. Note the different units for the different ions. $\mathrm{H}^{-}$and $\mathrm{O}^{-}$from the cross sections of Rawat et al. ${ }^{138}$ and $\mathrm{OH}^{-}$from the corrected cross sections of Melton et al.

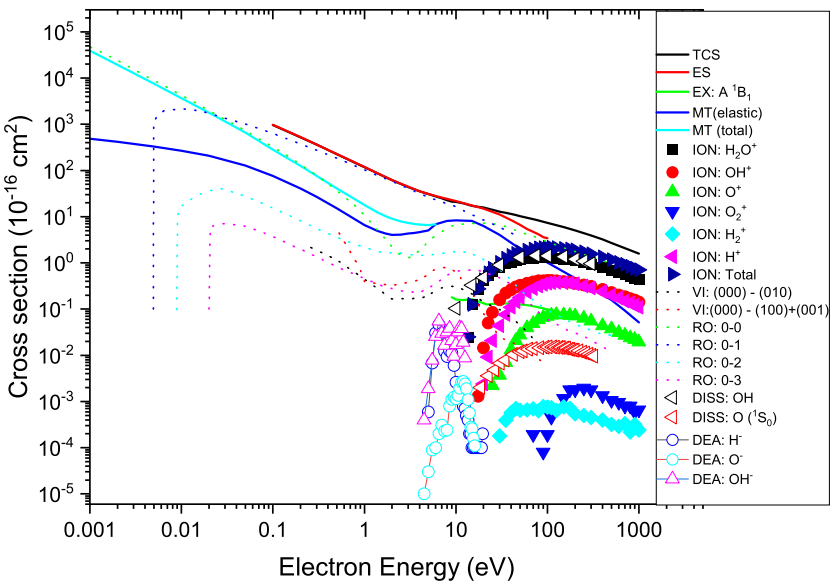

FIG. 26. Summary of the recommended cross section for electron collisions with $\mathrm{H}_{2} \mathrm{O}$. TCS-total scattering, ES-elastic scattering, MT-momentum transfer, ION-ionization, VI-vibrational excitation, RO-rotational excitation, EX-electronic excitation, DEA-dissociative electron attachment, and DISS-neutral dissociation.

In summary, it seems that the previous review ${ }^{21}$ triggered broad collaborations between the theory and experiment. This is particularly needed for such an important process like electron scattering on water in gas, liquid, and solid states.

\section{Supplementary Material}

See the supplementary material for the additional data on rotational excitation (by Faure, Gorfinkiel, and Tennyson ${ }^{50,60}$ ).

\section{Acknowledgments}

We thank Dagmar Jaksch, S. Matejcik, P. Limao Vieira, B. Marinkovic, S. Denifl, and B. Marinkovic. This research was supported by the R\&D Program Plasma BigData ICT Convergence Technology Research Project (Code No. 1711124799) through the Korea Institute of Fusion Energy (KFE) funded by the Government, Republic of Korea. It was also partially supported by the Technology Innovation Program (Code No. 1415168262, Development and Dissemination on National Standard Reference Data) funded by the Ministry of Trade, Industry and Energy (MOTIE, Republic of Korea).

\section{Data Availability}

The data that support the findings of this study are available within the article and its supplementary material.

\section{References}

${ }^{1}$ R. van Harrevelt and M. C. van Hemert, "Photodissociation of water in the Ã band revisited with new potential energy surfaces," J. Chem. Phys. 114, 9453-9462 (2001).

${ }^{2}$ T. Furtenbacher, R. Tóbiás, J. Tennyson, O. L. Polyansky, and A. G. Császár, "W2020: Database of validated rovibrational experimental transitions and empirical energy levels of $\mathrm{H}_{2}^{16} \mathrm{O}$,” J. Phys. Chem. Ref. Data 49, 033101 (2020). 
${ }^{3}$ T. Furtenbacher, R. Tóbiás, J. Tennyson, O. L. Polyansky, A. A. Kyuberis, R. I. Ovsyannikov, N. F. Zobov, and A. G. Császár, "The W2020 database of validated rovibrational experimental transitions and empirical energy levels of water isotopologues. II. $\mathrm{H}_{2}^{17} \mathrm{O}$ and $\mathrm{H}_{2}^{18} \mathrm{O}$ with an update to $\mathrm{H}_{2}^{16} \mathrm{O}$," J. Phys. Chem. Ref. Data 49, 043103 (2020)

${ }^{4}$ O. L. Polyansky, A. A. Kyuberis, N. F. Zobov, J. Tennyson, S. N. Yurchenko, and L. Lodi, "ExoMol molecular line lists XXX: A complete high-accuracy line list for water," Mon. Not. R. Astron. Soc. 480, 2597-2608 (2018).

${ }^{5}$ P. Ball, "Water is an active matrix of life for cell and molecular biology," Proc. Natl. Acad. Sci. U. S. A. 114, 13327-13335 (2017).

${ }^{6}$ P. G. Debenedetti and M. L. Klein, "Chemical physics of water," Proc. Natl. Acad. Sci. U. S. A. 114, 13325-13326 (2017).

${ }^{7}$ S. Sakong and A. Groß, "The electric double layer at metal-water interfaces revisited based on a charge polarization scheme," J. Chem. Phys. 149, 084705 (2018).

${ }^{8}$ A. Tsiaras, I. P. Waldmann, G. Tinetti, J. Tennyson, and S. N. Yurchenko, "Water vapour in the atmosphere of the habitable-zone eight-earth-mass planet K2-18b," Nat. Astron. 3, 1086-1091 (2019).

${ }^{9}$ G. P. Karwasz, R. S. Brusa, and A. Zecca, "One century of experiments on electronatom and molecule scattering. A critical review of integral cross sections. III. Hydrocarbons and halides," Riv. Nuovo Cimento 24, 1-101 (2001).

${ }^{10} \mathrm{~K}$. Anzai, H. Kato, M. Hoshino, H. Tanaka, Y. Itikawa, L. Campbell, M. Brunger, S. Buckman, H. Cho, F. Blanco, G. Garcia, P. Limão Vieira, and O. Ingólfsson, "Cross section data sets for electron collisions with $\mathrm{H}_{2}, \mathrm{O}_{2}, \mathrm{CO}, \mathrm{CO}_{2}, \mathrm{~N}_{2} \mathrm{O}$ and $\mathrm{H}_{2} \mathrm{O}$,” Eur. Phys. J. D 66, 36 (2012).

${ }^{11}$ G. Ruíz-Vargas, M. Yousfi, and J. de Urquijo, "Electron transport coefficients in the mixtures of $\mathrm{H}_{2} \mathrm{O}$ with $\mathrm{N}_{2}, \mathrm{O}_{2}, \mathrm{CO}_{2}$ and dry air for the optimization of nonthermal atmospheric pressure plasmas," J. Phys. D: Appl. Phys. 43, 455201 (2010). ${ }^{12}$ K. F. Ness, R. E. Robson, M. J. Brunger, and R. D. White, "Transport coefficients and cross sections for electrons in water vapour: Comparison of cross section sets using an improved Boltzmann equation solution," J. Chem. Phys. 136, 024318 (2012).

${ }^{13} \mathrm{M}$. Yousfi and M. D. Benabdessadok, "Boltzmann equation analysis of electronmolecule collision cross sections in water vapor and ammonia," J. Appl. Phys. 80, 6619-6630 (1996).

${ }^{14}$ J. de Urquijo, E. Basurto, A. M. Juárez, K. F. Ness, R. E. Robson, M. J. Brunger, and R. D. White, "Electron drift velocities in He and water mixtures: Measurements and an assessment of the water vapour cross-section sets," J. Chem. Phys. 141, 014308 (2014).

${ }^{15} \mathrm{H}$. Date, K. L. Sutherland, H. Hasegawa, and M. Shimozuma, "Ionization and excitation collision processes of electrons in liquid water," Nucl. Instrum. Methods Phys. Res., Sect. B 265, 515-520 (2007).

${ }^{16}$ A. Muñoz, F. Blanco, G. Garcia, P. A. Thorn, M. J. Brunger, J. P. Sullivan, and S. J. Buckman, "Single electron tracks in water vapour for energies below $100 \mathrm{eV}$," Int. J. Mass Spectrom. 277, 175-179 (2008).

${ }^{17}$ M. C. Fuss, L. Ellis-Gibbings, D. B. Jones, M. J. Brunger, M. J. Blanco, A. Munoz, P. Limão-Vieira, and G. García, "The role of pyrimidine and water as underlying molecular constituents for describing radiation damage in living tissue: A comparative study," J. Appl. Phys. 117, 214701 (2015).

${ }^{18}$ A. G. Sanz, M. C. Fuss, A. Muñoz, F. Blanco, P. Limão-Vieira, M. J. Brunger, S. J. Buckman, and G. García, "Modelling low energy electron and positron tracks for biomedical applications," Int. J. Rad. Biol. 88, 71-76 (2012).

${ }^{19}$ M.-Y. Song, J.-S. Yoon, H. Cho, G. P. Karwasz, V. Kokoouline, Y. Nakamura, and J. Tennyson, "'Recommended" cross sections for electron collisions with molecules," Eur. Phys. J. D 74, 60 (2020).

${ }^{20}$ T. Shirai, T. Tabata, and H. Tawara, "Analytic cross sections for electron collisions with $\mathrm{CO}, \mathrm{CO}_{2}$, and $\mathrm{H}_{2} \mathrm{O}$ relevant to edge plasma impurities," At. Data Nucl. Data Tables 79, 143-184 (2001).

${ }^{21}$ Y. Itikawa and N. Mason, "Cross sections for electron collisions with water molecules," J. Phys. Chem. Ref. Data 34, 1-22 (2005).

${ }^{22}$ P. Lenard, "Ueber die absorption der Kathodenstrahlen," Ann. Phys. 292, 255-275 (1895)

${ }^{23} \mathrm{E}$. Brüche, "Wirkungsquerschnitt und Molekelbau in der Pseudoedelgasreihe: $\mathrm{Ne}, \mathrm{HF}, \mathrm{H}_{2} \mathrm{O}, \mathrm{NH}_{3}, \mathrm{CH}_{4}$," Ann. Phys. 393, 93-134 (1929).
${ }^{24}$ J. L. Pack, R. E. Voshall, and A. V. Phelps, "Drift velocities of slow electrons in krypton, xenon, deuterium, carbon monoxide, carbon dioxide, water vapor, nitrous oxide, and ammonia," Phys. Rev. 127, 2084-2089 (1962).

${ }^{25} \mathrm{R}$. Tice and D. Kivelson, "Cyclotron resonance in gases. II. Cross sections for dipolar gases and for $\mathrm{CO}_{2}$," J. Chem. Phys. 46, 4748-4754 (1967).

${ }^{26}$ R. Kadokura, A. Loreti, Á. Kövér, A. Faure, J. Tennyson, and G. Laricchia, "Angleresolved electron scattering from $\mathrm{H}_{2} \mathrm{O}$ near $0^{\circ}$," Phys. Rev. Lett. 123, 033401 (2019).

${ }^{27} \mathrm{C}$. Szmytkowski and P. Mozejko, "Recent total cross section measurements in electron scattering from molecules," Eur. Phys. J. D 74, 90 (2020).

${ }^{28}$ G. Lindsay and M. Mangan, "Ionization," in Landolt-Börnstein Group I: Elementary Particles Nuclei and Atoms, (Springer, Berlin, Heidelberg, New York, 2003), pp. 5-1-5-7.

${ }^{29}$ B. Boudaiffa, P. Cloutier, D. Hunting, M. A. Huels, and L. Sanche, "Resonant formation of DNA strand breaks by low-energy ( 3 to $20 \mathrm{eV}$ ) electrons," Science 287, 1658-1660 (2000).

${ }^{30} \mathrm{M}$. Hayashi, "Electron collision cross-sections for molecules determined from beam and swarm data," in Swarm Studies and Inelastic Electron-Molecule Collisions, edited by L. C. Pitchford, V. McKoy, A. Chutjan, and S. Trajmar (Springer-Verlag, Berlin, 1987), pp. 167-187.

${ }^{31} \mathrm{O}$. Sueoka and S. Mori, "Total cross-sections for positrons and electrons colliding with $\mathrm{N}_{2}, \mathrm{CO}$ and $\mathrm{CO}_{2}$ molecules," J. Phys. Soc. Jpn. 53, 2491-2500 (1984).

${ }^{32} \mathrm{O}$. Sueoka, S. Mori, and Y. Katayama, "Total cross sections for electrons and positrons colliding with $\mathrm{H}_{2} \mathrm{O}$ molecules," J. Phys. B: At. Mol. Phys. 19, L373-L378 (1986).

${ }^{33}$ M. Kimura, O. Sueoka, A. Hamada, and Y. Itikawa, "A comparative study of electron- and positron-polyatomic molecule scattering," Adv. Chem. Phys. 111, 537-622 (2007).

${ }^{34}$ G. P. Karwasz, R. S. Brusa, and A. Zecca, "Total scattering cross sections," in Landolt-Börnstein Group I: Elementary Particles Nuclei and Atoms (Springer, Berlin, Heidelberg, New York, 2003), Vol. 17, pp. 6-1-6-51.

${ }^{35} \mathrm{C}$. Szmytkowski, "Absolute total cross sections for electron-water vapour scattering,” Chem. Phys. Lett. 136, 363-367 (1987).

${ }^{36} \mathrm{R}$. Curík, J.-P. Ziesel, N. Jones, T. Field, and D. Field, "Rotational excitation of $\mathrm{H}_{2} \mathrm{O}$ by cold electrons," Phys. Rev. Lett. 97, 123202 (2006).

${ }^{37}$ R. Zhang, A. Faure, and J. Tennyson, "Electron and positron collisions with polar molecules: Studies with the benchmark water molecule," Phys. Scr. 80, 015301 (2009).

${ }^{38}$ M. A. Khakoo, H. Silva, J. Muse, M. C. A. Lopes, C. Winstead, and V. McKoy, "Erratum: Electron scattering from $\mathrm{H}_{2} \mathrm{O}$ : Elastic scattering [Phys. Rev. A 78, 052710 (2008)]," Phys. Rev. A 87, 049902 (2013).

${ }^{39} \mathrm{C}$. Szmytkowski and P. Mozejko, "Electron-scattering total cross sections for triatomic molecules: $\mathrm{NO}_{2}$ and $\mathrm{H}_{2} \mathrm{O}$," Opt. Appl. 36, 543-550 (2006), available at https://opticaapplicata.pwr.edu.pl/files/pdf/2006/no4/optappl_3604p543.pdf.

${ }^{40} \mathrm{Z}$. Saglam and N. Aktekin, "Absolute total cross section for electron scattering on water in the energy range 25-300 eV," J. Phys. B: At., Mol. Opt. Phys. 23, 1529-1536 (1990).

${ }^{41} \mathrm{Z}$. Saglam and N. Aktekin, "Absolute total cross sections for scattering of electrons by $\mathrm{H}_{2} \mathrm{O}$ in the energy range $4-20 \mathrm{eV}$," J. Phys. B: At., Mol. Opt. Phys. 24, 3491-3496 (1991)

${ }^{42} \mathrm{H}$. Nishimura and K. Yano, "Total electron scattering cross sections for $\mathrm{Ar}, \mathrm{N}_{2}$, $\mathrm{H}_{2} \mathrm{O}$ and $\mathrm{D}_{2} \mathrm{O}$," J. Phys. Soc. Jpn. 57, 1951-1956 (1988).

${ }^{43}$ A. Zecca, G. Karwasz, S. Oss, R. Grisenti, and R. S. Brusa, "Total absolute cross sections for electron scattering on $\mathrm{H}_{2} \mathrm{O}$ at intermediate energies,"J. Phys. B: At. Mol. Phys. 20, L133-L136 (1987).

${ }^{44}$ A. Munoz, J. C. Oller, F. Blanco, J. D. Gorfinkiel, P. Limao-Vieira, and G. Garcia, "Electron-scattering cross sections and stopping powers in $\mathrm{H}_{2} \mathrm{O}$," Phys. Rev. A 76, 052707 (2007).

${ }^{45}$ M.-Y. Song, J.-S. Yoon, H. Cho, G. P. Karwasz, V. Kokoouline, Y. Nakamura, and J. Tennyson, "Cross sections for electron collisions with $\mathrm{NO}, \mathrm{N}_{2} \mathrm{O}$, and $\mathrm{NO}_{2}$," J. Phys. Chem. Ref. Data 48, 043104 (2019).

${ }^{46}$ G. P. Karwasz, A. Karbowski, Z. Idziaszek, and R. S. Brusa, "Total cross sections for positron scattering on benzene-Angular resolution corrections," Nucl. Instrum. Methods Phys. Res., Sect. B 266, 471-477 (2008). 
${ }^{47}$ Y. Okamoto, K. Onda, and Y. Itikawa, "Vibrationally elastic cross sections for electron scattering from water molecules," J. Phys. B: At., Mol. Opt. Phys. 26, 745-758 (1993).

${ }^{48}$ J. C. Nickel, K. Imre, D. F. Register, and S. Trajmar, "Total electron scattering cross sections. I. He, Ne, Ar, Xe,” J. Phys. B: At. Mol. Phys. 18, 125-133 (1985).

${ }^{49}$ M.-Y. Song, J.-S. Yoon, H. Cho, Y. Itikawa, G. P. Karwasz, V. Kokoouline, Y. Nakamura, and J. Tennyson, "Cross sections for electron collisions with methane," J. Phys. Chem. Ref. Data 44, 023101 (2015).

${ }^{50}$ A. Faure, J. D. Gorfinkiel, and J. Tennyson, "Electron-impact rotational excitation of water," Mon. Not. R. Astron. Soc. 347, 323-333 (2004).

${ }^{51}$ A. Zecca, G. Karwasz, R. S. Brusa, and C. Szmytkowski, "Absolute total cross sections for electron scattering on $\mathrm{CH}_{4}$ molecules in the 1-4000 eV energy range," J. Phys. B: At., Mol. Opt. Phys. 24, 2747-2754 (1991).

${ }^{52}$ A. Loreti, R. Kadokura, S. E. Fayer, A. Kövér, and G. Laricchia, "High-resolution measurements of $e^{+}+\mathrm{H}_{2} \mathrm{O}$ total cross section," Phys. Rev. Lett. 117, 253401 (2016).

${ }^{53}$ G. P. Karwasz, "Positrons-An alternative probe to electron scattering," Eur. Phys. J. D 35, 267-278 (2005).

${ }^{54}$ A. Zecca, D. Sanyal, M. Chakrabarti, and M. J. Brunger, "Positron scattering from water," J. Phys. B: At., Mol. Opt. Phys. 39, 1597-1604 (2006)

${ }^{55}$ G. P. Karwasz, M. Barozzi, M. Bettonte, R. S. Brusa, and A. Zecca, "A very lowenergy apparatus for positron scattering on atoms and molecules," Nucl. Instrum. Methods Phys. Res., Sect. B 171, 178-181 (2000).

${ }^{56}$ C. Makochekanwa, R. Kajita, H. Kato, M. Kitajima, H. Cho, M. Kimura, and H. Tanaka, "Individual fundamental mode dependence of $\mathrm{H}_{2} \mathrm{O}$ vibrational excitation in the $6-8 \mathrm{eV}$ resonance region by electron impact," J. Chem. Phys. 122, 014314 (2005).

${ }^{57}$ W. Tattersall, L. Chiari, J. R. Machacek, E. Anderson, R. D. White, M. J. Brunger, S. J. Buckman, G. Garcia, F. Blanco, and J. P. Sullivan, "Positron interactions with water-total elastic, total inelastic, and elastic differential cross section measurements," J. Chem. Phys. 140, 044320 (2014).

${ }^{58}$ J. Beale, S. Armitage, and G. Laricchia, "Positronium- and positron- $\mathrm{H}_{2} \mathrm{O}$ total cross sections," J. Phys. B: At., Mol. Opt. Phys. 39, 1337-1344 (2006).

${ }^{59}$ F. Arretche, W. Tenfen, K. T. Mazon, S. E. Michelin, M. A. P. Lima, M.-T. Lee, L. E. Machado, M. M. Fujimoto, and O. A. Pessoa, "Low energy scattering of positrons by $\mathrm{H}_{2} \mathrm{O}$," Nucl. Instrum. Methods Phys. Res., Sect. B 268, 178-182 (2010).

${ }^{60} \mathrm{~A}$. Faure, J. D. Gorfinkiel, and J. Tennyson, "Low-energy electron collisions with water: Elastic and rotationally inelastic scattering," J. Phys. B: At., Mol. Opt. Phys. 37, 801-807 (2004)

${ }^{61}$ L. Álvarez, F. Costa, A. I. Lozano, J. C. Oller, A. Muñoz, F. Blanco, P. LimãoVieira, R. D. White, M. J. Brunger, and G. García, "Electron scattering cross sections from nitrobenzene in the energy range $0.4-1000 \mathrm{eV}$ : The role of dipole interactions in measurements and calculations," Phys. Chem. Chem. Phys. 22, 13505-13515 (2020).

${ }^{62}$ F. Costa, A. Traoré-Dubuis, L. Álvarez, A. I. Lozano, X. Ren, A. Dorn, P. LimãoVieira, F. Blanco, J. C. Oller, A. Muñoz, A. García-Abenza, J. D. Gorfinkiel, A. S. Barbosa, M. H. F. Bettega, P. Stokes, R. D. White, D. B. Jones, M. J. Brunger, and G. García, "A complete cross section data set for electron scattering by Pyridine: Modelling electron transport in the energy range $0-100$ eV," Int. J. Mol. Sci. 21, 6947 (2020).

${ }^{63}$ A. Danjo and H. Nishimura, "Elastic scattering of electrons from $\mathrm{H}_{2} \mathrm{O}$ molecule," J. Phys. Soc. Jpn. 54, 1224-1227 (1985).

${ }^{64}$ T. W. Shyn and S. Y. Cho, "Vibrationally elastic scattering cross section of water vapor by electron impact," Phys. Rev. A 36, 5138-5142 (1987).

${ }^{65}$ T. W. Shyn and A. Grafe, "Angular distribution of electrons elastically scattered from water vapor,” Phys. Rev. A 46, 4406-4409 (1992).

${ }^{66}$ W. M. Johnstone and W. R. Newell, "Absolute vibrationally elastic cross sections for electrons scattered from water molecules between $6 \mathrm{eV}$ and $50 \mathrm{eV}$," J. Phys. B: At., Mol. Opt. Phys. 24, 3633-3643 (1991).

${ }^{67}$ H. Cho, Y. S. Park, H. Tanaka, and S. J. Buckman, "Measurements of elastic electron scattering by water vapour extended to backward angles," J. Phys. B: At., Mol. Opt. Phys. 37, 625-634 (2004).

${ }^{68}$ H. Silva, J. Muse, M. C. A. Lopes, and M. A. Khakoo, "Low energy elastic differential electron scattering from $\mathrm{H}_{2} \mathrm{O}$," Phys. Rev. Lett. 101, 033201 (2008).
${ }^{69}$ M. Matsui, M. Hoshino, H. Kato, F. F. da Silva, P. Limão-Vieira, and H. Tanaka, "Measuring electron-impact cross sections of water: Elastic scattering and electronic excitation of the $\tilde{a}^{3} B_{1}$ and $\tilde{A}^{1} B_{1}$ states," Eur. Phys. J. D 70, 77 (2016).

${ }^{70}$ T. N. Rescigno and B. H. Lengsfield, "A fixed-nuclei, $a b$ initio treatment of lowenergy electron- $\mathrm{H}_{2} \mathrm{O}$ scattering," Z. Phys. D: At. Mol. Clusters 24, 117-124 (1992). ${ }^{71}$ F. A. Gianturco, S. Meloni, P. Paioletti, R. R. Lucchese, and N. Sanna, "Lowenergy electron scattering from the water molecule: Angular distributions and rotational excitation," J. Chem. Phys. 108, 4002-4012 (1998).

${ }^{72}$ M. T. do N. Varella, M. H. F. Bettega, M. A. P. Lima, and L. G. Ferreira, "Lowenergy electron scattering by $\mathrm{H}_{2} \mathrm{O}, \mathrm{H}_{2} \mathrm{~S}, \mathrm{H}_{2} \mathrm{Se}$, and $\mathrm{H}_{2} \mathrm{Te}$," J. Chem. Phys. 111, 6396-6406 (1999).

${ }^{73}$ J. D. Gorfinkiel, L. A. Morgan, and J. Tennyson, "Electron impact dissociative excitation of water within the adiabatic nuclei approximation," J. Phys. B: At., Mol. Opt. Phys. 35, 543-555 (2002).

${ }^{74}$ L. E. Machado, L. Mu-Tao, L. M. Brescansin, M. A. Lima and V. McKoy, "Elastic electron-scattering by water-molecules," J. Phys. B: At. Mol. Opt. Phys. 28, 467-476 (1995).

${ }^{75}$ M. Vinodkumar, C. G. Limbachiya, K. N. Joshipura, and N. J. Mason, "Electron impact calculations of total elastic cross sections over a wide energy range $-0.01 \mathrm{eV}$ to $2 \mathrm{keV}$ for $\mathrm{CH}_{4}, \mathrm{SiH}_{4}$ and $\mathrm{H}_{2} \mathrm{O}$," Eur. Phys. J. D 61, 579-585 (2011).

${ }^{76}$ A. Katase, K. Ishibashi, Y. Matsumoto, T. Sakae, S. Maezono, E. Murakami, K. Watanabe, and H. Maki, "Elastic scattering of electrons by water molecules over the range 100-1000 eV," J. Phys. B: At. Mol. Phys. 19, 2715-2734 (1986).

${ }^{77}$ F. H. Read and J. M. Channing, "Production and optical properties of an unscreened but localized magnetic field," Rev. Sci. Instrum. 67, 2372-2377 (1996). ${ }^{78}$ M. Zubek, N. Gulley, G. C. King, and F. H. Read, "Measurements of elastic electron scattering in the backward hemisphere," J. Phys. B: At., Mol. Opt. Phys. 29, L239-L244 (1996).

${ }^{79}$ K. F. Ness and R. E. Robson, "Transport properties of electrons in water vapor," Phys. Rev. A 38, 1446-1456 (1988).

${ }^{80} \mathrm{~L}$. Pitchford, "Definition of 'effective momentum transfer, LXCat open-access database (2010-06-07), http://fr.lxcat.net/notes/.

${ }^{81}$ R. D. White, D. Cocks, G. Boyle, M. Casey, N. Garland, D. Konovalov, B. Philippa, P. Stokes, J. de Urquijo, O. González-Magaña, R. P. McEachran, S. J. Buckman, M. J. Brunger, G. Garcia, S. Dujko, and Z. L. Petrovic, "Electron transport in biomolecular gaseous and liquid systems: Theory, experiment and self-consistent cross-sections," Plasma Sources Sci. Technol. 27, 053001 (2018).

${ }^{82}$ K. Jung, T. Antoni, R. Muller, K.-H. Kochem, and H. Ehrhardt, "Rotational excitation of $\mathrm{N}_{2}, \mathrm{CO}$ and $\mathrm{H}_{2} \mathrm{O}$ by low-energy electron collisions," J. Phys. B: At. Mol. Phys. 15, 3535-3555 (1982).

${ }^{83}$ L. E. Machado, L. M. Brescansin, I. Iga, and M.-T. Lee, "Elastic and rotational excitation cross-sections for electron-water collisions in the low- and intermediateenergy ranges," Eur. J. Phys. D 33, 193-199 (2005).

${ }^{84}$ J. Tennyson, N. F. Zobov, R. Williamson, O. L. Polyansky, and P. F. Bernath, "Experimental energy levels of the water molecule," J. Phys. Chem. Ref. Data 30, 735-831 (2001)

${ }^{85} \mathrm{M}$. Allan and O. Moreira, "Excitation of the symmetric and antisymmetric stretch vibrations of $\mathrm{H}_{2} \mathrm{O}$ by electron impact," J. Phys. B: At., Mol. Opt. Phys. 35, L37-L42 (2002).

${ }^{86} \mathrm{G}$. Seng and F. Linder, "Vibrational excitation of polar molecules by electron impact. II. Direct and resonant excitation in $\mathrm{H}_{2} \mathrm{O}$," J. Phys. B: At. Mol. Phys. 9, 2539-2551 (1976).

${ }^{87}$ T. W. Shyn, S. Y. Cho, and T. E. Cravens, "Vibrational-excitation cross sections of water molecules by electron impact," Phys. Rev. A 38, 678 (1988).

${ }^{88} \mathrm{~A}$. A. A. El-Zein, M. J. Brunger, and W. R. Newell, "Excitation of vibrational quanta in water by electron impact," J. Phys. B: At., Mol. Opt. Phys. 33, 5033 (2000). ${ }^{89} \mathrm{M}$. A. Khakoo, C. Winstead, and V. McKoy, "Vibrational excitation of water by electron impact,” Phys. Rev. A 79, 052711 (2009).

${ }^{90} \mathrm{~T}$. Nishimura and Y. Itikawa, "Electron-impact vibrational excitation of water molecules,” J. Phys. B: At., Mol. Opt. Phys. 28, 1995-2005 (1995).

${ }^{91}$ R. Curik and P. Carsky, "Vibrationally inelastic electron scattering on polyatomic molecules by the discrete momentum representation (DMR) method," J. Phys. B: At., Mol. Opt. Phys. 36, 2165 (2003).

${ }^{92} \mathrm{~T}$. Nishimura and F. A. Gianturco, "Vibrational excitation of water by low-energy electron scattering: Calculations and experiments," Europhys. Lett. 65, 179 (2004). 
${ }^{93}$ A. Faure and E. Josselin, "Collisional excitation of water in warm astrophysical media. I. Rate coefficients for rovibrationally excited states," Astron. Astrophys. 492, 257-264 (2008).

${ }^{94}$ H. Liu, S. F. dos Santos, C. H. Yuen, P. Cortona, V. Kokoouline, and M. Ayouz, "Theoretical study of electron-induced vibrational excitation of $\mathrm{NO}_{2}$," Plasma Sources Sci. Technol. 28, 105017 (2019).

${ }^{95}$ J. Tennyson, D. B. Brown, J. J. Munro, I. Rozum, H. N. Varambhia, and N. Vinci, "Quantemol-N: An expert system for performing electron molecule collision calculations using the R-matrix method," J. Phys. Conf. Ser. 86, 012001 (2007).

${ }^{96} \mathrm{~T}$. Shimanouchi, "Tables of molecular vibrational frequencies," Consolidated Volume I. NSRDS-NBS 39, National Bureau of Standards, Gaithersburg, MD, 1972.

${ }^{97}$ E. N. Lassettre, A. Skerbele, M. A. Dillon, and K. J. Ross, "High-resolution study of electron-impact spectra at kinetic energies between 33 and $100 \mathrm{eV}$ and scattering angles to 16," J. Chem. Phys. 48, 5066-5096 (1968).

${ }^{98}$ S. Trajmar, W. Williams, and A. Kuppermann, "Electron impact excitation of $\mathrm{H}_{2} \mathrm{O}$," J. Chem. Phys. 58, 2521-2531 (1973).

${ }^{99}$ L. Hargreaves, K. Ralphs, G. Serna, M. A. Khakoo, C. Winstead, and V. McKoy, "Excitation of the $\tilde{a}^{3} B_{1}$ and $\tilde{A}^{1} B_{1}$ states of $\mathrm{H}_{2} \mathrm{O}$ by low-energy electron impact," J. Phys. B: At., Mol. Opt. Phys. 45, 201001 (2012).

${ }^{100}$ K. Ralphs, G. Serna, L. R. Hargreaves, M. A. Khakoo, C. Winstead, and V. McKoy, "Excitation of the six lowest electronic transitions in water by $9-20 \mathrm{eV}$ electrons," J. Phys. B: At., Mol. Opt. Phys. 46, 125201 (2013).

${ }^{101}$ P. A. Thorn, M. J. Brunger, P. J. O. Teubner, N. Diakomichalis, T. Maddern, M. A. Bolorizadeh, W. R. Newell, H. Kato, M. Hoshino, H. Tanaka et al., "Cross sections and oscillator strengths for electron-impact excitation of the $\tilde{A}^{1} B_{1}$ electronic state of water," J. Chem. Phys. 126, 064306 (2007).

${ }^{102} \mathrm{P}$. Thorn, L. Campbell, and M. Brunger, "Electron excitation and energy transfer rates for $\mathrm{H}_{2} \mathrm{O}$ in the upper atmosphere," PMC Phys. B 2, 1 (2009).

${ }^{103}$ P. A. Thorn, M. J. Brunger, H. Kato, M. Hoshino, and H. Tanaka, "Cross sections for the electron impact excitation of the $a^{3} B_{1}, b^{3} A_{1}$ and $B^{1} A_{1}$ dissociative electronic states of water," J. Phys. B: At., Mol. Opt. Phys. 40, 697-708 (2007).

${ }^{104}$ M. J. Brunger, P. A. Thorn, L. Campbell, N. Diakomichalis, H. Kato, H. Kawahara, M. Hoshino, H. Tanaka, and Y.-K. Kim, "Excitation of the lowest lying ${ }^{3} B_{1},{ }^{1} B_{1},{ }^{3} A_{2},{ }^{1} A_{2},{ }^{3} A_{1}$, and ${ }^{1} A_{1}$ electronic states in water by $15 \mathrm{eV}$ electrons," Int. J. Mass Spectrom. 271, 80-84 (2008), part of Special Issue: Yong-Ki Kim Honour Issue

${ }^{105}$ Y.-K. Kim, "Scaled Born cross sections for excitations of $\mathrm{H}_{2}$ by electron impact," J. Chem. Phys. 126, 064305 (2007).

${ }^{106}$ H. Tanaka, M. J. Brunger, L. Campbell, H. Kato, M. Hoshino, and A. R. P. Rau, "Scaled plane-wave Born cross sections for atoms and molecules," Rev. Mod. Phys. 88, 025004 (2016)

${ }^{107} \mathrm{M}$. J. Brunger, "Electron scattering and transport in biofuels, biomolecules and biomass fragments," Int. Rev. Phys. Chem. 36, 333-376 (2017).

${ }^{108} \mathrm{~L}$. Campbell and M. J. Brunger, "Electron-impact vibrational excitation of the hydroxyl radical in the nighttime upper atmosphere," Planet. Space Sci. 151, 11-18 (2018).

${ }^{109}$ J. Lelieveld, "Atmosphere cleans itself more efficiently than previously thought," Max-Planck Gesellschaft Research News (January 13, 2011), accessed April 14, 2021, https://www.mpg.de/990456/earths_atmosphere_cleaning.

${ }^{110}$ S. A. Montzka, M. Krol, E. Dlugokencky, B. Hall, P. Jöckel, and J. Lelieveld, "Small interannual variability of global atmospheric hydroxyl," Science 331, 67-69 (2011).

${ }^{111}$ J. W. McConkey, C. P. Malone, P. V. Johnson, C. Winstead, V. McKoy, and I. Kanik, "Electron impact dissociation of oxygen-containing molecules-A critical review," Phys. Rep. 466, 1-103 (2008).

${ }^{112}$ C. E. Melton, "Cross sections and interpretation of dissociative attachment reactions producing $\mathrm{OH}^{-}, \mathrm{O}^{-}$, and $\mathrm{H}^{-}$in $\mathrm{H}_{2} \mathrm{O}$," J. Chem. Phys. 57, 4218-4225 (1972).

${ }^{113}$ T. Harb, W. Kedzierski, and J. W. McConkey, "Production of ground state $\mathrm{OH}$ following electron impact on $\mathrm{H}_{2} \mathrm{O}$,” J. Chem. Phys. 115, 5507-5512 (2001).

${ }^{114}$ R. S. Schappe and E. Urban, "Cross sections for $\mathrm{OH}$ transitions due to electron impact on water molecules," Phys. Rev. A 73, 052702 (2006).

${ }^{115}$ C. I. M. Beenakker, F. J. D. Heer, H. B. Krop, and G. R. Möhlmann, "Dissociative excitation of water by electron impact," Chem. Phys. 6, 445-454 (1974).
${ }^{116}$ M. A. Khodorkovskii, S. V. Murashov, T. O. Artamonova, L. P. Rakcheeva, A. A. Beliaeva, A. L. Shakhmin, D. Michael, N. A. Timofeev, A. S. Mel'nikov, I. A. Shevkunov, and G. Zissis, "Excitation of water molecules by electron impact with formation of $\mathrm{OH}$-radicals in the $\mathrm{A}^{2} \Sigma^{+}$state," J. Phys. B: At., Mol. Opt. Phys. 42, 215201 (2009).

${ }^{117}$ W. Kedzierski, J. Derbyshire, C. Malone, and J. W. McConkey, "Isotope effects in the electron impact break-up of water," J. Phys. B: At., Mol. Opt. Phys. 31, 5361-5368 (1998).

${ }^{118}$ H. C. Straub, B. G. Lindsay, K. A. Smith, and R. F. Stebbings, "Absolute partial cross sections for electron-impact ionization of $\mathrm{H}_{2} \mathrm{O}$ and $\mathrm{D}_{2} \mathrm{O}$ from threshold to 1000 eV," J. Chem. Phys. 108, 109-116 (1998).

${ }^{119} \mathrm{~N}$. Djurić, I. Čadež, and M. Kurepa, " $\mathrm{H}_{2} \mathrm{O}$ and $\mathrm{D}_{2} \mathrm{O}$ total ionization crosssections by electron impact," Int. J. Mass Spectrom. Ion Processes 83, R7-R10 (1988).

${ }^{120}$ J. M. Carr, P. G. Galiatsatos, J. D. Gorfinkiel, A. G. Harvey, M. A. Lysaght, D. Madden, Z. Mašín, M. Plummer, J. Tennyson, and H. N. Varambhia, "UKRmol: A low-energy electron- and positron-molecule scattering suite," Eur. Phys. J. D 66, 58 (2012).

${ }^{121}$ T. Mārk and F. Egger, "Cross-section for single ionization of $\mathrm{H}_{2} \mathrm{O}$ and $\mathrm{D}_{2} \mathrm{O}$ by electron impact from threshold up to $170 \mathrm{eV}$," Int. J. Mass Spectrom. Ion Phys. 20, 89-99 (1976)

${ }^{122} \mathrm{O}$. J. Orient and S. K. Strivastava, "Electron impact ionisation of $\mathrm{H}_{2} \mathrm{O}, \mathrm{CO}, \mathrm{CO}_{2}$ and $\mathrm{CH}_{4}$," J. Phys. B: At. Mol. Phys. 20, 3923-3936 (1987).

${ }^{123} \mathrm{M}$. V. V. S. Rao, I. Iga, and S. K. Srivastava, "Ionization cross-sections for the production of positive ions from $\mathrm{H}_{2} \mathrm{O}$ by electron impact," J. Geophys. Res. Planet. 100, 26421-26425 (1995).

${ }^{124}$ E. C. Montenegro, S. W. J. Scully, J. A. Wyer, V. Senthil, and M. B. Shah, "Evaporation, fission and auto-dissociation of doubly charged water," J. Electron Spectrosc. Relat. Phenom. 155, 81-85 (2007).

${ }^{125}$ S. J. King and S. D. Price, "Electron ionization of $\mathrm{H}_{2} \mathrm{O}$," Int. J. Mass Spectrom. 277, 84-90 (2008).

${ }^{126} \mathrm{M}$. A. Bolorizadeh and M. E. Rudd, "Angular and energy dependence of cross sections for ejection of electrons from water vapor. I. 50-2000-eV electron impact," Phys. Rev. A 33, 882-887 (1986).

${ }^{127}$ R. N. Compton and L. G. Christophorou, "Negative-ion formation in $\mathrm{H}_{2} \mathrm{O}$ and $\mathrm{D}_{2} \mathrm{O}$," Phys. Rev. 154, 110-116 (1967).

${ }^{128}$ S. P. Khare and W. J. Meath, "Cross sections for the direct and dissociative ionisation of $\mathrm{NH}_{3}, \mathrm{H}_{2} \mathrm{O}$ and $\mathrm{H}_{2} \mathrm{~S}$ by electron impact," J. Phys. B: At. Mol. Phys. 20, 2101-2116 (1987).

${ }^{129}$ Y.-K. Kim and M. E. Rudd, "Binary-encounter-dipole model for electronimpact ionization," Phys. Rev. A 50, 3954-3967 (1994).

${ }^{130}$ D. Rapp and D. D. Briglia, "Total cross sections for ionization and attachment in gases by electron impact. II. Negative-ion formation," J. Chem. Phys. 43, 1480-1489 (1965).

${ }^{131}$ J. Schutten, F. J. de Heer, H. R. Moustafa, A. J. H. Boerboom, and J. Kistemaker, "Gross- and partial-ionization cross sections for electrons on water vapor in the energy range 0.1-20 keV," J. Chem. Phys. 44, 3924-3928 (1966).

${ }^{132}$ L. Bárdoš, I. Štěpánek, and G. Karwasz, "Neutral gas flow velocity profiles in the jet plasma-chemical reactor," Vacuum 40, 449-452 (1990).

${ }^{133}$ G. P. Karwasz, P. Możejko, and M.-Y. Song, "Electron-impact ionization of fluoromethanes-Review of experiments and binary-encounter models," Int. J. Mass Spectrom. 365-366, 232-237 (2014), part of Special Issue: Tilmann Mäerk. ${ }^{134}$ W. Hwang, Y. K. Kim, and M. E. Rudd, "New model for electron-impact ionization cross sections of molecules," J. Chem. Phys. 104, 2956-2966 (1996).

${ }^{135}$ D. Gupta, H. Choi, M.-Y. Song, G. P. Karwasz, and J.-S. Yoon, "Electron impact ionization cross section studies of $\mathrm{C}_{2} \mathrm{~F}_{x}(\mathrm{x}=1-6)$ and $\mathrm{C}_{3} \mathrm{~F}_{x}(\mathrm{x}=1-8)$ fluorocarbon species," Eur. Phys. J. D 71, 88 (2017).

${ }^{136}$ D. S. Belic, M. Landau, and R. I. Hall, "Energy and angular dependence of $\mathrm{H}^{-}\left(\mathrm{D}^{-}\right)$ions produced by dissociative electron attachment to $\mathrm{H}_{2} \mathrm{O}\left(\mathrm{D}_{2} \mathrm{O}\right)$," J. Phys. B: At. Mol. Phys. 14, 175-190 (1981).

${ }^{137}$ J. Fedor, P. Cicman, B. Coupier, S. Feil, M. Winkler, K. Głuch, J. Husarik, D. Jaksch, B. Farizon, N. J. Mason, P. Scheier, and T. D. Märk, "Fragmentation of transient water anions following low-energy electron capture by $\mathrm{H}_{2} \mathrm{O} / \mathrm{D}_{2} \mathrm{O}$, ” J. Phys. B: At., Mol. Opt. Phys. 39, 3935-3944 (2006). 
${ }^{138}$ P. Rawat, V. S. Prabhudesai, G. Aravind, M. A. Rahman, and E. Krishnakumar, "Absolute cross sections for dissociative electron attachment to $\mathrm{H}_{2} \mathrm{O}$ and $\mathrm{D}_{2} \mathrm{O}$," J. Phys. B: At., Mol. Opt. Phys. 40, 4625-4636 (2007).

${ }^{139}$ C. E. Klots and R. N. Compton, "Electron attachment to van der Waals polymers of water," J. Chem. Phys. 69, 1644-1647 (1978).

${ }^{140}$ D. J. Haxton, T. N. Rescigno, and C. W. McCurdy, "Dissociative electron attachment to the $\mathrm{H}_{2} \mathrm{O}$ molecule. II. Nuclear dynamics on coupled electronic surfaces within the local complex potential model," Phys. Rev. A 75, 012711 (2007).
${ }^{141}$ K. Varela, L. R. Hargreaves, K. Ralphs, M. A. Khakoo, C. Winstead, V. Mckoy, T. N. Rescigno, and A. E. Orel, "Excitation of the 4 lowest electronic transitions in methanol by low-energy electrons," J. Phys. B: At., Mol. Opt. Phys. 48, 115208 (2015).

${ }^{142}$ Y. Itikawa, "Electron-impact vibrational excitation of $\mathrm{H}_{2} \mathrm{O}$," J. Phys. Soc. Jpn. 36, 1127-1132 (1974).

${ }^{143}$ R. Čurík, P. Čársky, and M. Allan, "Vibrational excitation of methane by slow electrons revisited: Theoretical and experimental study," J. Phys. B: At., Mol. Opt. Phys. 41, 115203 (2008). 